\title{
Potential Tank Waste Material Anomalies Located Near the Liquid Observation Wells: Model Predicted Responses of a Neutron Moisture Detection System
}

\author{
S. H. Finfrock \\ H. Toffer \\ W. T. Watson \\ Date Published \\ September 1994
}

Prepared for the U.S. Department of Energy Office of Environmental Restoration and Waste Management

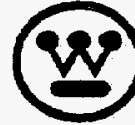




\section{RELEASE AUTHORIZATION}

Document Number: WHC-EP-0809

\begin{tabular}{|ll|}
\hline Document Title: & $\begin{array}{l}\text { Potential Tank Waste Material Anomalies Located Near } \\
\text { the Liquid Observation Wells: Model Predicted } \\
\text { Responses of a Neutron Moisture Detection System }\end{array}$ \\
\hline Release Date: & $9 / 30 / 94$
\end{tabular}

This document was reviewed following the procedures described in WHC.CM-3-4 and is:

\section{APPROVED FOR PUBLIC RELEASE}

WHC Information Release Administration Specialist:

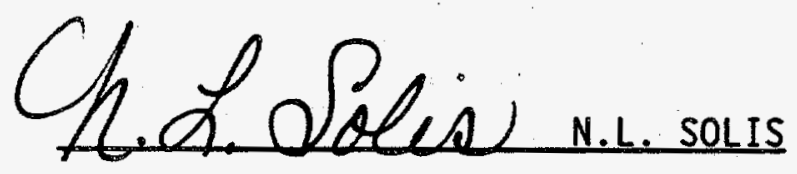

(Signature)

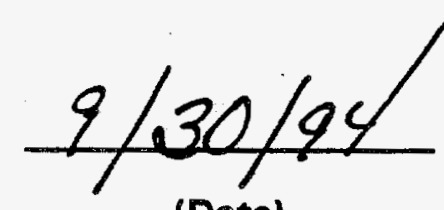

(Date) 


\section{DISCLAIMER}

This report was prepared as an account of work sponsored by an agency of the United States Government. Neither the United States Government nor any agency thereof, nor any of their employees, make any warranty, express or implied, or assumes any legal liability or responsibility for the accuracy, completeness, or usefulness of any information, apparatus, product, or process disclosed, or represents that its use would not infringe privately owned rights. Reference herein to any specific commercial product, process, or service by trade name, trademark, manufacturer, or otherwise does not necessarily constitute or imply its endorsement, recommendation, or favoring by the United States Government or any agency thereof. The views and opinions of authors expressed herein do not necessarily state or reflect those of the United States Government or any agency thereof. 


\section{DISCLAIMER}

Portions of this document may be illegible in electronic image products. Images are produced from the best available original document. 


\section{EXECUTIVE SUMMARY}

Extensive analyses have been completed to demonstrate that a neutron moisture probe can be used to recognize anomalies in materials and geometry surrounding the liquid observation wells (LOWs). Furthermore, techniques can be developed that will permit the interpretation of detector readings, perturbed by the presence of anomalies, as more accurate moisture concentrations. This analysis effort extends the usefulness of a neutron moisture probe system significantly, especially in the complicated geometries and material conditions that may be encountered in the waste tanks. Both static-source and pulsed-source neutron probes were considered in the analyses. Four different detector configurations were investigated: thermal and epithermal neutron detectors located in both the near and far field. Analyses suggest that, for more complicated features, tank scans using all four detector configurations would be needed to identify the anomaly and to provide a correction to the moisture determination. The specific anomalies considered around the LOW, in the current study, included concentric and nonconcentric air annuli, low-moisture material regions, high-moisture material regions, liquid-filled annuli, and the presence of fissionable material waste. For all modeled cases, characteristic detector responses were obtained that allowed identification of features and placed bounds upon the application of moisture measurement corrections. Some of the anomalies modeled in this study will be included in the experimental evaluation of the prototype neutron probe system currently being developed by simulating the feature in waste simulant calibration standards. 
WHC-EP-0809

CONTENTS

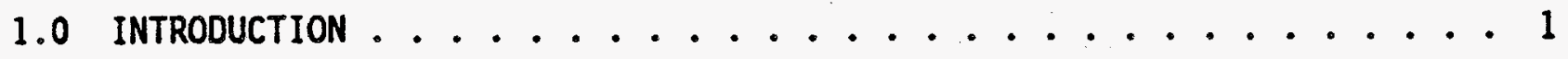

2.0 TANK MATERIAL MODEL-LIQUID OBSERVATION WELLS . . . . . . . 2

2.1 Model ed Waste and Low Materials . . . . . . . . . . . 2

2.2 Material or Material Geometry Anomalies Near the

Liquid Observation Wells ............. 2

3.0 STATIC-SOURCE NEUTRON PROBE $\ldots \ldots \ldots \ldots$

3.1 Homogeneous Surrounding Moisture Concentrations . . . . . . . 3

3.2 Concentric Air-filled Annulus ............. 4

3.3 Nonconcentric Air-Filled Annulus ............ 6

3.4 Low-Moisture Concentration Waste Annulus .......... 7

3.5 High-Moisture Concentration Waste Annulus .......... 8

3.6 Liquid-Filled Annulus ............... 8

3.7 High Transuranic Concentration Waste ........... 9

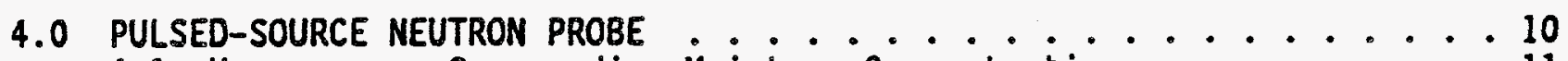

4.1 Homogeneous Surrounding Mojsture Concentration ........11

4.2 Concentric Air-filled Annulus . . . . . . . . . . 12

4.3 Concentric Liquid-Filled Annulus ............ 13

4.4 Pulsed-Neutron Response to Fissionable Material Waste ..... 14

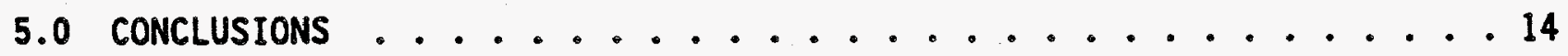

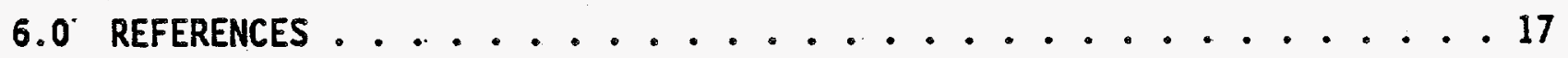

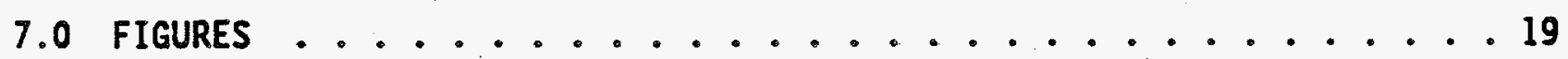


WHC-EP-0809

\section{LIST OF FIGURES}

3-1 Cross-Sectional Sketch of a Static-Source Thermal Neutron Detector Probe Model Geometry ................. 19

3-2 Thermal Neutron Probe Detector Section Responses to Increasing Moisture Concentration Waste .......... 20

3-3 Epithermal Neutron Probe Detector Section Responses to Increasing Moisture Concentration Waste .......... 21

3-4 Response of Near- and Far-Field Thermal Neutron Detectors to Homogeneous Moisture Concentration Waste ..........

3-5 Thermal Neutron Detector Near-Field/Far-Field Ratio for Increasing Moisture Concentration Waste ..........

3-6 Responses of Near- and Far-Field Epithermal Neutron Detectors to Homogeneous Moisture Concentration Waste ..........

3-7 Epithermal Neutron Detector Near-Field/Far-Field Ratio for Increasing Moisture Concentration Waste ...........

3-8 Thermal Neutron Detector Responses to Concentric Air Annuli Between the Liquid Observation Well and Two Moisture Concentration Wastes

3-9 Thermal Neutron Detector Near-Field/Far-Field Ratio for Increasing Concentric Air Annulus Thickness

3-10 Epithermal Neutron Detector Responses to Concentric Air Annuli Between the Liquid Observation We11 and Two Moisture Concentration Wastes

3-11 Near-Field Epithermal Detector Response to Waste Moisture Concentration Compared With That Expected to Different Thickness Air Annuli

3-12 Epithermal Neutron Detector Near-Field/Far-Field Ratio for Increasing Air Annulus Thickness

3-13 Comparison of Thermal Neutron Detector Responses to Concentric and Nonconcentric Air Annuli Between the Liquid Observation Well and $30 \mathrm{Wt} \%$ Moisture Waste .................

3-14 Comparison of Thermal Neutron Detector Near-Field/Far-Field Ratio for Concentric and Nonconcentric Air Annuli and $30 \mathrm{Wt} \%$ Moisture Waste 
3-15 Comparison of Epithermal Neutron Detector Responses to Concentric and Nonconcentric Air Annuli Between the Liquid Observation Well and $30 \mathrm{Wt} \%$ Moisture Waste. . . . . . . . . . . . . . .

3-16 Predicted Near-Field/Far-Field Responses to Concentric Air Annuli Surrounded by 15 or $30 \mathrm{Wt} \%$ Moisture Waste. . . . . . . . . . . .

3-17 Thermal Neutron Detector Response to Different Thickness 0 Wt\% Inner Annular Waste Regions Surrounded by 15 or 30 Wt\% Moisture Waste . .

3-18 Epithermal Neutron Detector Response to Different Thickness $0 \mathrm{Wt \%}$ Inner Annular Waste Regions Surrounded by 15 or $30 \mathrm{Wt} \%$ Moisture Waste

3-19 Thermal Neutron Detector Responses to Concentric Air Annuli Between the Liquid Observation We11 and Four Moisture Concentration Wastes

3-20 Thermal Neutron Detector Response to Different Thickness 15 or 30 Wt\% Moisture Waste Regions Surrounded by 0 Wt\% Outer Annular

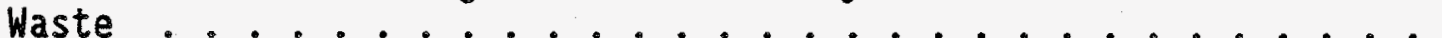

3-21 Epithermal Neutron Detector Response to Different Thickness 15 or 30 Wt\% Moisture Waste Regions Surrounded by 0 Wt\% Outer Annular Waste

3-22 Thermal Neutron Detector Response to Different Thickness Water-Filled Annuli Surrounded by 15 or 30 Wt\% Moisture Waste . . .

3-23 Epithermal Neutron Detector Response to Different Thickness Water-Filled Annuli Surrounded by 15 or 30 Wt\% Moisture Waste . . .

3-24 MCNP Predicted Passive Neutron Detector Count Rate for Increasing Waste Concentrations of ${ }^{239} \mathrm{Pu} . \ldots . . . . . . .$.

3-25 MCNP Predicted Active Neutron Probe Response to Increasing Waste ${ }^{239} \mathrm{Pu}$ Concentration

3-26 Comparison of the Near- and Far-Field Detector Responses to Increasing Waste Moisture and TRU Concentration ..........33

4-1 Pulsed-Source Neutron Probe ................ 34

4-2 Near-Thermal Detector Time-Dependant Responses to Waste Moisture Content

4-3 Far-Thermal Detector Time-Dependant . . . . . . . . 36

4-4 Normalized Near-Thermal Detector Time-Dependant Responses to Waste Moisture Content 
WHC-EP-0809

4-5 Normalized Far-Thermal Detector Time-Dependant Responses to

Waste Moisture Content .............. 38

4-6 Near-Epithermal Detector Time-Dependant Responses to Waste Moisture Content

4-7 Normalized Far-Epithermal Time-Dependant Responses to Waste Moisture Content

4-8 Normalized Near-Epithermal Detector Time-Dependant Responses to Waste Moisture Content

4-9 Far-Epithermal Detector Time-Dependant Responses to Waste Moisture Content

4-10 Near-Thermal Detector Time-Dependant Responses to Air-Filled Annuli

4-11 Far-Thermal Detector Time-Dependant Responses to Air-Filled Annuli

4-12 Normalized Near-Thermal Detector Time-Dependant Responses to Air-Filled Annuli

4-13 Normalized Far-Thermal Detector Time-Dependant Responses to Air-Filled Annuli

4-14 Near-Epithermal Detector Time-Dependant Responses to Air-Filled Annuti

4-15 Far-Epithermal Detector Time-Dependant Responses to Air-Filled Annuli

4-16 Normalized Near-Epithermal Detector Time-Dependant Responses to Air-Filled Annuli

4-17 Normalized Far-Epithermal Time-Dependant Responses to Air-Filled Annuli

4-18 Near-Thermal Detector Time-Dependant Responses to Water-Filled Annuli

4-19 Far-Thermal Detector Time-Dependant Responses to Water-Filled Annuli

4-20 Normalized Near-Thermal Detector Time-Dependant Responses to Water-Filled Annuli

4-21 Normalized Far-Thermal Detector Time-Dependant Response to Water-Filled Annuli 
4-22 Near-Epithermal Detector Time-Dependant Responses to Water-Fi1led Annuli ....................... 55

4-23 Far-Epithermai Detector Time-Dependant Responses to Water-Filled

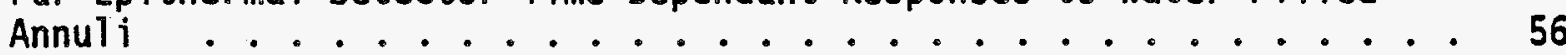

4-24 Normalized Near-Epithermal Detector Time-Dependant Responses to Water-Filled Annuli ............... 57

4-25 Normalized Far-Epithermal Time-Dependant Responses to Water-Filled

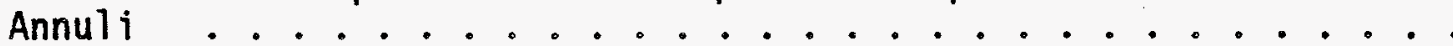


WHC-EP-0809

\section{LIST OF TABLES}

\section{5-1 Neutron Probe Responses to Several Possible Tank Waste} Conditions and Their Possible Interpretations ......... 16 


\section{WHC-EP-0809}

\section{LIST OF TERMS}

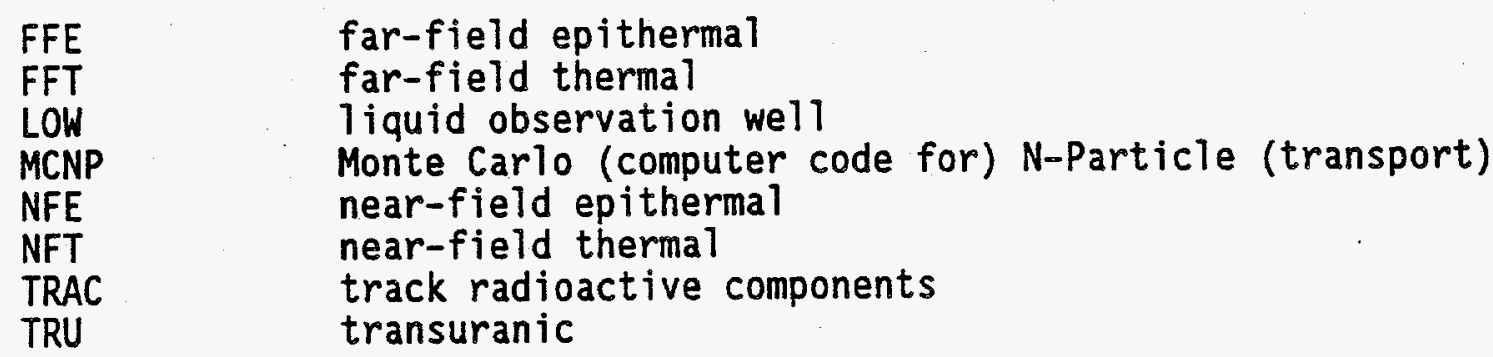

TRU 


\subsection{INTRODUCTION}

The ability of a neutron probe to measure average moisture concentrations of surrounding homogeneous media has been demonstrated in controlled experiments (Watson 1993). A comparison of neutron moderation moisture measurement techniques used by soil science, agriculture, and construction, with those used by the petroleum industry may be found in "A Comparison of the Moisture Gauge and the Neutron Log in Air-filled Holes" (Hearst and Carlson 1994). A partially calibrated neutron probe has been used by Westinghouse Hanford Company to make preliminary test measurements in the more complicated, radioactive tank environment. The neutron probe test scans of the waste tanks, in-tank photographs, in-tank passive gamma scans, and information about the insertion method for the liquid observation wells (LOW) all provide evidence that material or material geometry immediately surrounding a LOW may sometimes not represent the tank waste. A moisture measurement of the surrounding waste made from with in the LOW may be perturbed by material or material geometry anomalies found near the LOW. To obtain the best moisture measurement possible from within the LOW, the moisture measurement technique should be able to identify the presence of material anomalies near the LOW that could perturb the moisture measurement and then make appropriate corrections to the measurement. The current study investigated the ability of a neutron-based moisture probe to identify several possible material anomalies near the LOW and then to assess the ability of such a system to measure data that would allow correction to the moisture measurement.

To assess the neutron probe responses to changes in the materials surrounding the LOW, several computer models were developed using the radiation transport code Monte Carlo N-Particle (MCNP) (LANL 1993). The computer models allow for material and geometry changes and will calculate estimates for the detector responses to these changes. Two different neutron probe models were developed for the current study: a static-source neutron probe and a pulsed-source neutron probe. Both models were also altered to model the response expected from thermal and epithermal neutron detectors. The epithermal detector models were produced by placing an outer cadmium encapsulation and an inner polyethylene encapsulation around the detector region.

We $\mathrm{plan}$ to perform 7 imited experimental tests to verify the modeling results presented in this study. Prototype thermal and epithermal neutron probes are being developed to measure tank waste moisture concentrations. These probes will be used to measure the perturbation to the moisture measurement caused by several simple material geometry anomalies of waste simulants or other media surrounding a LOW. These experimental validations are desirable to ensure that modeling results and their interpretations are reasonable. 


\subsection{TANK MATERIAL MODEL}

\subsection{MODELED WASTE AND LOW MATERIALS}

The modeled tank waste matrix was derived from availabie Track Radioactive Components (TRAC) data for the BY Tank Farm ferrocyanide tanks and was assumed to have a constant $1.5-\mathrm{g} / \mathrm{cm}^{3}$ density for all calculations. The exact waste composition should have a relatively small effect upon the results calculated in this study. The neutron absorber and moderator properties of the waste are the two more important attributes that determine the detector response. The neutron absorber properties of the surrounding waste will, in general, be eliminated when using an epithermal neutron detector. The LOW model was derived from available information on the composition of the epoxy-fiberglass material combined with previous computer modeling of tank neutron scan data obtained from within a LOW (Watson 1993). The LOW model contains about $10 \mathrm{wt} \%$ borosilicate fiberglass.

\subsection{MATERIAL OR MATERIAL GEOMETRY ANOMALIES NEAR THE LIQUID OBSERVATION WELL}

Because information available on the waste tank contents is limited, many material or material geometry anomalies could be postulated to exist near the LOWs. Many of the more plausible anomalies that could exist would likely have resulted from the method by which the LOWs were installed into the tank waste. Tank salt cake and underlying wastes were lanced with a pressurized hot-water spray to create an opening through the hardened waste in which the LOW was inserted. To investigate the possible anomalies that could affect a moisture measurement, several idealized scenarios were modeled that could be representative of possible anomalies. The anomalies considered in the current study are as follows:

- Concentric air-filled annulus immediately around the LOW

- Nonconcentric air-filled annulus immediately around the LOW

- Low-moisture concentration waste annulus immediately around the LOW

- High-moisture concentration waste annulus immediately around the LOW

- Liquid-filled annulus immediately around the LOW

- High-transuranic (TRU) concentration waste surrounding the LOW. 
The identification of any of these features would be performed using all available data. To recognize these features and then to correct the moisture measurement appropriately, an interpretation of the scan data should be consistent with the information gained from each of the detector arrangements. For the more complex features, using only one or even two detector configurations could lead to an interpretation of the data that is not unique. With data from three or even four detector arrangements, the ability to interpret the anomalous features and provide a correction improves significantly. There are several nearly independent parameters that could vary with many of the possible anomalies. The extra information available from multiple configuration moisture measurement scans should, for many cases, allow these parameters to be constrained so that a reasonable, best estimate of the surrounding waste moisture concentration can be obtained.

\subsection{STATIC-SOURCE NEUTRON PROBE}

Figure 3-1 shows a cross-sectional sketch of the computer model used to approximate the static-source thermal neutron probe. This model contains a $1.2 \mathrm{mCi}{ }^{252} \mathrm{Cf}$ neutron source (average neutron energy $\approx 2.2 \mathrm{MeV}$ ) and a 22-in.-long, 1.5-in.-diameter neutron detector region subdivided into 2 -in.-long sections. In this model, the detector region is filled with air, but the neutron interaction rate in this region is calculated for a ${ }^{10} \mathrm{~B}$ atomic density equivalent to that present in a detector filled with $40 \mathrm{~cm}$ Mercury of boron-trifluoride $\left(\mathrm{BF}_{3}\right)$ gas enriched to $96 \%$ in ${ }^{10} \mathrm{~B}$. This detector model allowed the expected response of both short and long source-to-detector spacings to be investigated in a single calculation. While the model has the advantage of preventing neutrons that may be detected in the detector sections positioned far from the source from being actually absorbed at short source-to-detector spacings, it does allow a single neutron to potentially interact more than once in a given detector section. The calculations using this model are, therefore, less precise than could be obtained by modeling actual individual $\mathrm{BF}_{3}$ detectors one at a time at each 2 in. increment source-to-detector spacing.

\subsection{HOMOGENEOUS SURROUNDING MOISTURE CONCENTRATIONS}

The static-source neutron probe models were used to predict the response of each subdivided section of the detector region to changes in the moisture concentration of surrounding ferrocyanide sludge, as a baseline with which to compare the predicted responses with the various material anomalies.

Figure 3-2 shows the predicted detector subsection responses as a function of waste moisture concentration for the thermal neutron detector model. Error bars plotted for all data points, in all figures, are representative of the statistical precision of an individual calculation. The detector region subsections are labeled 1 through 11 , with section 1 at the shortest source-to-detector spacing $(2.77 \mathrm{in}$. from center of source to center of section) and each subsequent section spaced 2 inches further from the source. The detector regions that exhibit an increased count rate in response to an increased surrounding moisture concentration may be referred to as located in 
the near field, while those that exhibit a decreased count rate in response to an increased surrounding moisture concentration are located in the far field. Figure 3-2 shows that, for the thermal probe, detector sections 1 through 3 are located in the near field, while sections 5 through 11 are located in the far field. For the remainder of the static source portion of this report, detector sections 1 and 2 will be referred to as the near-field thermal detector (NFT) and detector sections 5 through 8 will be referred to as the far-field thermal detector (FFT).

An epithermal neutron detector model, nearly identical to the thermal model shown in Figure 3-1, was developed. This model differed from the thermal model in that an outer cadmium and inner polyethylene wraps were modeled encapsulating the entire detector region. Figure 3-3 shows the predicted detector subsection responses as a function of moisture

concentration for the epithermal neutron detector model. Figure 3-3 shows that, for the epithermal probe, detector section 1 is located partially in the near field, while sections 2 through 11 are located in the far field. For the remainder of the static source portion of this report, detector section 1 will be referred to as the near-field epithermal detector (NFE) and detector sections 2 through 5 will be referred to as the far-fiefd epithermal detector (FFE). The near-field region for an epithermal probe is confined much more closely to the source than for a thermal probe. The range of the epithermal near-field is reduced primarily because the neutrons slow, on average, to epithermal energies after fewer collisions or over a shorter average distance than that required to reach thermal energies. A near-field epithermal detector must be located very near the source to show good sensitivity to moisture. In the epithermal model, detector section 1 would obtain better sensitivity to moisture if it were located closer to the source.

Figure 3-4 displays the results from Figure 3-2 reformulated to produce the expected detector responses from the NFT detector and the FFT detector. Figure 3-5 shows the result of dividing the NFT detector response by the FFT detector response as a function of surrounding moisture concentration. The processing of the data in this way will tend to cancel some systematic errors in a calculation or measurement and is a useful way to view the combined results of near- and far-field data.

Figure 3-6 displays the results from Figure 3-3 reformulated to produce the expected detector responses from the NFE and FFE detectors. Figure 3-7 shows the result of dividing the NFE detector response by the FFE detector response as a function of surrounding moisture concentration.

\subsection{CONCENTRIC AIR-FILLED ANNULUS}

An air-filled annulus is present between some LOWs and the surrounding salt cake. Such features are observed near the waste surface in some in-tank photographs. The shape, average radius, and concentricity of the airhole (with respect to the LOW) may be irregular. The simplest air-filled annulus case to consider is a concentric air-filled annulus of uniform radius between the LOW and surrounding waste. 
WHC-EP-0809

Figure 3-8 shows the predicted response of the NFT and FFT detectors to increasing air-filled annulus thickness between the LOW and waste material containing 15 or $30 \mathrm{wt} \%$ moisture. As the air annulus is increased in thickness, the NFT and FFT detector responses behave, in general, as if the surrounding moisture content is being reduced. It is also observed that for an air annulus thickness greater than about $3 \mathrm{~cm}$, the far-field detector response to higher moisture waste is greater than that for lower moisture waste. Comparing the responses to air annulus thicknesses larger than about $10 \mathrm{~cm}$ with those expected for different moisture concentration wastes with no air annulus (Figure 3-4), it is clear that there are no reasonable moisture content wastes that would produce a FFT response greater than or equal to the NFT response. Another way to analyze this effect is to compare the near-tofar-field ratios for an air annulus effect with that expected from a change in surrounding moisture concentration. Figure 3-9 shows the data presented in Figure 3-8 processed to produce the thermal near-to-far-field ratio as a function of air annulus thickness for two different waste moisture contents. This ratio quickly drops below a value of 2 for either moisture content by the time the air gap has reached a $6-\mathrm{cm}$ thickness. A response ratio in this range is not consistent with any possible moisture content waste interpretation (see Figure 3-5), without supposing the existence of some type of anomalous feature. Thus, combinations of properly located thermal detectors should be able to conclusively identify a concentric air annulus thicker than $\approx 6 \mathrm{~cm}$. Figure 3-8 shows that both the NFT and FFT detector responses to the two moisture concentration wastes remain separated for air gaps from $6 \mathrm{~cm}$ to at least $21 \mathrm{~cm}$ in thickness. Once an air gap of this size has been identified it should be possible, using properly calibrated detectors, to make a correction to the moisture measurement based upon-absolute detector responses. The analyses required to apply a correction to the moisture measurement will most likely increase the uncertainty of the moisture determination.

For an air-filled annulus less than about $6 \mathrm{~cm}$ thick, a combination of epithermal probes supplies a clearer indication of this feature. Figure 3-10 shows the predicted response of the NFE and FFE detectors to increasing air-filled annulus thickness between the LOW and sludge material containing 15 or $30 \mathrm{wt} \%$ moisture. As the air annuTus is increased in thickness, the FFE detector response behaves, in general, as if the surrounding moisture content is being increased, while the NFE detector response behaves as if the surrounding moisture is decreasing rapidly below physically possible levels. Figure 3-11 compares the NFE detector response to moisture with its response to increasing air annulus. For an air annulus as thin as $1 \mathrm{~cm}$ the NFE detector count rate is predicted to have dropped to only about 525 counts per second for either moisture concentration surrounding waste. This response is below the count rate expected for 0 wt\% moisture (completely dry) waste without an air annulus. For this same size air annulus the count rates expected in the FFE detector range from about 725 per second for $15 \mathrm{wt} \%$ waste to about 850 per second for 30 wt\% waste. Count rates in this range would be interpreted, using Figure 3-6, as corresponding to about 18 to 32 wt\% waste if no air annulus were assumed. The wholly inconsistent moisture interpretations derived from the NFE and FFE detector responses would identify the likely existence of a small air annulus. The NFE detector response appears to supply the most information on the size of thin air gaps and could be used in conjunction with collaborative data from the other detectors. to derive a best 
estimate of the air annulus thickness. With a possible thin air annulus identified, information gained from the epithermal and/or thermal near-tofar-field ratio should enable a reasonable correction of the moisture measurement. Corrections obtained from the thermal and epithermal near-to-far-field ratios should be consistent if the feature has been properly identified. Figure 3-12 shows the epithermal near-to-far-field ratio plotted as a function of air annulus thickness for the two moisture wastes. This ratio remains clearly separated for the two moisture contents for all air annulus thicknesses investigated.

From data obtained using NFT, FFT, NFE, and FFE detectors it should be possible to identify the existence of any significant (thickness $\geq 1 \mathrm{~cm}$ ) concentric air annulus around the LOW and to make an appropriate correction to the moisture determination. For an air annulus smaller than about $1 \mathrm{~cm}$ thickness, the information gained from these detectors may not be sufficient to clearly identify the presence of the air gap. If an air gap of this size existed but was not identified, the moisture concentration interpreted from the available data should be about 1 to 4 wt\% less than the actual moisture content of the surrounding waste.

\subsection{NONCONCENTRIC AIR-FILLED ANNULUS}

Some complexity is added to the interpretation of the idealized air annulus anomaly if it is assumed that, while retaining uniform outer diameter, the annulus is no longer placed concentric with the LOW. Figure 3-13 shows a comparison of the NFT and FFT detector responses expected for 30 wt\% moisture waste surrounding identical diameter airholes: one hole is concentric with the LOW and one hole is positioned so that the nearest point of its outer diameter is fixed at $1 \mathrm{~cm}$ from the outer wall of the LOW. This airhole placement represents a large off-center displacement. For smaller air annuli (equivalent concentric thickness $\leq 5 \mathrm{~cm}$ ), there is little effect upon the response expected from either detector and, therefore, there would be only a negligible perturbation upon the moisture measurement interpretation. For larger airholes, a perturbation in the predicted detector responses becomes apparent, especially for the NFT detector. It should be possible to obtain an estimate of the nonconcentricity of the airhole by examining both the absolute count rates and the near-to-far-field ratio for both the thermal and epithermal detectors. Figure 3-14 shows a comparison of the near-to-far-field ratios for the concentric and nonconcentric air annulus data given in Figure 3-13. Figure 3-15 shows a comparison of the NFE and FFE detector responses for 30 wt\% moisture waste surrounding the same concentric and nonconcentric air annuli shown for the thermal detector in Figure 3-13.

The interpretation of data from a larger, nonconcentric airhole would be challenging, but the information gained from the four types of scans predicted in Figures 3-13 through 3-15 would provide clues to aid in a more accurate moisture assessment. For instance, if scans were obtained from a nonconcentric air annulus with $10 \mathrm{~cm}$ average thickness and surrounding sludge moisture of $30 \mathrm{wt} \%$, the following data would be expected: NFT/FFT $\approx 1.4$, and $\mathrm{NFE} / \mathrm{FFE} \approx 0.54$. As can be seen in Figure $3-16$, if a concentric air-filled annulus interpretation of this data were attempted, there would be 
inconsistencies between interpretations of thermal and epithermal measured responses. For the average moisture to lie between 15 and 30 wt\%, Figure 3-16 shows that the predicted air annulus thickness, for a NFT to FFT ratio of 1.4, is between 6 and $8 \mathrm{~cm}$. In contrast, for a NFE to FFE ratio of 0.54 , an air annulus of between 2 and $3 \mathrm{~cm}$ is expected for the same moisture range. This inconsistency is indicative of a nonconcentric airhole. Once a nonconcentric airhole is assumed, the concentricity of the airhole and the moisture concentration of the surrounding waste could be varied in the model to give best agreement with all available data.

\subsection{LOW-MOISTURE CONCENTRATION WASTE ANNULUS}

Because the dryout, by an unpostulated mechanism, of waste materials immediately surrounding the LOW could have an impact upon moisture measurements, the ability of neutron measurements to identify and correct for such features has been investigated. In the models, concentric annuli of different thicknesses containing $0 \mathrm{wt} \%$ moisture waste were placed between the LOW and an outer waste region containing either 15 or 30 wt\% moisture. Figure 3-17 shows the predicted NFT and FFT detector responses to these different thickness dry-waste annuli for the two surrounding moisture concentrations. Figure 3-18 presents the predicted NFE and FFE detector responses to the same dry-waste rings surrounded by the two moisture concentration wastes as Figure 3-17. Although Figure 3-17 shows that thermal detectors could not clearly differentiate between the two moisture levels for dry annular thicknesses greater than about $10 \mathrm{~cm}$, the responses of the two epithermal detectors for this large of a dry-waste annulus remains well separated for the two moisture concentrations.

In order to estimate the likelihood that this type of dry-waste anomaly could be differentiated from uniform dry waste or the presence of an air gap, a given case will be investigated. If scan data were collected from a $10 \mathrm{~cm}$ thick dry-waste annulus surrounded by 15 wt\% moisture waste, the following predicted values should be measured: NFT $\approx 3100 \mathrm{~s}^{-1}$, FFT $\approx 1500 \mathrm{~s}^{-1}, \mathrm{NFE} \approx$ $510 \mathrm{~s}^{-1}, \mathrm{FFE} \approx 970 \mathrm{~s}^{-1}, \mathrm{NFT} / F F T \approx 2.1$, and NFE/FFE $\approx 0.53$ (Figures $3-17$ and 3-18). If a homogeneous moisture interpretation of these measurements were attempted using Figures 3-4 through 3-7, inconsistencies would be found. While both the NFT to FFT ratio and the NFE to FFE ratio would be interpreted as homogeneous waste containing 5 wt\% moisture, the NFE detector response would be more than $10 \%$ below the lowest count rate expected for any homogeneous moisture content waste while the FFE detector response would correspond to about a $10 \mathrm{wt} \%$ homogeneous moisture content waste. Obtaining a NFE detector response below that expected for dry homogeneous waste seems to be characteristic of data from both a dry-waste or air-filled annulus.

Reviewing the predicted example data against the predictions for a concentric air annulus shown in Figures 3-8 through $3-12$ should give an indication of the ability of these probes to differentiate between a dry-waste or air-filled annulus. Figure 3-10 shows that the NFE response, which changes little with moisture concentration for these air gaps, would be consistent with an air annulus thickness of about $1.5 \mathrm{~cm}$. The FFE response could be interpreted as from a similar size air annulus with surrounding waste moisture 
of about 10 wt\%. The NFT response in Figure 3-8 does not extend down to count rates near $3100 \mathrm{~s}^{-1}$ for the modeled moistures. The predictions in Figure 3-4 for homogeneous moisture content waste show that NFT count rates around $3000 \mathrm{~s}^{-1}$ are expected for dry waste. It is reasonable, therefore, to extrapolate the airhole predictions in Figure 3-8 to give a count rate around $3100 \mathrm{~s}^{-1}$ for a sma 11, $1.5-\mathrm{cm}$ thick air annulus surrounded by 5 to 10 wt\% moisture waste. The final data value to consider is the FFT detector response. This detector provides the only data value that is not consistent with a $1.5 \mathrm{~cm}$ air gap surrounded by about 5 wt\% moisture waste. Figure 3-19 shows that for a $1.5 \mathrm{~cm}$ thick concentric air annulus, a FFT count rate of about 1800 to $2000 \mathrm{~s}^{-1}$ is expected. This absolute count rate is about 20 to $30 \%$ higher than the $1500 \mathrm{~s}^{-1}$ count rate that would be expected for the FFT detector in the supposed dry-waste anomaly. With such good agreement among the interpretations made for the other three detectors, a small perturbation upon the thin $1.5-\mathrm{cm}$ air gap might be expected rather than interpreting the data as a dry waste ring. In a case such as this one, several interpretations of the available neutron data may give satisfactory agreement with the measured data. Additional data, obtained for other source-to-detector spacings or using other average initial energy source neutrons, may be able to supply the information needed to more conclusively determine the true nature of the anomaly. The interpretation of an air-annulus or, alternatively, a dry-waste annulus around the LOW may be facilitated by incorporating information available from passive gamma scans of the waste.

\subsection{HIGH-MOISTURE CONCENTRATION WASTE ANNULUS}

If a region of relatively high-moisture concentration waste were to exist immediately around the LOW, a moisture measurement from within the LOW might overestimate the moisture content of the surrounding semi-solid waste. Figure 3-20 shows the NFT and FFT detector responses to different thickness annuli containing either 15 or $30 \mathrm{wt} \%$ moisture waste surrounded by 0 wt\% moisture waste. The prediction shows that, as long as the relatively highmoisture waste annulus is surrounded by comparable matrix dry material, both the NFT and FFT detectors have reached the response values expected for waste containing a homogeneous moisture content of the inner annulus for all annulus thicknesses greater than about $10 \mathrm{~cm}$. Figure 3-21 shows the NFE and FFE detector responses to different thickness waste annuli containing either 15 or 30 wt\% moisture surrounded by 0 wt\% moisture waste. The FFE detector shows no sensitivity to the outer surrounding dry waste for moist annular waste thicknesses greater than about $12 \mathrm{~cm}$. For 15 to 30 wt\% waste inner annular thicknesses greater than or equal to about $12 \mathrm{~cm}$, it should not be possible for a static-source neutron probe to identify the outer surrounding dry waste or to provide data that would allow for a moisture measurement correction.

\subsection{LIQUID-FILLED ANNULUS}

If a liquid-filled region were to exist immediately around the LOW, the interpretation of a moisture measurement from within the LOW might overestimate the moisture concentration of the surrounding waste. Figure 3-22 shows the NFT and FFT detector responses to different thickness annular 
water-filled annuli surrounded by either 15 or 30 wt\% moisture waste. The prediction shows that, as long as the liquid-filled annulus is surrounded by semi-solid moist waste material, both the NFT and FFT detectors will reach the response values expected for infinite surrounding water for all 1 iquid annulus thicknesses greater than about $5 \mathrm{~cm}$. Although a FFT neutron probe may interrogate up to about $45 \mathrm{~cm}$ into the waste (at $30 \mathrm{wt} \%$ moisture), the majority of the returning thermalized neutron signal is usually most indicative of the first 10 to $20 \mathrm{~cm}$ of surrounding waste. Similar results for the epithermal detectors to this thin liquid-filled annulus are given in Figure 3-23. For liquid-filled annular thicknesses greater than about 5 to $6 \mathrm{~cm}$ it should not be possible for a static-source neutron probe to identify this liquid annulus or to provide data that would allow a moisture measurement correction to be applied for the surrounding waste.

It might be possible to differentiate a thin liquid-filled annulus from a slightly thicker relative high-moisture waste annulus by obtaining additional neutron probe scan data. If epithermal detectors are used in conjunction with a lower initial average energy neutron source, possibly made by wrapping an existing source in polyethylene, the average depth of investigation of the neutron probe could be controlled in a way that should allow a thin liquid annulus to be differentiated from a thicker high-moisture waste annulus. Also, using multiple, near- or far-field detector spacings would provide additional identifying information.

\subsection{HIGH TRANSURANIC CONCENTRATION WASTE}

We investigated the potential effects of possible interference from surrounding TRU waste concentrations upon a neutron probe moisture measurement. The probe modeled for these calculations is the current in-tank neutron probe used for interstitial liquid level determinations. This probe uses an 8-in.-long thermal detector most of which is located in the near field. The neutron source used in this probe model is $1.5 \mathrm{Ci}$ of ${ }^{241} \mathrm{AmBe}$ (average neutron energy $\approx 4.5 \mathrm{MeV}$ ). Figure $3-24$ shows the predicted in-tank neutron probe detector response to passive counting in 30 wt\% moisture waste as the TRU concentrations are increased. Neutrons detected during passive counting would be produced primarily by spontaneous fissions of fissile waste materials and by (alpha, $n$ ) reactions resulting from alpha-particle emissions from TRU waste. The modeled tank waste relative proportions of the TRU isotopes were taken from TRAC data. The waste TRU concentration was increased in this model, keeping the TRAC data isotopic TRU ratios constant, and the results are reported as a function of ${ }^{239} \mathrm{Pu}$ concentration. Figure $3-24$ shows that the rate of neutrons detected during passive counting will very slowly increase from less than 1 per second at expected ferrocyanide tank TRU concentrations (about $0.003 \mathrm{~g} / \mathrm{L}{ }^{239} \mathrm{Pu}$ ) to about 50 per second at $1 \mathrm{~g} / \mathrm{L}{ }^{239} \mathrm{Pu}$. Above these concentrations, the expected neutron flux rapidly begins to rise, producing a large signal in the detector. Available tank sampling data have shown no ${ }^{239} \mathrm{Pu}$ concentrations above $1 \mathrm{~g} / \mathrm{L}$.

Figure 3-25 shows the MCNP predicted probe response to 30 wt\% moisture content waste containing increasing ${ }^{239} \mathrm{Pu}$ concentration. This prediction only includes neutrons from the probe source and any that are produced in the waste 
by induced fissions of fissionable materials. It is clear that the detector response will remain unaffected by concentrations of ${ }^{239} \mathrm{Pu}$ below $1 \mathrm{~g} / \mathrm{L}$. At this concentration the observed detector count rate is expected to be about 50 counts per second higher than that expected for the given moisture concentration, as seen in Figure 3-24. This effect is easily corrected by first performing a passive neutron scan to determine any baseline count rate from TRU waste content and then subtracting this baseline profile from the active scan profile. Therefore, for tank wastes containing below approximately $1 \mathrm{~g} / \mathrm{L}{ }^{239} \mathrm{Pu}$, neutron probe moisture measurements should be unaffected by the presence of TRU wastes.

Figure 3-25 shows a sketch that compares the typical near-and far-field neutron detector responses for increasing waste moisture concentration with those expected for increasing waste TRU concentration. As the figure demonstrates, an increase in the TRU content of the waste may be clearly differentiated from an increase in the moisture content by obtaining both near- and far-field scans. Near- and far-field responses react oppositely to increasing moisture, while both near- and far-field responses are expected to increase with increased TRU concentrations.

\subsection{PULSED-SOURCE NEUTRON PROBE}

The pulsed-source neutron probe produces neutron by a fusion reaction using a small particle accelerator. The result is a short, typically 10 microsecond pulse of high energy (14 MeV) neutrons. This type of source has two advantages over the static source: the high energy neutrons penetrate further into the surrounding material, and the resulting neutron count rate has a time dependency that may provide additional information about the surrounding material. The pulsed-source may be adjusted to produce more neutrons per unit time than can be obtained from static sources -- higher flux static sources are possible but are prohibitively difficult to handle.

The MCNP model of the pulsed-source neutron probe, shown in Figure 4-1, is very similar to the one used for the static source. The major difference is the location of the detectors. A high voltage power supply is required for the pulsed-neutron source, and it must be placed immediately above the neutron source itself. As a result the neutron detectors have been placed below the neutron source. In addition, in the pulsed-source neutron probe model, the detectors have been modeled explicitly as a 10.0-cm-high near-field detector and a 20.0-cm-high far-field detector. Two versions of the model were used: thermal and epithermal. The epithermal model is essentially the same as the thermal model except that the detectors are covered by a layer of polyethylene and a layer of cadmium. The cadmium absorbs most of the thermal neutrons before they can reach the detector, and the polyethylene thermalizes the epithermal neutrons so that they can be detected more efficiently.

The evaluation of the pulsed-source neutron probe was conducted largely as an extension of the static source evaluation, which resulted in less time to complete the study. In addition, because of the time dependency, each pulsed-source calculation requires substantially more computer time than an 
equivalent static source calculation. As a result of these limitations, the scope of the pulsed-source neutron probe study was reduced from that of the static probe. This evaluation focused on the ability to recognize differences in waste moisture concentration, and air-or water-filled annuli, using the shape of the neutron response curve. No effort was made at the time to use the time-dependent features of neutrons to resolve anomalies. Time gating, pulse width, and pulse frequency may be useful device parameters with which to investigate both homogeneous and inhomogeneous media.

\subsection{HOMOGENEOUS SURROUNDING MOISTURE CONCENTRATION}

The primary application of the probe is to determine the moisture content of the waste. The first modeling effort demonstrated the ability to do this with the pulsed-source neutron probe. Two moisture levels were considered for this evaluation: $15 \mathrm{wt} \%$ and $30 \mathrm{wt} \%$. Additional calculations would allow finer resolution of the moisture content.

Figure 4-2 shows the response for the NFT detector and Figure 4-3 shows the response for the FFT detector. Figures 4-4 and 4-5 show the same information normalized to a peak response of 1.0 . This is useful in comparing the shapes of the curves. In general, the pulsed probe response is similar to that of the static probe, i.e., the NFT detector response increases with increasing water content and the FFT detector response decreases with increasing water content. The fall-off rate decreases with increasing moisture content for both the NFT and FFT detectors. Overall, the shapes of the thermal response curves are somewhat difficult to interpret because of oscillations in the fall-off rate. This is a result of poor statistics, (i.e., insufficient calculational time) in the MCNP calculations. There was not sufficient time to refine these calculations further but work is currently underway to develop a more efficient model to reduce the very long calculational time.

By using this data, a relationship can be established that would allow a moisture content identification based on a pulsed-source neutron probe measurement. The following listings provide a simple example of such a relationship.

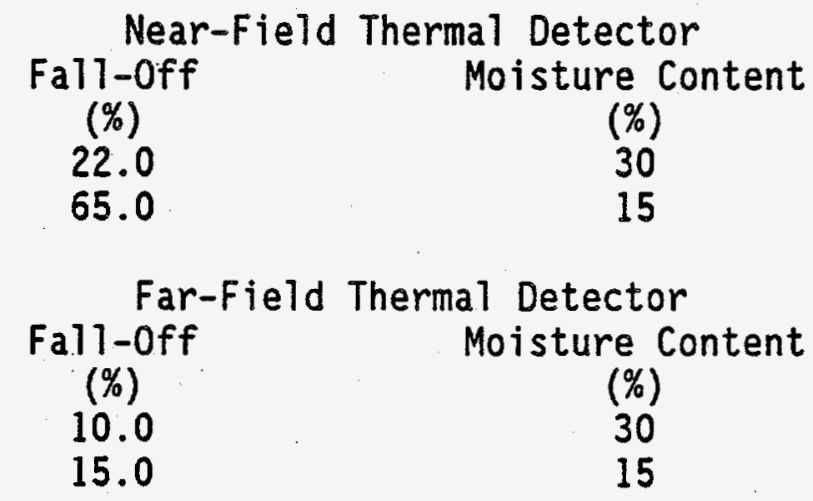


Figure 4-6 shows the response for the NFE detector and Figure 4-7 shows the response for the FFE detector. Figures 4-8 and 4-9 show the same information normalized to a peak response of 1.0 . The epithermal detectors give a similar total response to that of the thermal detectors, except that the dependency on water content is smaller. In addition, the fall-off rate of the detector response increases with increasing moisture content. The fal1-off can be related to the moisture content in the same manner as it was for the thermal detectors.

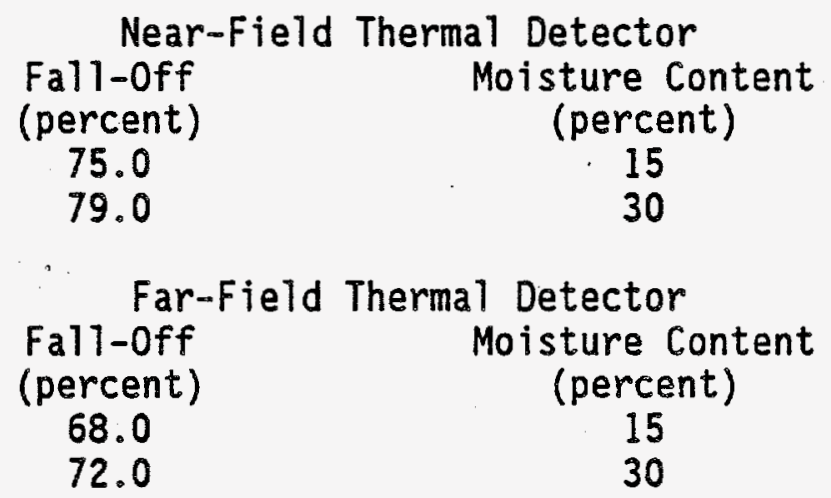

In order to determine the moisture content, a probe measurement would be made and the fall-off (percent drop in count rate after 40 microseconds) would be calculated for both the thermal and epithermal detectors. The calculated fall-off would then be found on the table and the moisture content read off: All four relationship tables should provide the same results. If the relationships do not agree, then an anomaly in the waste is indicated that must be accounted for before the moisture content can be determined.

\subsection{CONCENTRIC AIR-FILLED ANNULUS}

A concentric air-filled annulus is one of the anomalies that can interfere with the determination of the waste moisture content. The purpose of this evaluation is to determine how the pulsed-source neutron probe responded to different sizes of annuli. Annulus thicknesses of $0.0 \mathrm{~cm}$, $1.0 \mathrm{~cm}$, and $2.0 \mathrm{~cm}$ were evaluated.

Figure 4-10 shows the response for the NFT detector and Figure 4-11 shows the response for the FFT detector. Figures 4-12 and 4-13 show the same information normalized to a peak response of 1.0 . As indicated in these figures, the fall-off rate of the detector response decreases with increasing moisture content.

Figure 4-14 shows the response for the NFE detector and Figure 4-15 shows the response for the FFE detector. Figures 4-16 and 4-17 show the same information normalized to a peak response of 1.0. Again, the fall-off rate of the detector response decreases with increasing moisture content. 
The same type of relationships can be developed with this data as was developed when the waste moisture content was determined. In this evaluation, the relationships would provide the air annulus thickness, given the waste moisture content and the measured fall-off. However, the more important result is the ability to assess how the presence of an air-filled annulus will interfere with the determination of the moisture content. The presence of the air-filled annulus causes the thermal detector fall-off to decrease. This is a similar effect to that seen when the moisture content of the waste is decreased. The epithermal detectors, however, also show a decrease in the fall-off when an air annulus is introduced. This is a similar effect to that observed when the moisture content of the waste is increased. Therefore, an epithermal measurement that indicates a higher moisture content than the thermal measurement is an indicator of an air gap.

\subsection{CONCENTRIC LIQUID-FILLED ANNULUS}

A concentric liquid-filled annulus is another anomaly that can interfere with the determination of the waste moisture content. The purpose of this evaluation was to determine how the pulsed-source neutron probe responded to different sizes of annuli. Annulus thicknesses of $0.0 \mathrm{~cm}, 1.0 \mathrm{~cm}$, and $2.0 \mathrm{~cm}$ were investigated with the model.

Figure 4-18 shows the response for the NFT detector and Figure 4-19 shows the response for the FFT detector. Figures 4-20 and 4-21 show the same information normalized to a peak response of 1.0 . For both the NFT and the FFT detector, the fall-off rate decreases with increasing water content.

Figure 4-22 shows the response for the NFE detector and Figure 4-23 shows the response for the FFE detector. Figures 4-24 and 4-25 show the same information normalized to a peak response of 1.0 . As the figures indicate, the fall-off rate of the detector response increases with increasing moisture content.

Again, the same type of relationships can be developed with this data as was developed when the waste moisture content was determined. In this case, the relationships would provide the liquid-filled annulus thickness, given the waste moisture content and the measured fall-off. As with the air-filled annulus, the important result is the ability to assess how the presence of a liquid-filled annulus will interfere with the determination of the moisture content. The presence of the liquid-filled annulus causes the thermal detector fall-offs to decrease. This is a similar effect to that seen when the moisture content of the waste is increased. In this case, the epithermal detectors show an increase in the fall-off when a liquid-annulus is introduced. This is also a similar effect to that seen when the moisture content of the waste is increased and therefore implies that a liquid-filled gap will cause a detector response similar to what would be found with a higher-moisture content waste material. 
WHC-EP-0809

\subsection{PULSED-NEUTRON RESPONSE TO FISSIONABLE MATERIAL WASTE}

Pulsed-neutron logging for fissionable materials in earth formations is a developed technique (Givens and Stromswold 1989). It operates by injecting a pulse of neutrons into the formation and then detecting secondary neutrons that are produced as a result of induced fission. This technique should be adaptable to the high-radiation $(50-400 \mathrm{R} / \mathrm{hr})$ waste tank conditions through integration with the current in-tank neutron probe detector technology. The expected detection limit for ${ }^{239} \mathrm{Pu}$ is about $10^{-7} \mathrm{~g} / \mathrm{L}$. The signal produced from the induced fissions would be easily distinguished from background neutron production resulting from (alpha, $n$ ) reactions and other sources. Initial modeling has been completed that simulates fissionable material measurements for waste tank materials (Toffer et a1. 1993).

\subsection{CONCLUSIONS}

Information obtained from static-source neutron probes provides a means of identifying possible material and material geometry anomalies. Annular air-filled gaps between the LOW and waste should be identified, making appropriate corrections to the waste moisture measurements possible. These corrections will introduce some additional uncertainty into the moisture measurement. For high-moisture concentration or liquid-filled regions near the LOW, the probes are clearly limited in their range of detection beyond these features. Thick, high-moisture regions immediately surrounding the LOW, will completely mask any material differences in outer surrounding wastes. For complicated low-moisture content material anomalies, the interpretation of the feature and the surrounding moisture may not always be unique. Table 5-1 gives a brief summary of predicted neutron probe responses to several material anomalies and possible explanations for the individual response from each basic type of probe. If additional neutron scan data are obtained using different probe configurations, such as time-dependant response or additional source-to-detector spacings, more constraints can be applied to the material and its geometry to make a more reliable interpretation of the anomaly and of the surrounding waste moisture content. Modeling, specific to each set of tank neutron scans, may be needed to best identify and correct the moisture measurement for any individual, unique anomalies in the moisture interpretation.

The pulsed-source neutron probe is capable of providing the same information as the static source probe. The static source results in a constant neutron interaction rate at the neutron detector. This same result can be achieved by integrating the total response of the pulsed source. The pulsed-source probe can, therefore, resolve any feature that the static source probe can resolve. In addition, the shape of the response curve for the pulsed-source probe provides an additional indicator that can help verify any conclusion based on the total count rate. This additional information may also identify some features that cannot be detected with the static source probe. The results of the modeling completed for this study have demonstrated that the shape of the curve, specifically the fall-off rate can be used to identify various features such as different sized air gaps. However, more 
modeling is needed to determine if similar features can be distinguished by use of the fall-off rate alone: by distinguishing between a liquid-filled annulus and a higher moisture concentration waste material. More modeling is also needed to explore the impact of other features, such as horizontal layers with different water contents, and waste materials with different concentrations of thermal absorbers. 


\begin{tabular}{|c|c|c|c|c|c|c|}
\hline 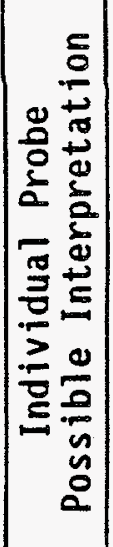 & 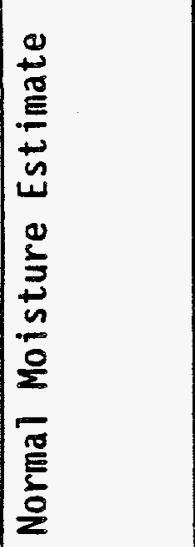 & 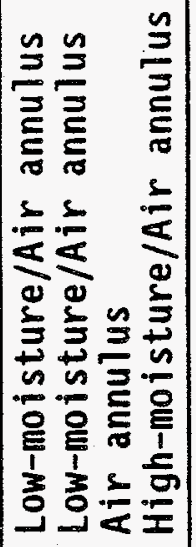 & 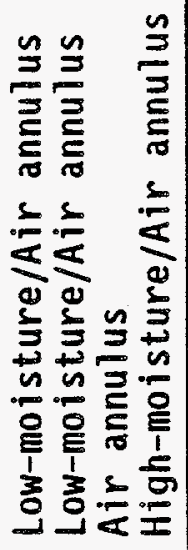 & 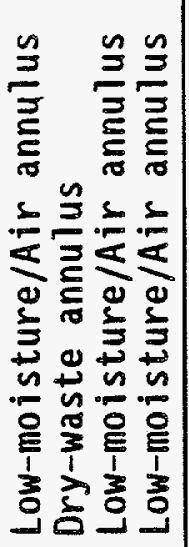 & 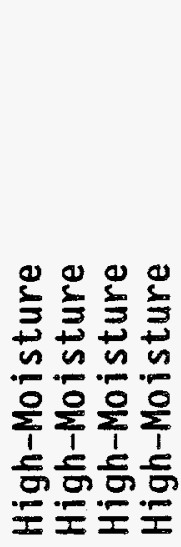 & 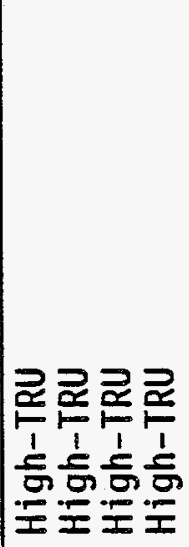 \\
\hline 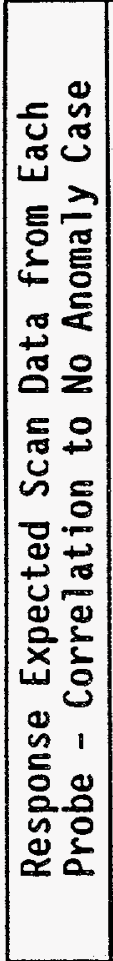 & 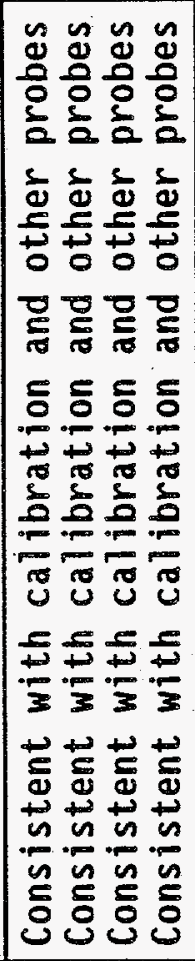 & 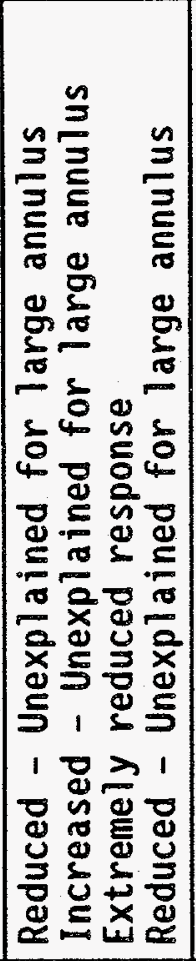 & 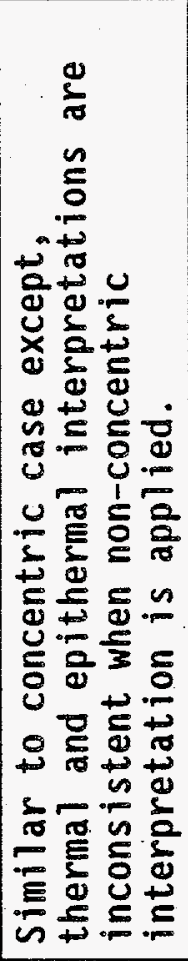 & 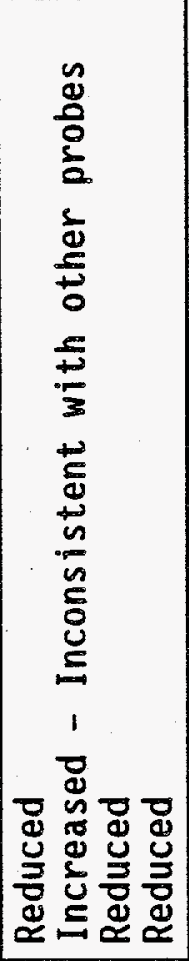 & 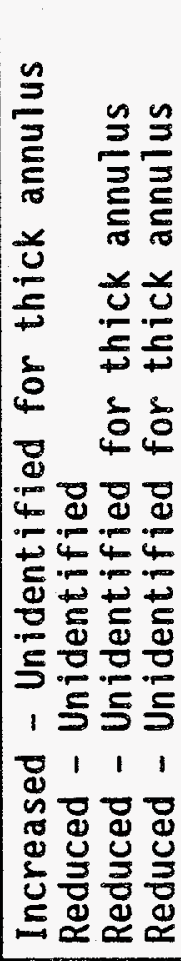 & 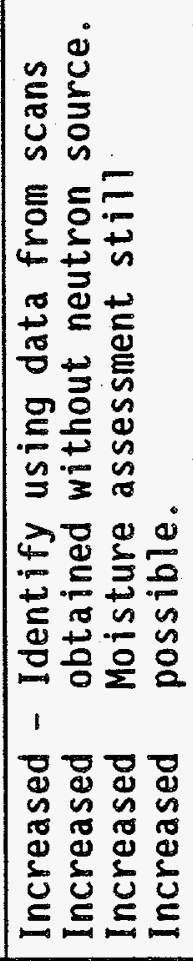 \\
\hline $\begin{array}{l}\text { 定 } \\
\text { L }\end{array}$ & 迠㫐岕崖 & 㫐㫐岕岕 & 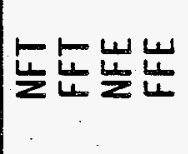 & 㫐志崖岌 & 㫐㫐岕岕 & 㫐㫐崖崖 \\
\hline 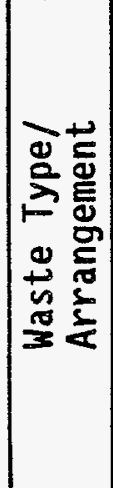 & 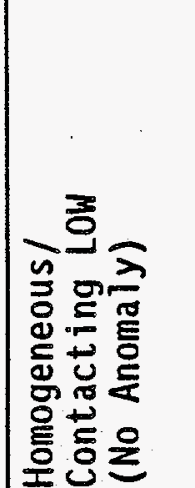 & 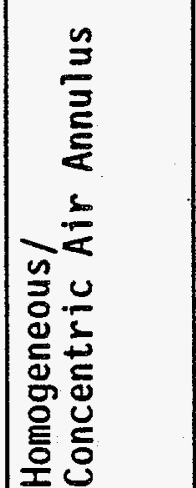 & 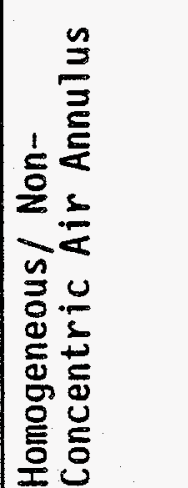 & 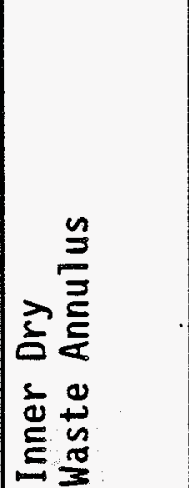 & 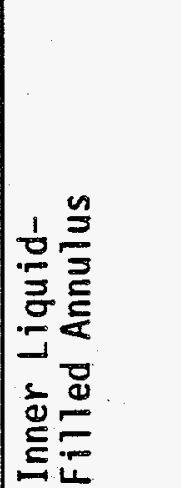 & 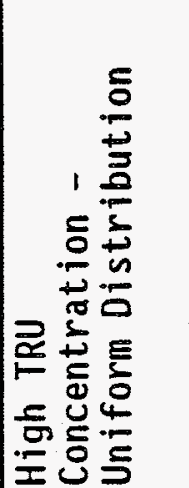 \\
\hline
\end{tabular}




\subsection{REFERENCES}

Givens, W. W. and D. C. Stromswold, Prompt Fission Neutron Logging for Uranium, Nuclear Geophysics, Vol. 3, No. 4, pp. 299-307, 1989.

Hearst, Joseph R. and Richard C. Carlson, A Comparison of the Moisture Gauge and the Neutron Log in Air-filled Holes, Nuclear Geophysics, Vol. 8, No. 2, pp. 165-172, 1994.

LANL, 1993, MCNP - A General Monte Carlo N-Particle Transport Code, Version 4A, LA-12625, (J. F. Briesmeister, Ed.), Los Alamos National Laboratory, Los Alamos, New Mexico.

Toffer, H., W. T. Watson, and V. E. Roetman, 1993, Neutron Pulse Simulation in Nuclear Waste for Waste Characterization, WHC-SA-2159-FP, Westinghouse Hanford Company, Richland, Washington.

Watson, W. T., 1993, Proof of Principle Report for In-Tank Moisture Monitoring Using an Active Neutron Probe, WHC-EP-0695, Westinghouse Hanford Company, Richland, Washington. 
WHC-EP-0809

This page intentionally left blank. 
WHC-EP-0809

Figure 3-1. Cross-Sectional Sketch of a Static-Source Thermal Neutron Detector Probe Model Geometry.

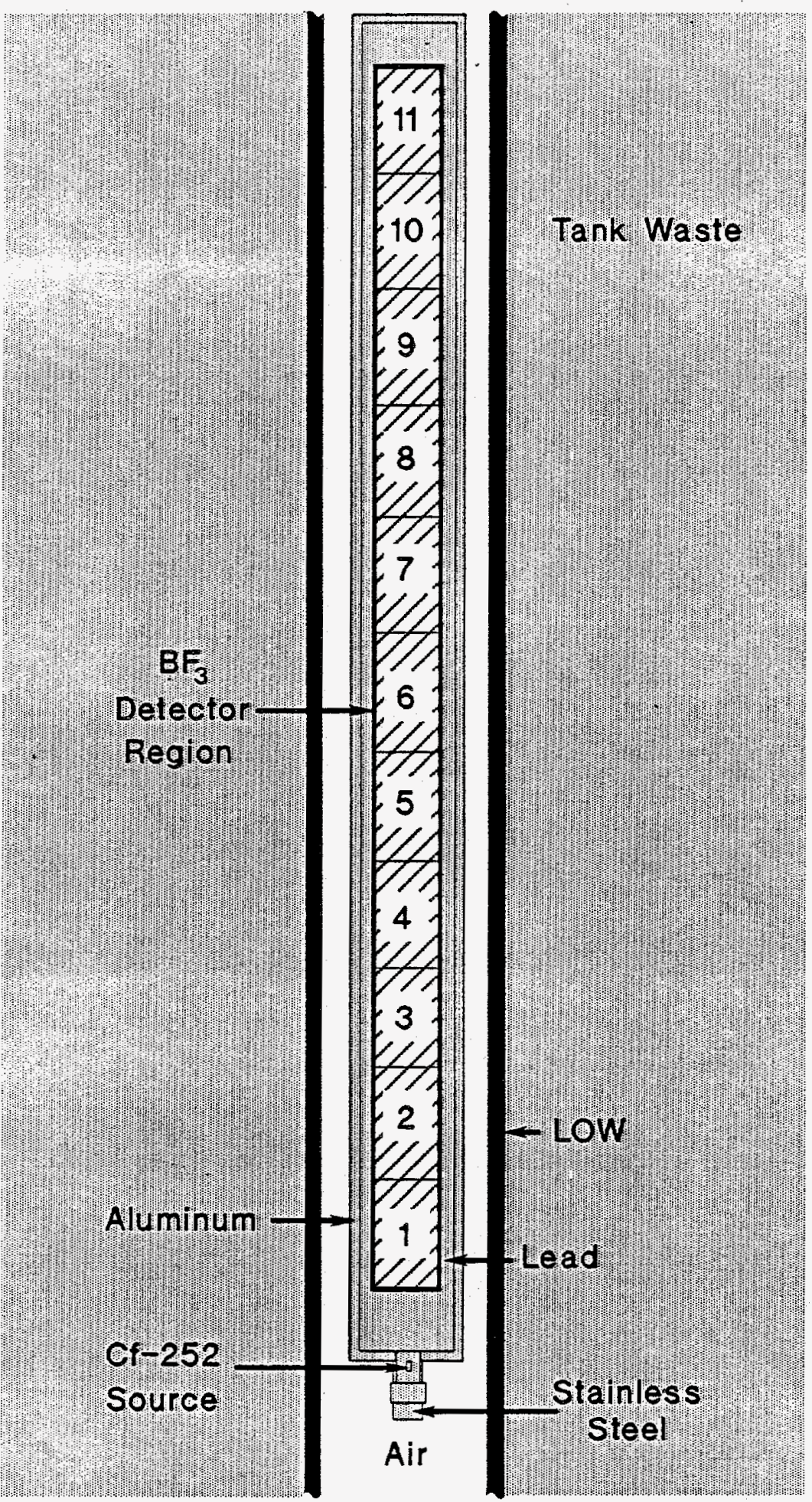


Figure 3-2. Thermal Neutron Probe Detector Section Responses to Increasing Moisture Concentration Waste.

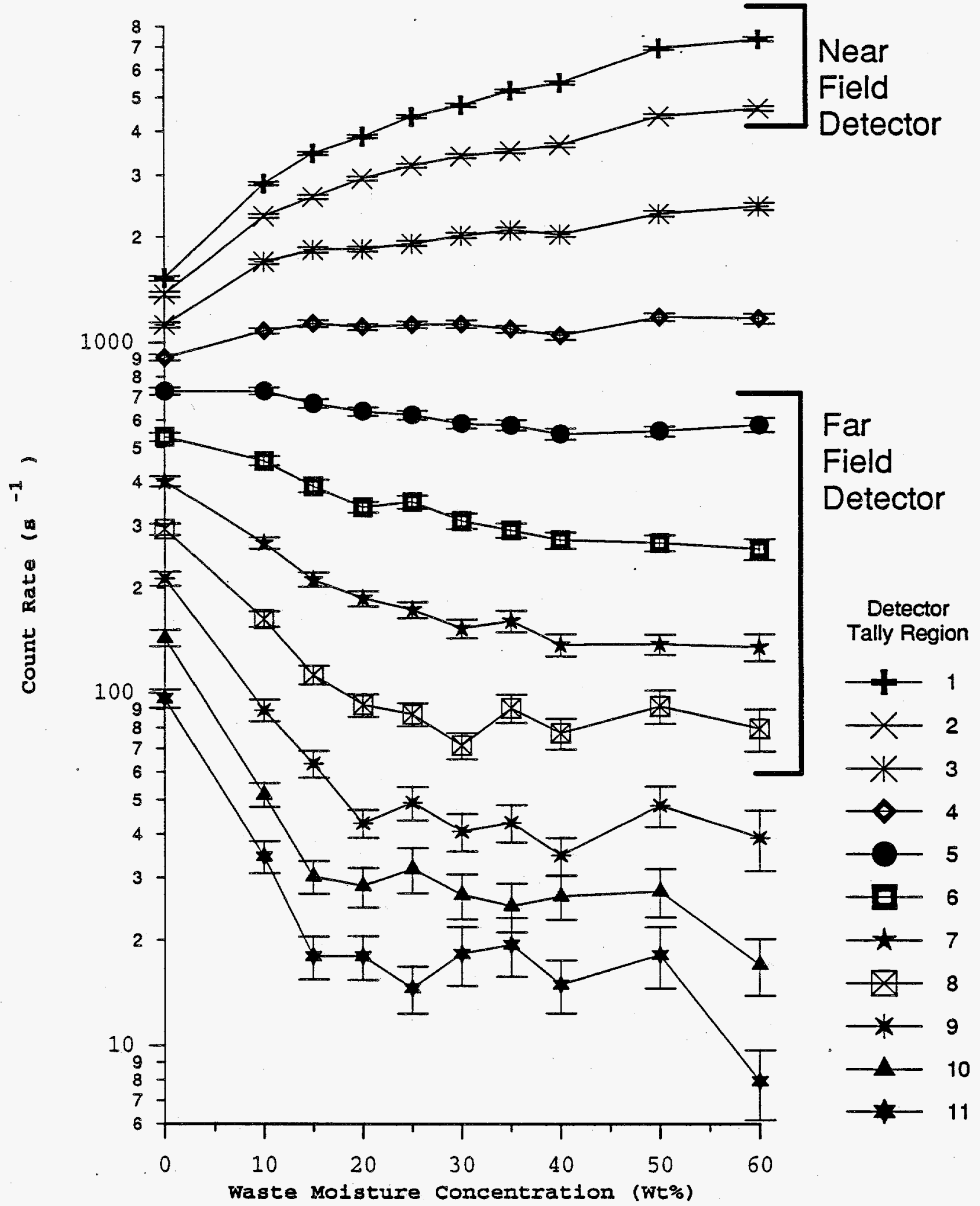


Figure 3-3. Epithermal Neutron Probe Detector section Responses to Increasing Moisture Concentration Waste.

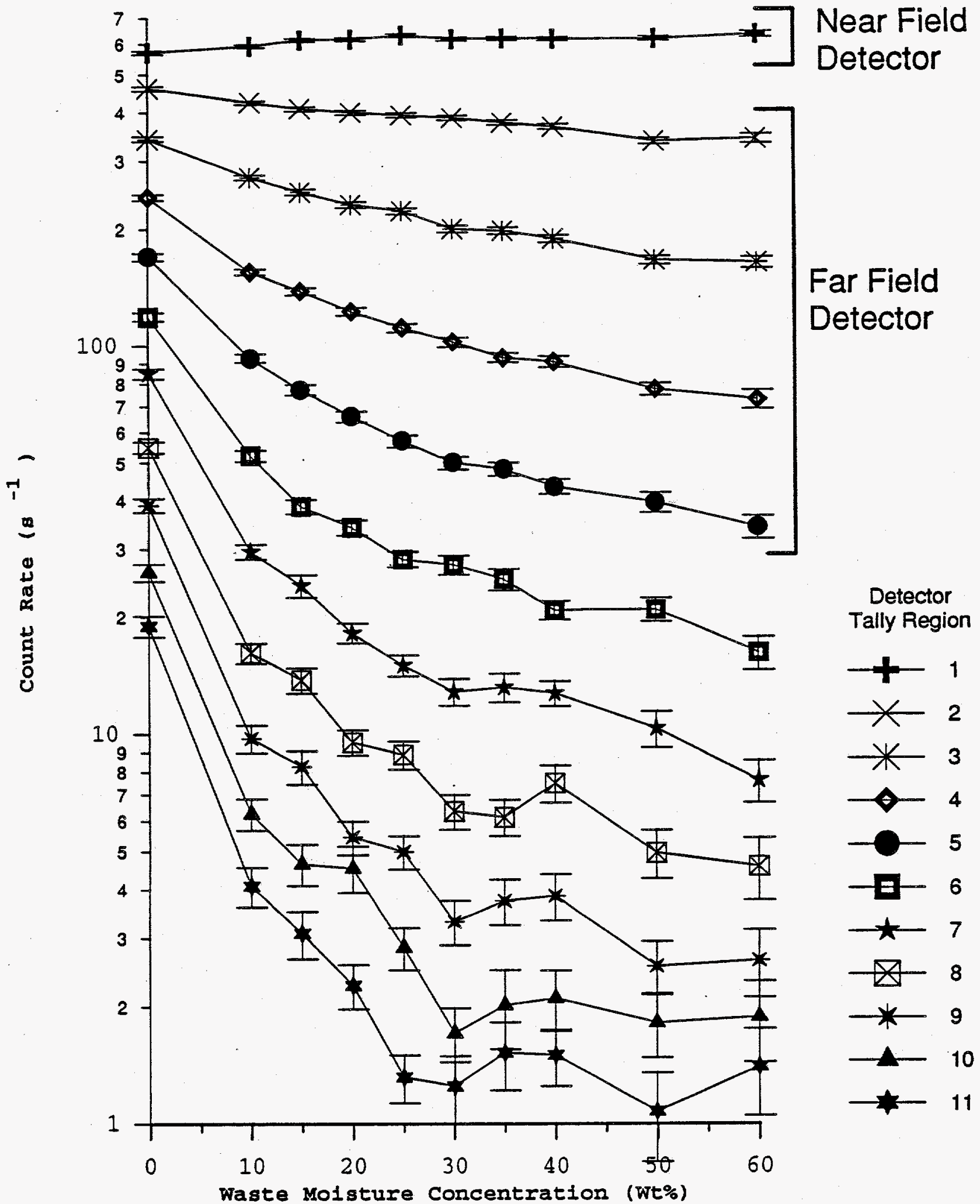


F1gure 3-4. Response of Near-and Far-Fleld Thermal Neutron Detectors to Homogeneous Molsture Concentration Waste.
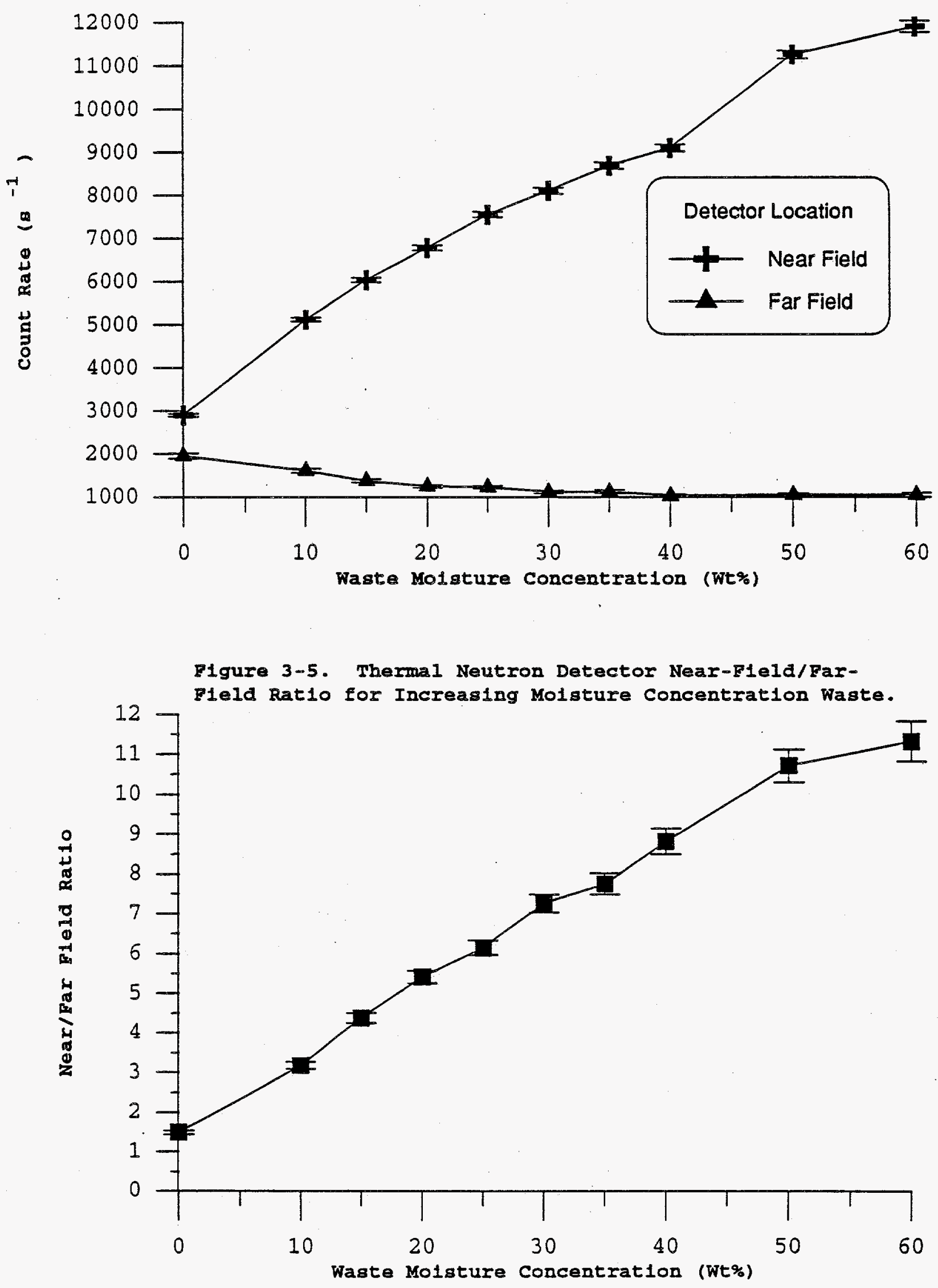
F1gure 3-6. Responses of Near- and Far-Field Epithermal Neutron Detectors to Homogeneous Molsture Concentration Waste.

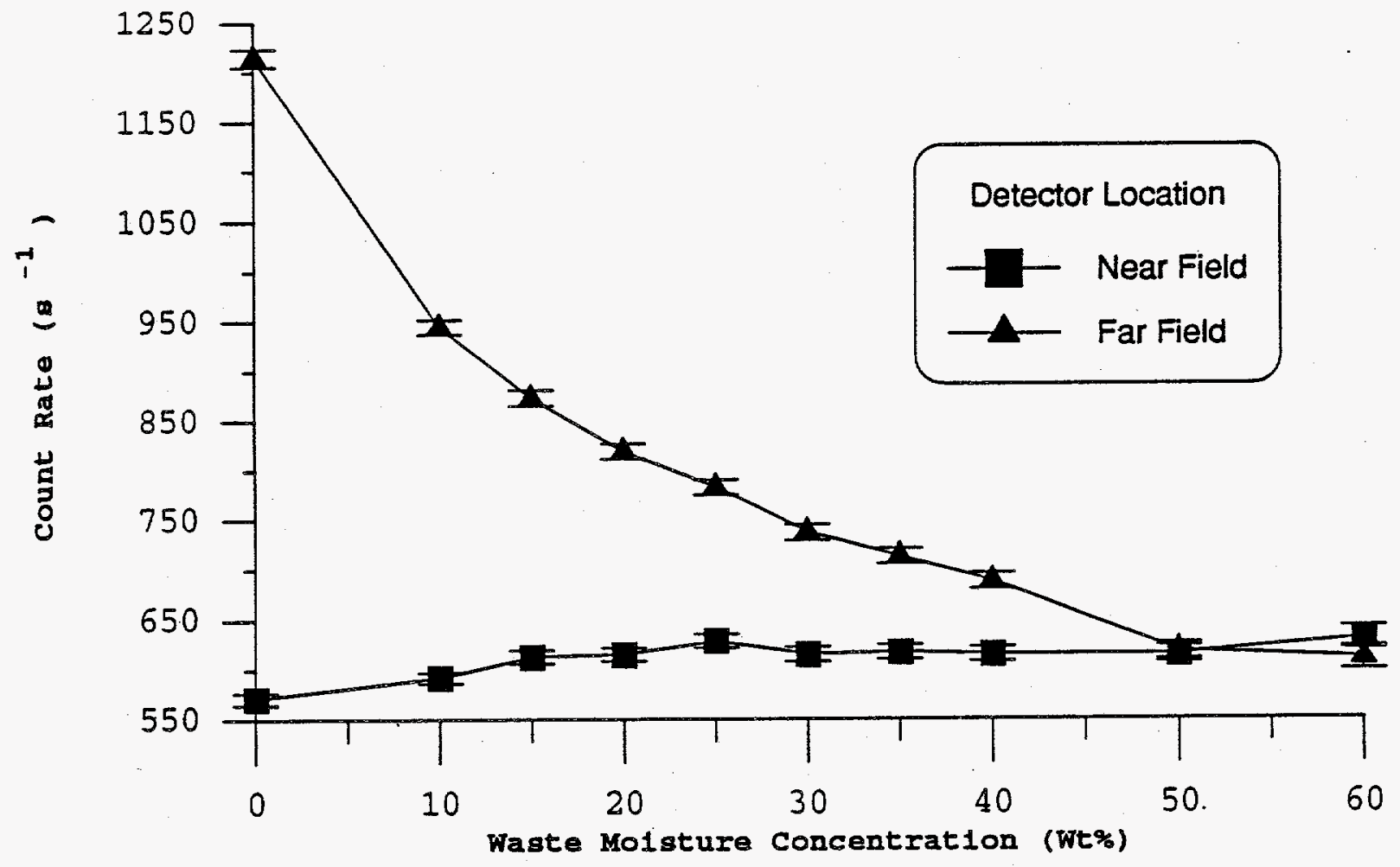

F1gure 3-7. Eplthermal Neutron Detector Near-Fleld/Far-Field Rat10. for Increasing Molsture Concentration Waste.

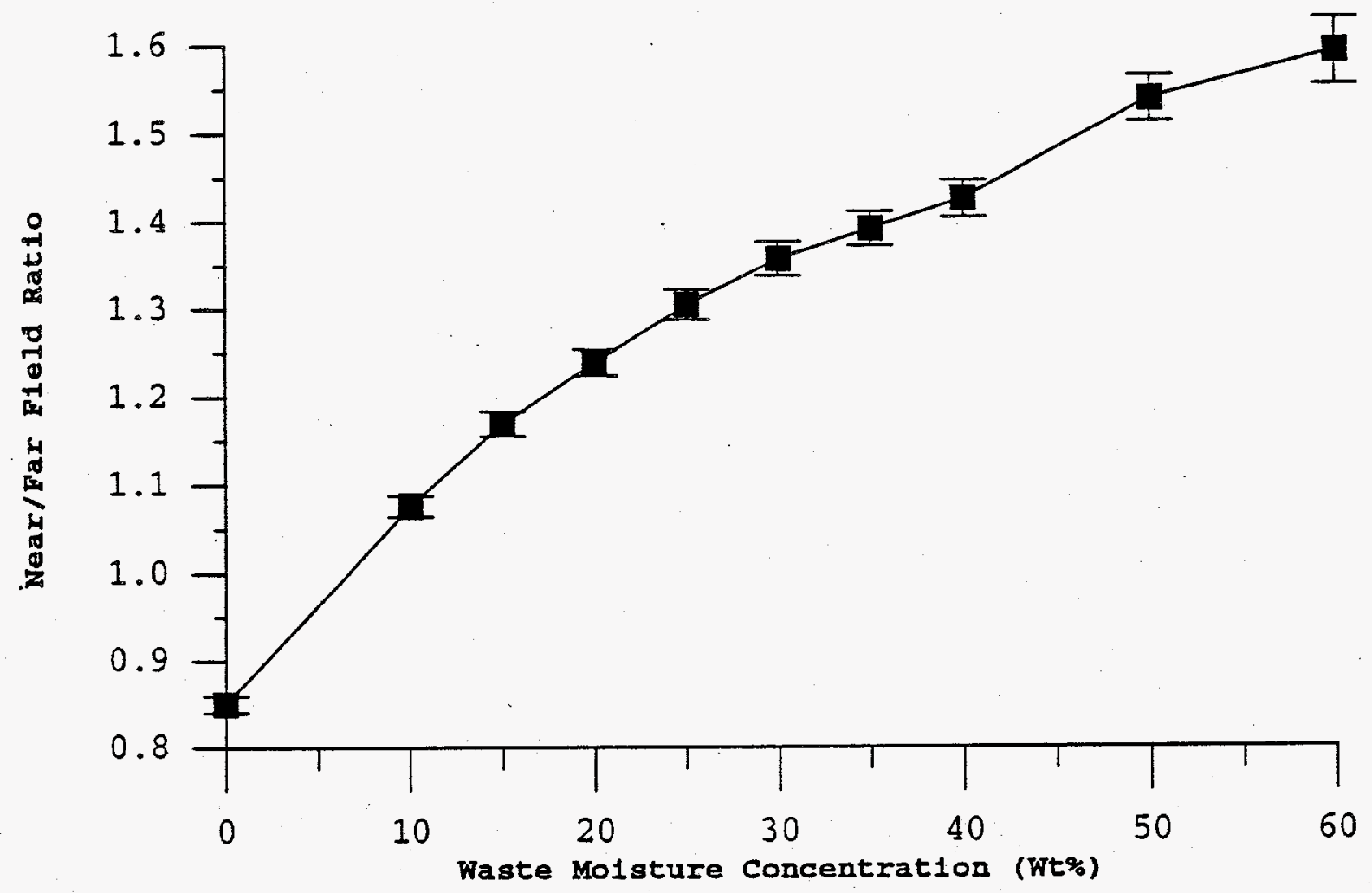


F1gure 3-8. Thermal Neutron Detector Responsea to Concentric AlI Annuli Between the Ilquid observation Well and Two Molsture Concentration Wastes.

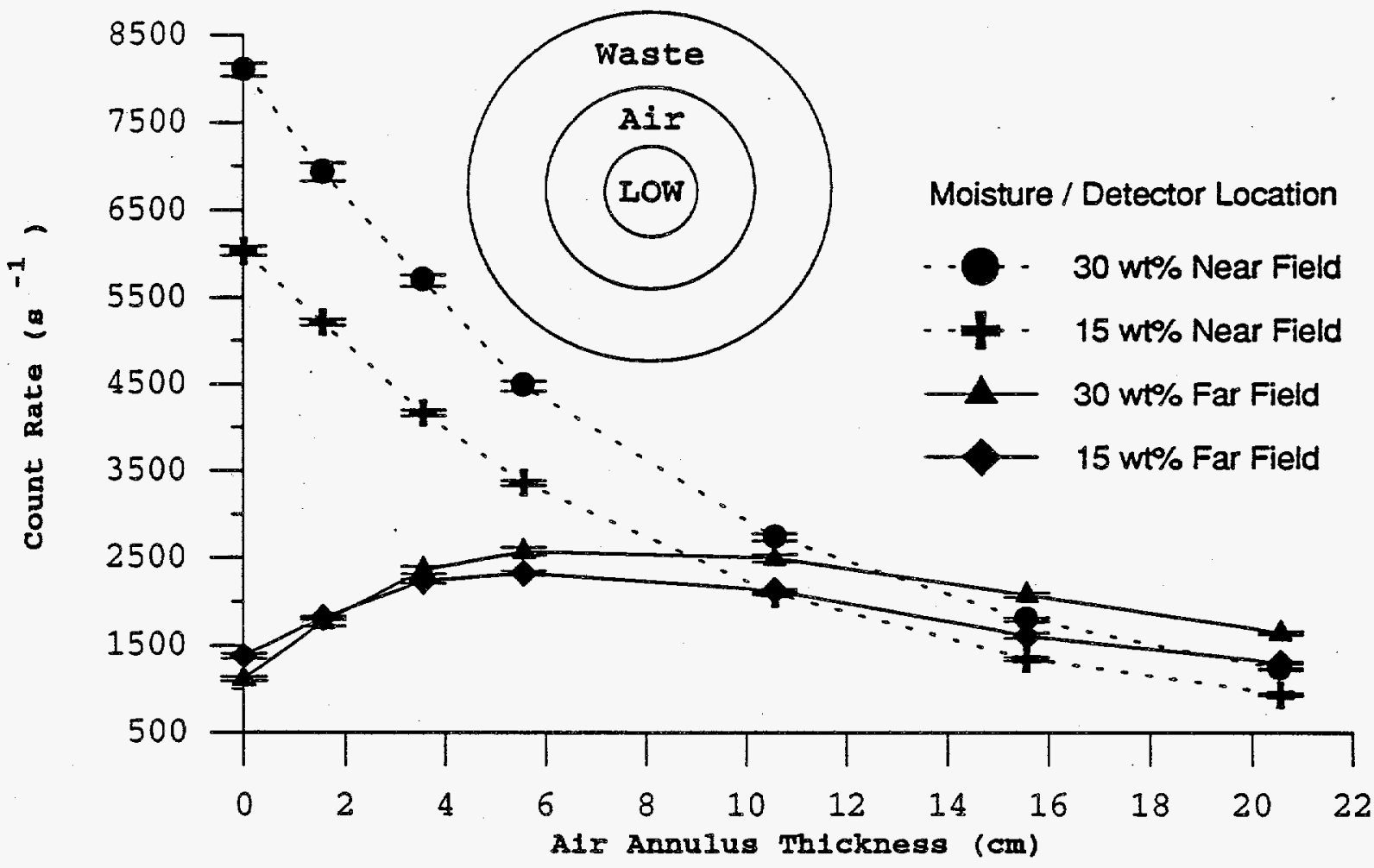

Figure 3-9. Thermal Neutron Detector Near-Field/Far-Field Ratio for Increasing Concentric Alr Annulus Thickness.

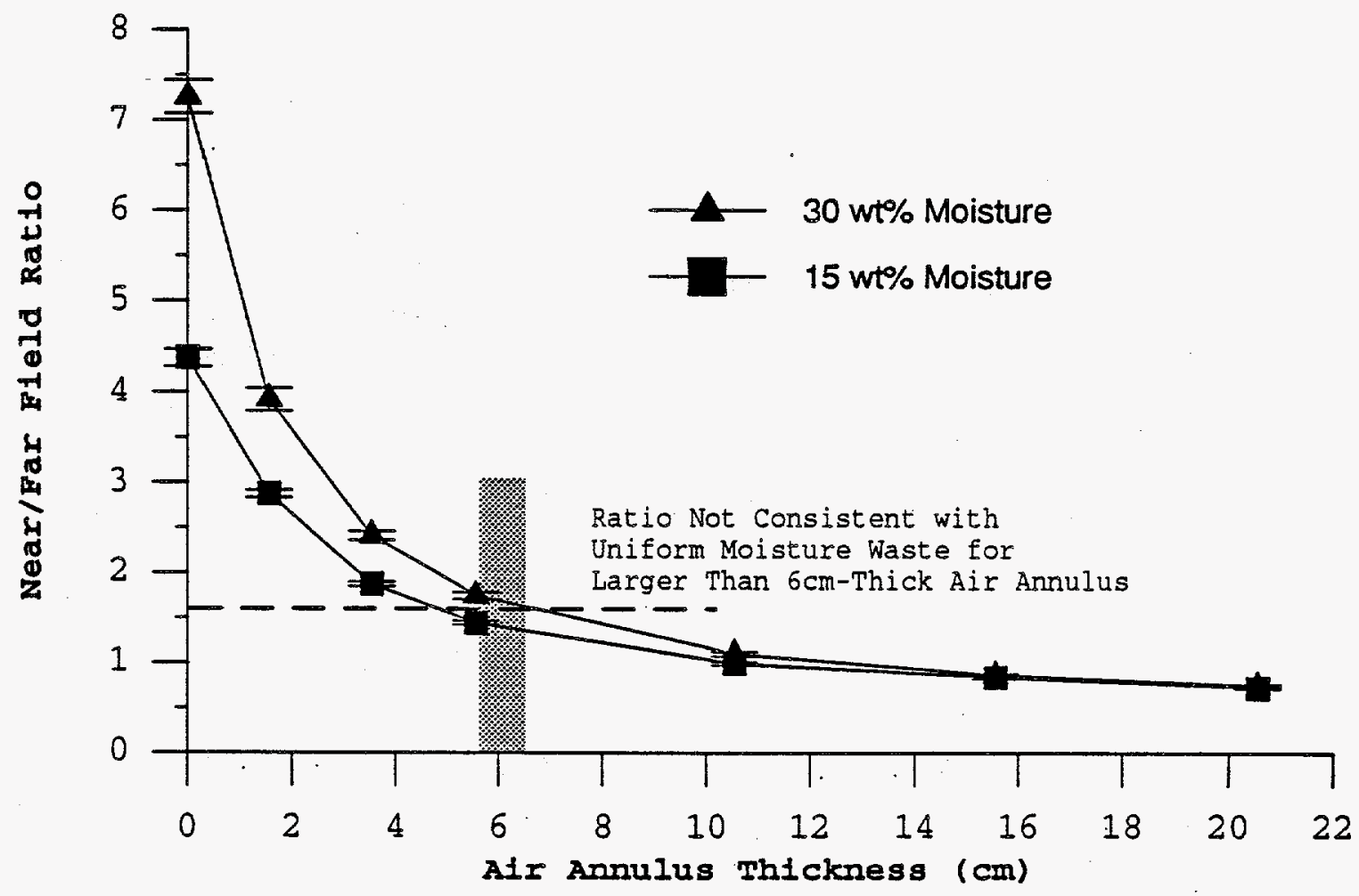


WHC-EP-0809

igure 3-10. Epithermal Neutron Detector Responses to Concentric Air Annuli Between the Liquid Observation Well and Two Moisture Concentration Wastes.

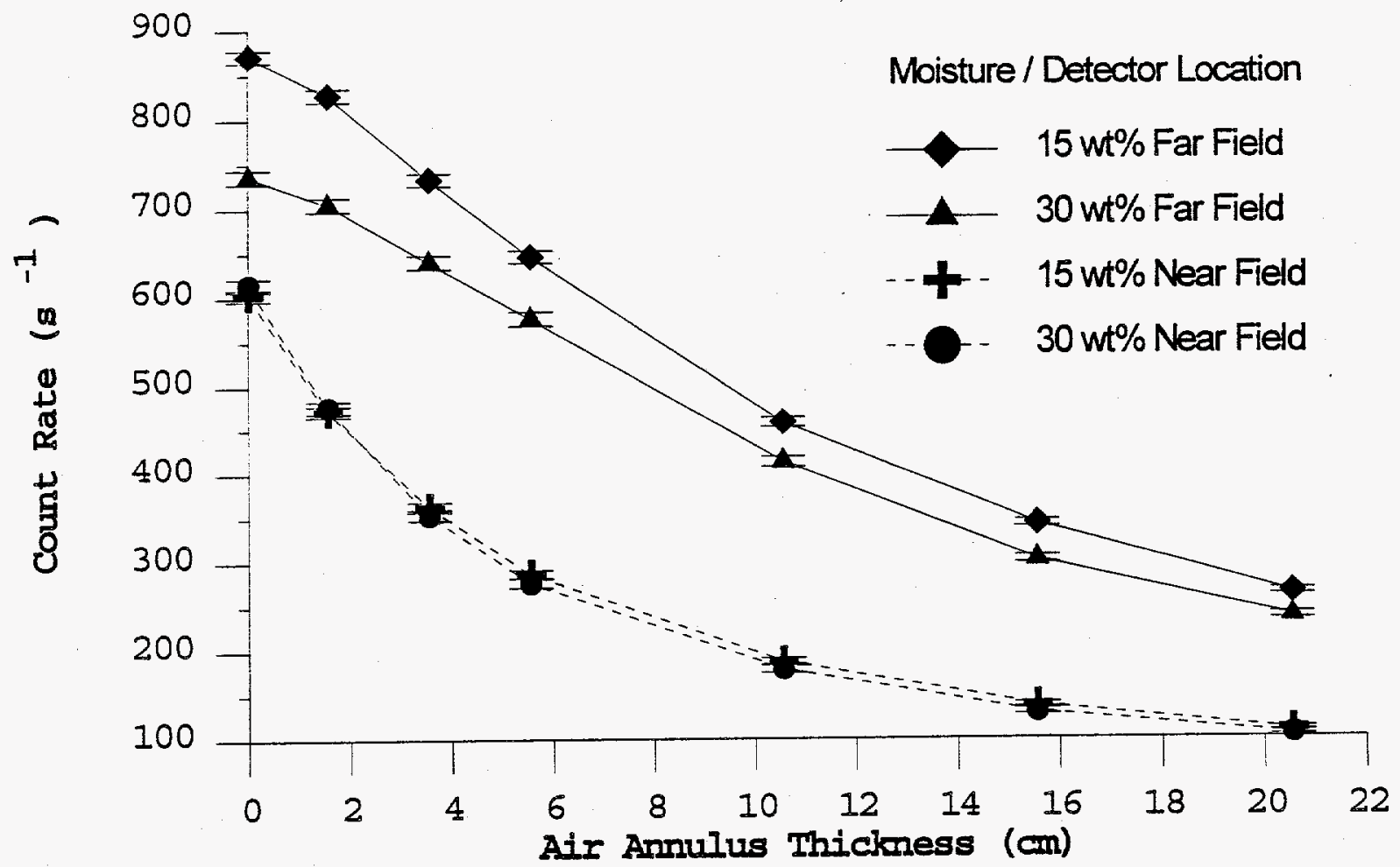

Figure 3-11. The Near Field Fithermal Detector Response to Waste Moisture Concentration Compared With That Expected to Different Thickness Air Anmuli.

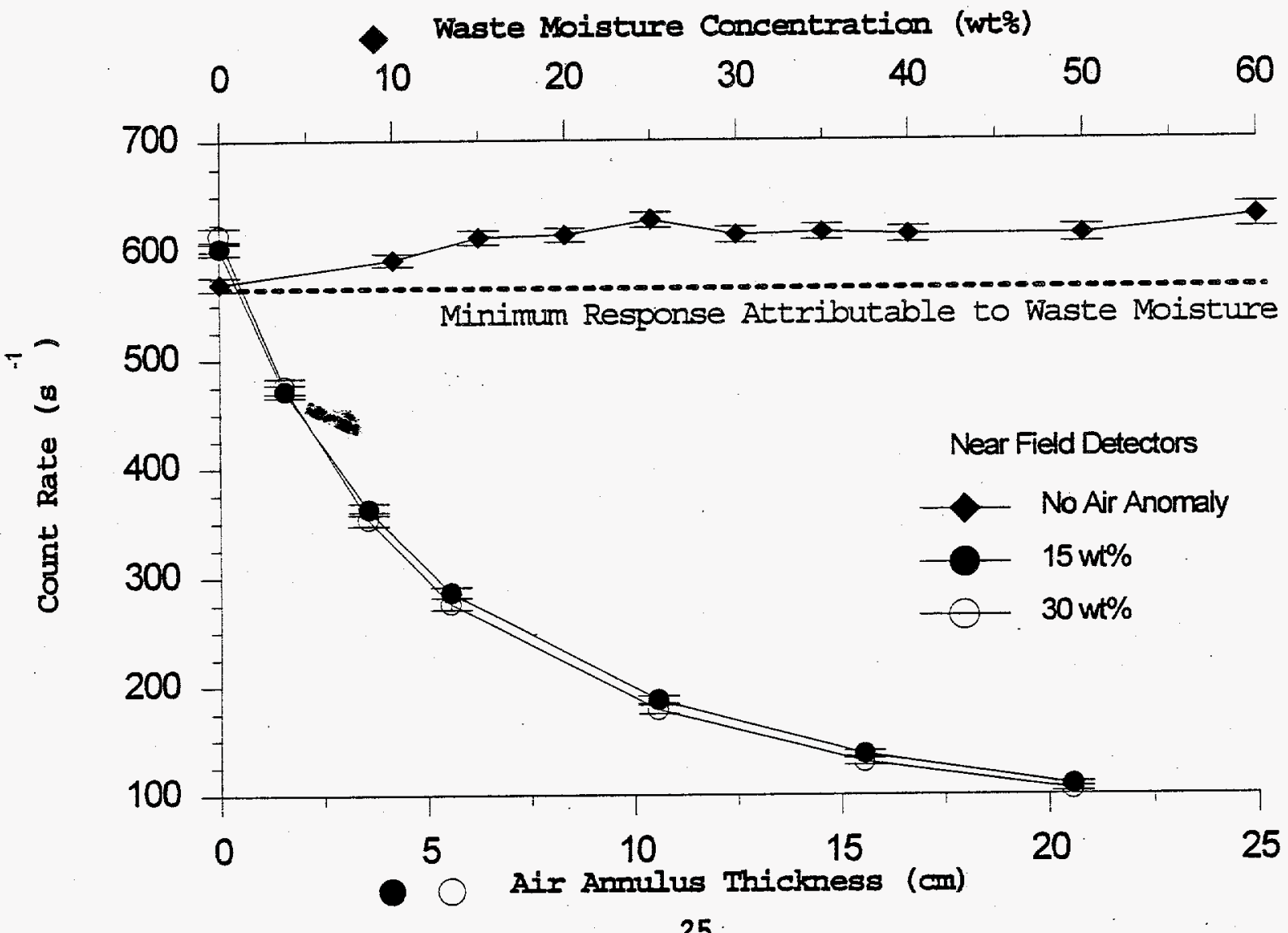


F1gure 3-12. Eplthermal Neutron Detector Near-F1eld/Far-F1eId Rat 1o for Increasing Concentration Air Annulus Thlckness.

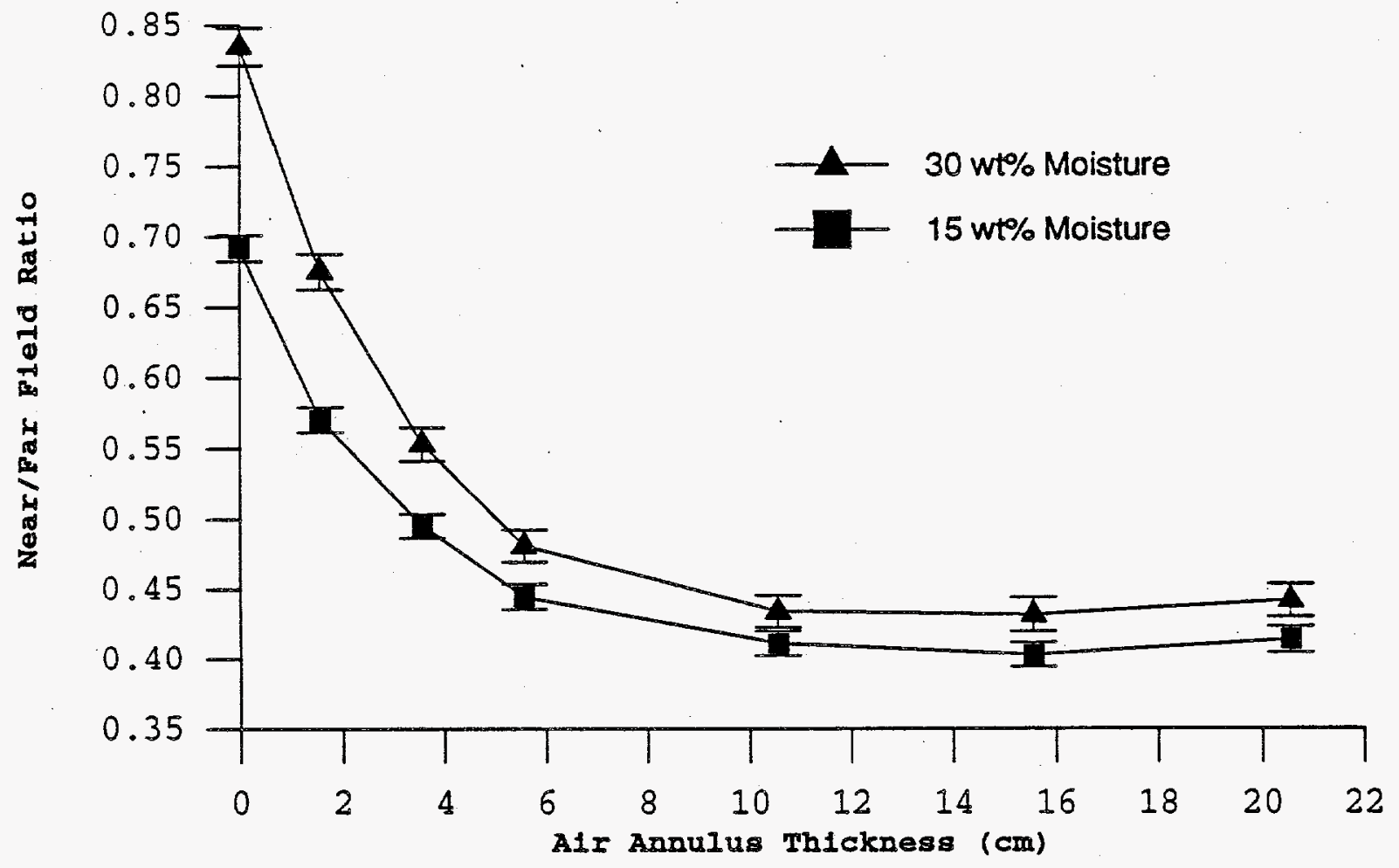

F1gure 3-13. Comparison of Thermal Neutron Detector Responses to Concentric and Nonconcentric Alr Annull Between the L1quid Observation We11 and 30 wt\% Molsture Waste.

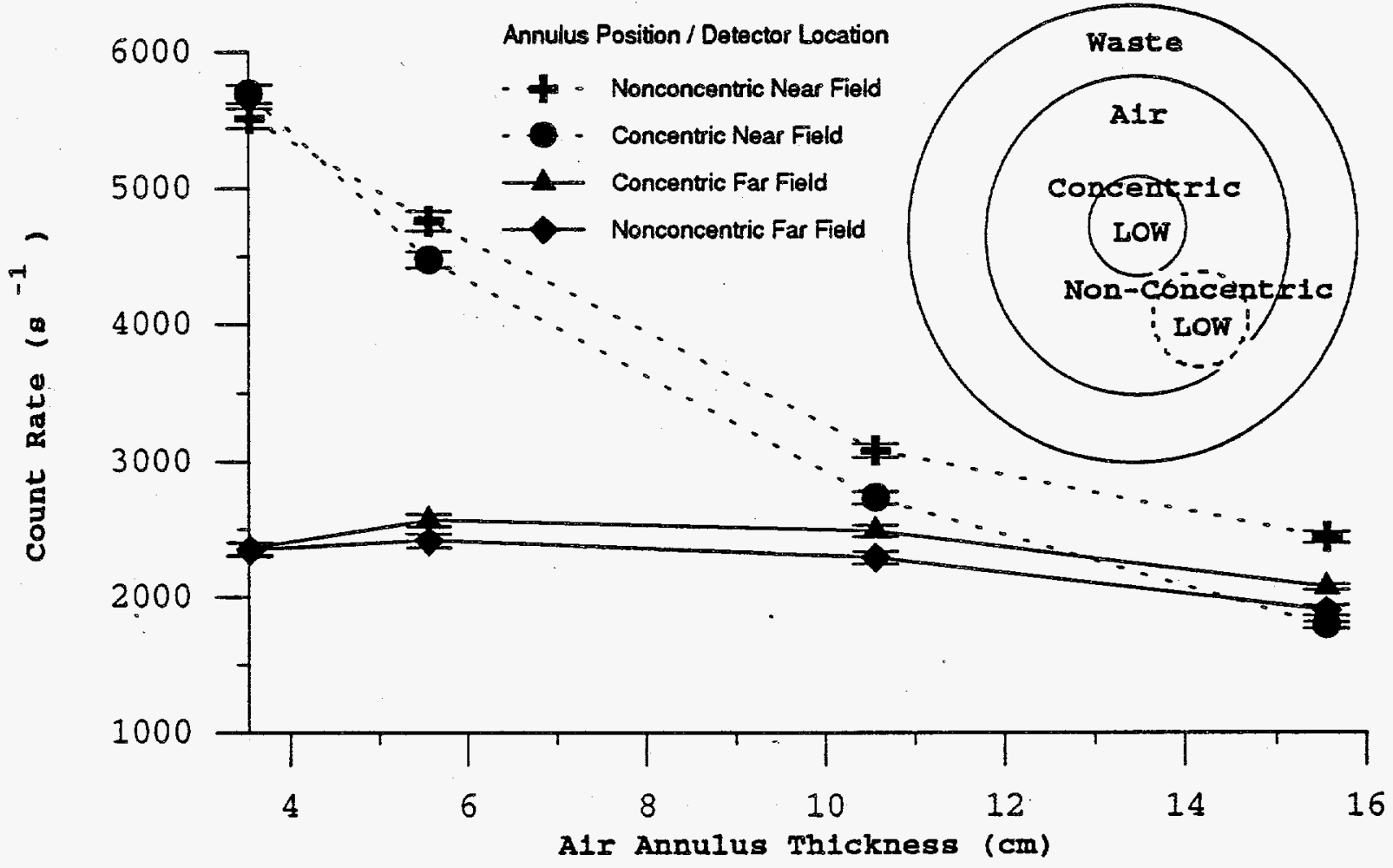




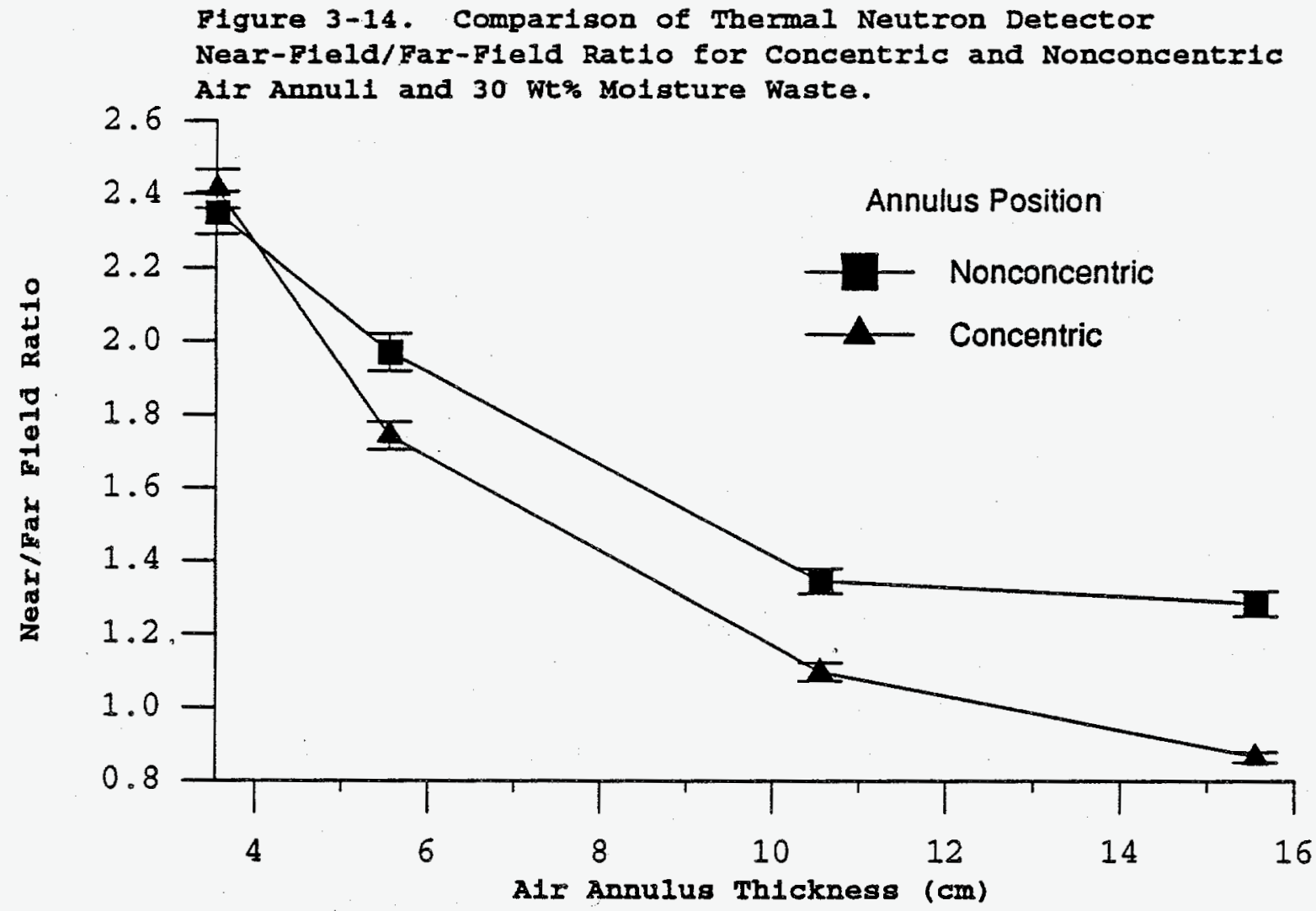

F1gure 3-15. Compartson of Epithermal Neutron Detector Responses to Concentric and Nonconcentric Air Annuli Between the Liquid Observation WeII and 30 Wt\% Molsture Waste.

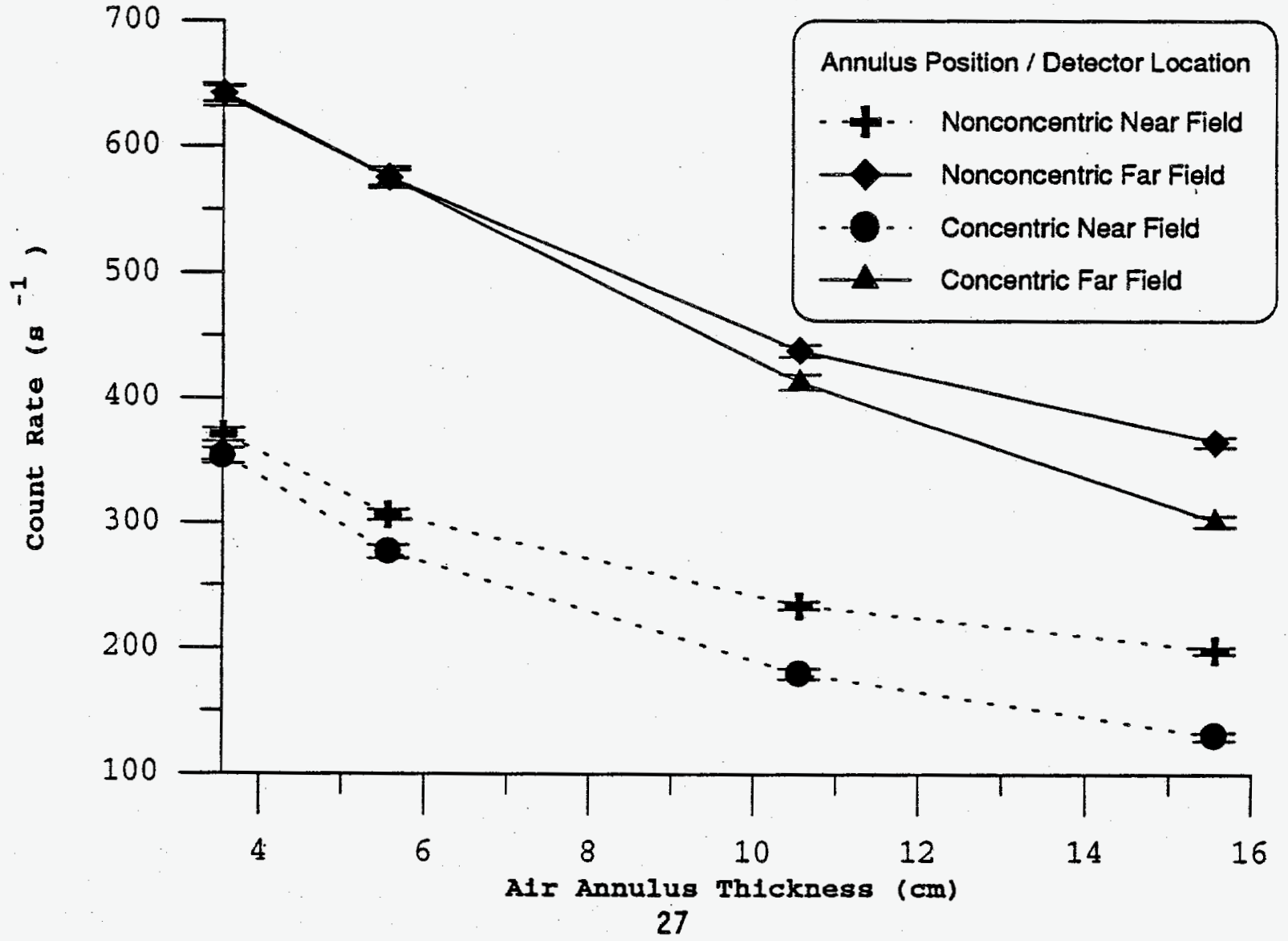


Figure 3-16. Predicted Near-Fleld/Far-F1eld Responses to

Concentric Air Annul1 surrounded by 15 or 30 wt\% Motsture Waste.

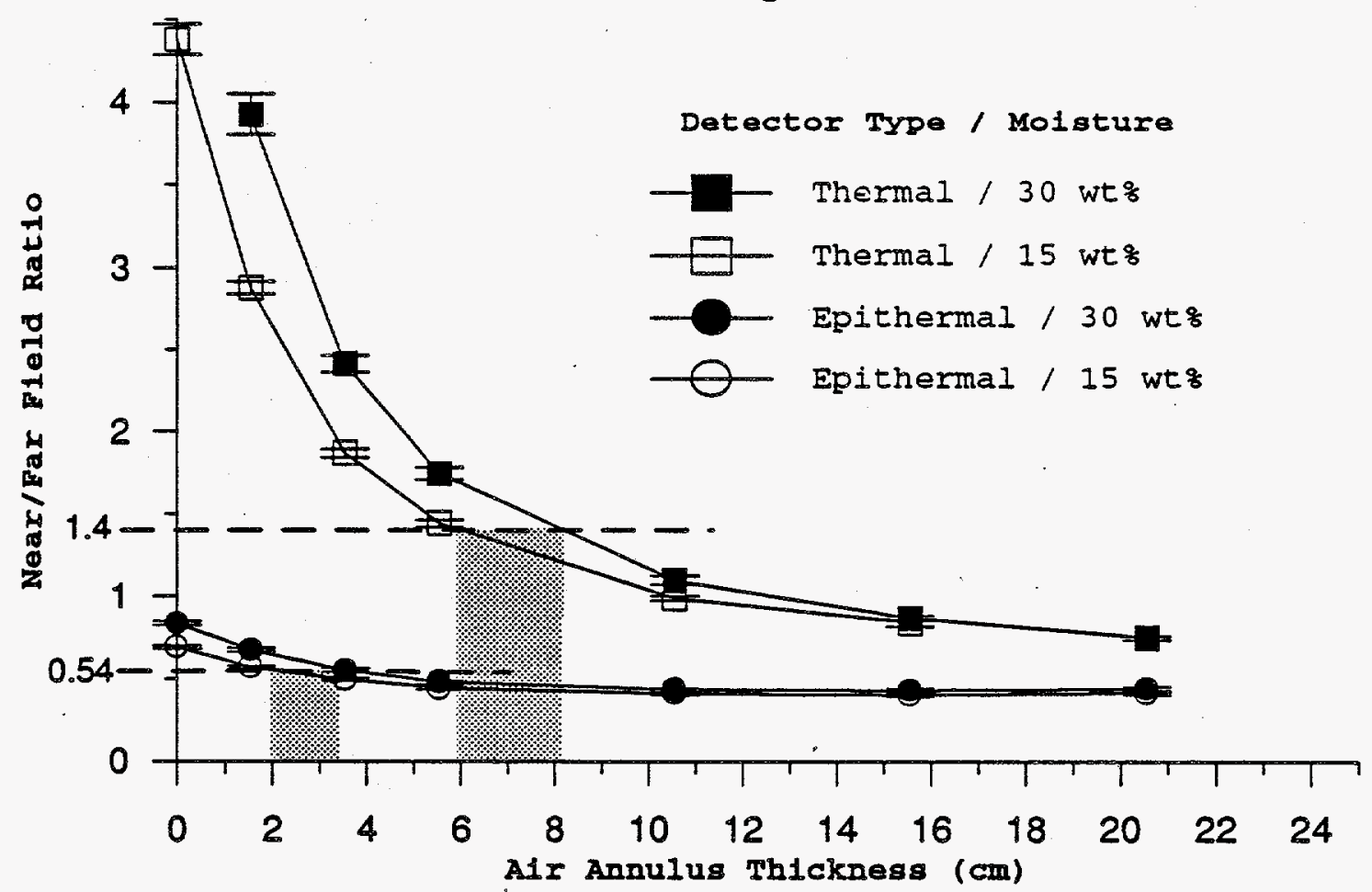

The shaded bands represent an attempt to interpret example data expected from a non-concentric air-filled annulus using this concentric air-filled modeling.

F1gure 3-17. Thermal Neutron Detector Response to Different Thlckness 0 Wt\% Inner Annular Waste Reglons Surrounded by 15 or $30 \mathrm{wt} \%$ Molsture Waste.

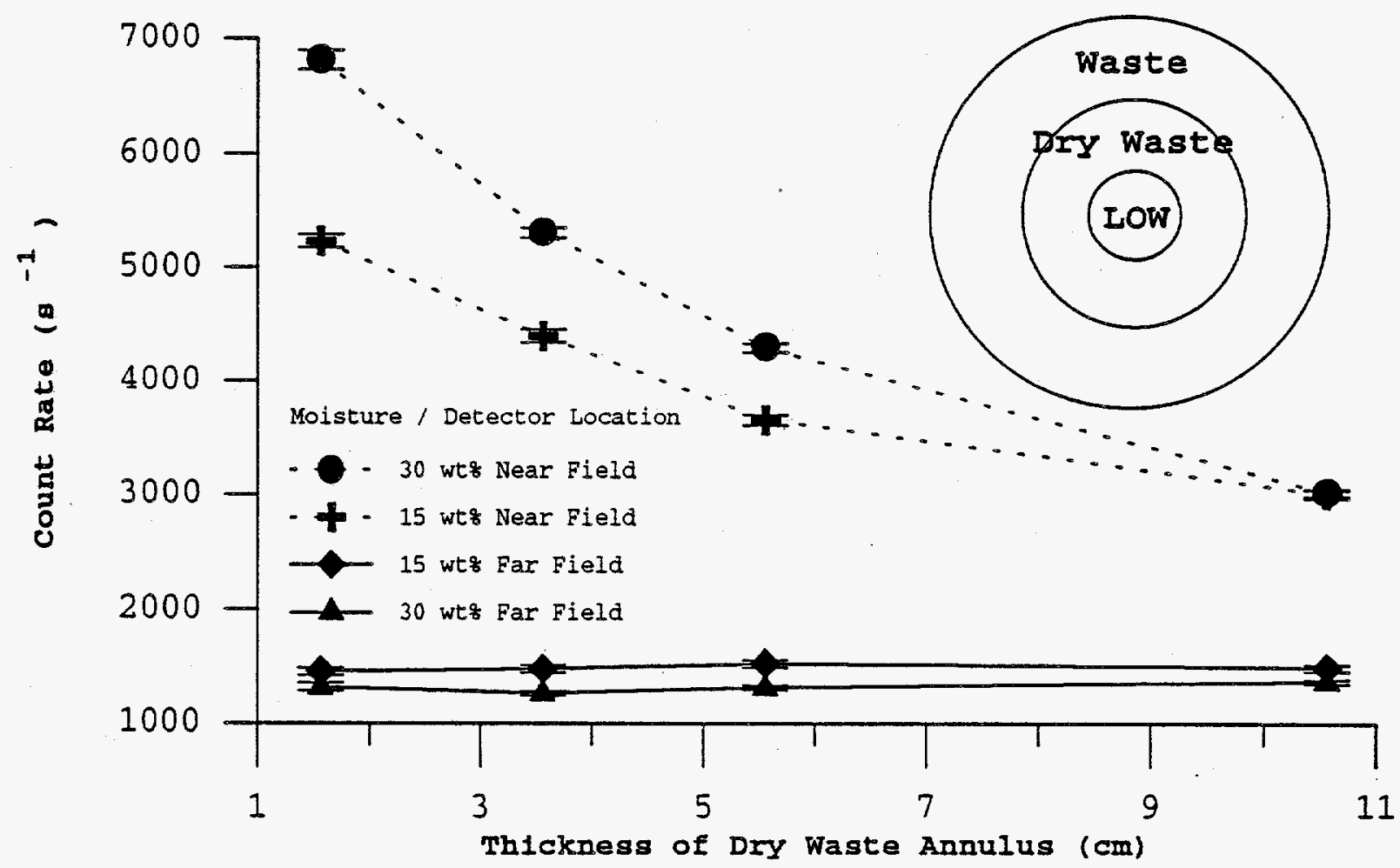


Figure 3-18. Epithermal Neutron Detector Response to Different Thickness 0 Wto Inner Annular Waste Regions Surrounded by 15 or 30 Wt\% Moisture Waste.

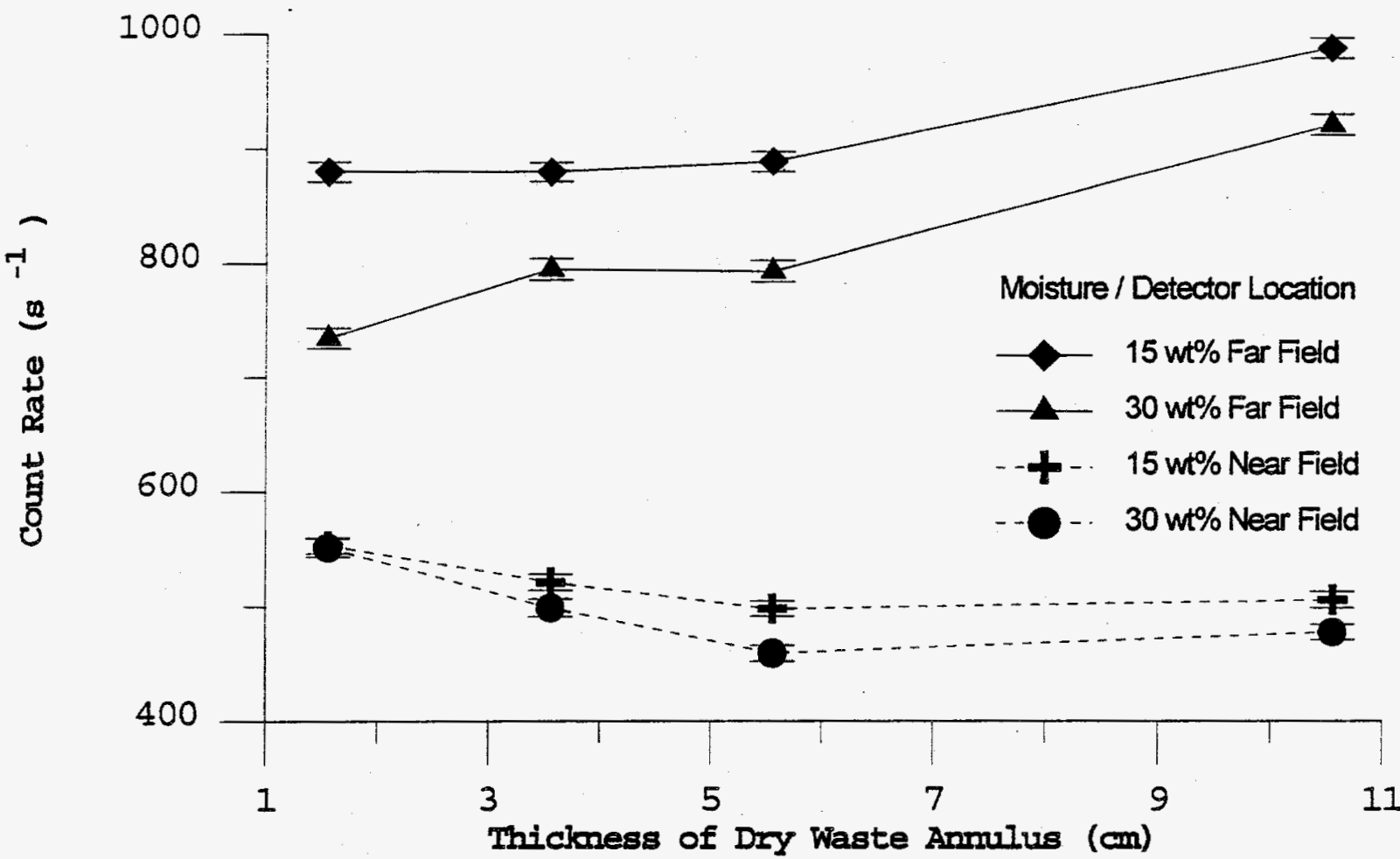

Figure 3-19. Thermal Neutron Detector Responses to Concentric Air Annuli Between the Liquid Observation Well and Four Moisture Concentration Wastes.

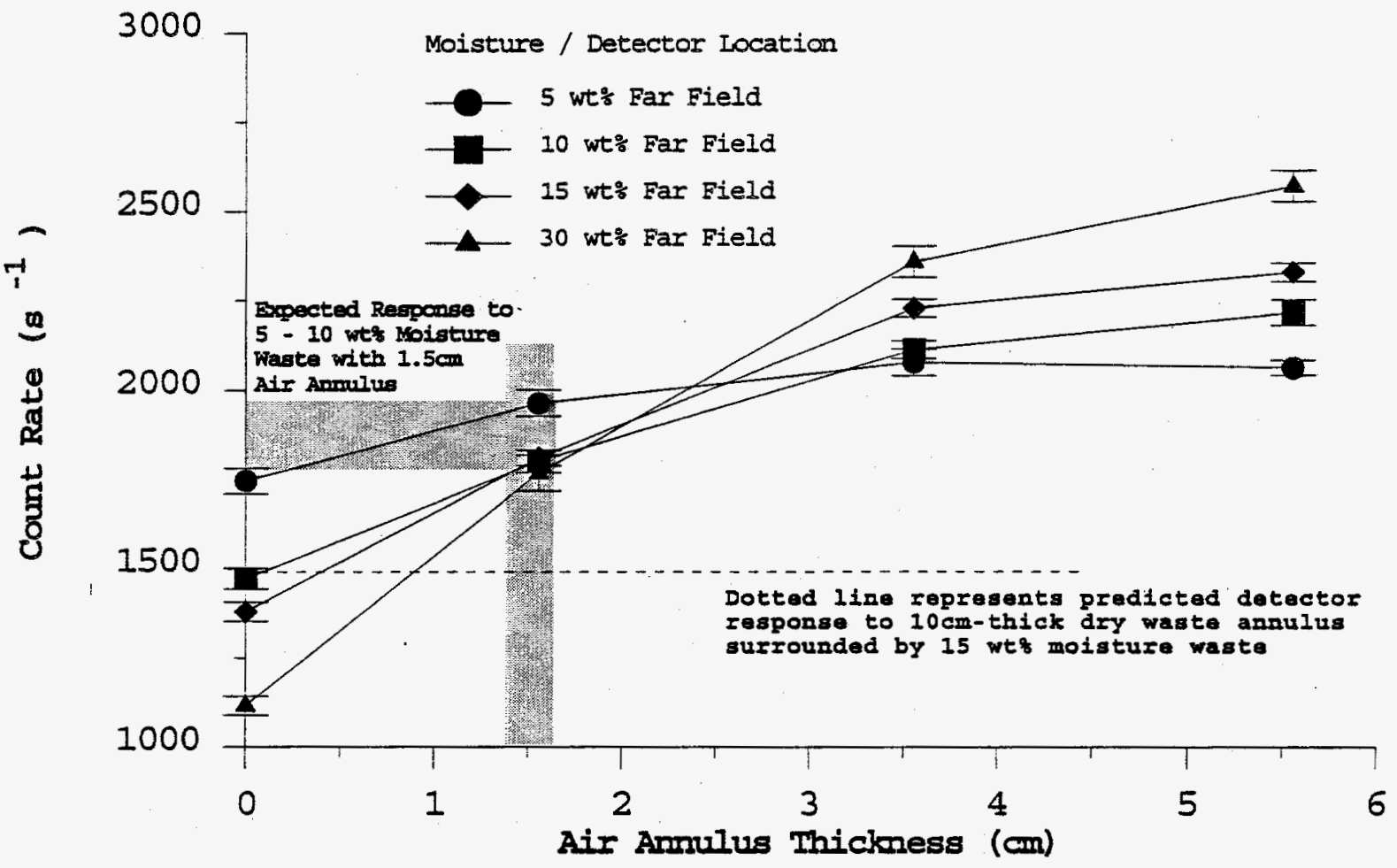


Figure 3-20. Thermal Neutron Detector Response to Different Thickness 15 or 30 Wt\% Moisture Waste Regions Surrounded by 0 wt: Outer Annular Waste.

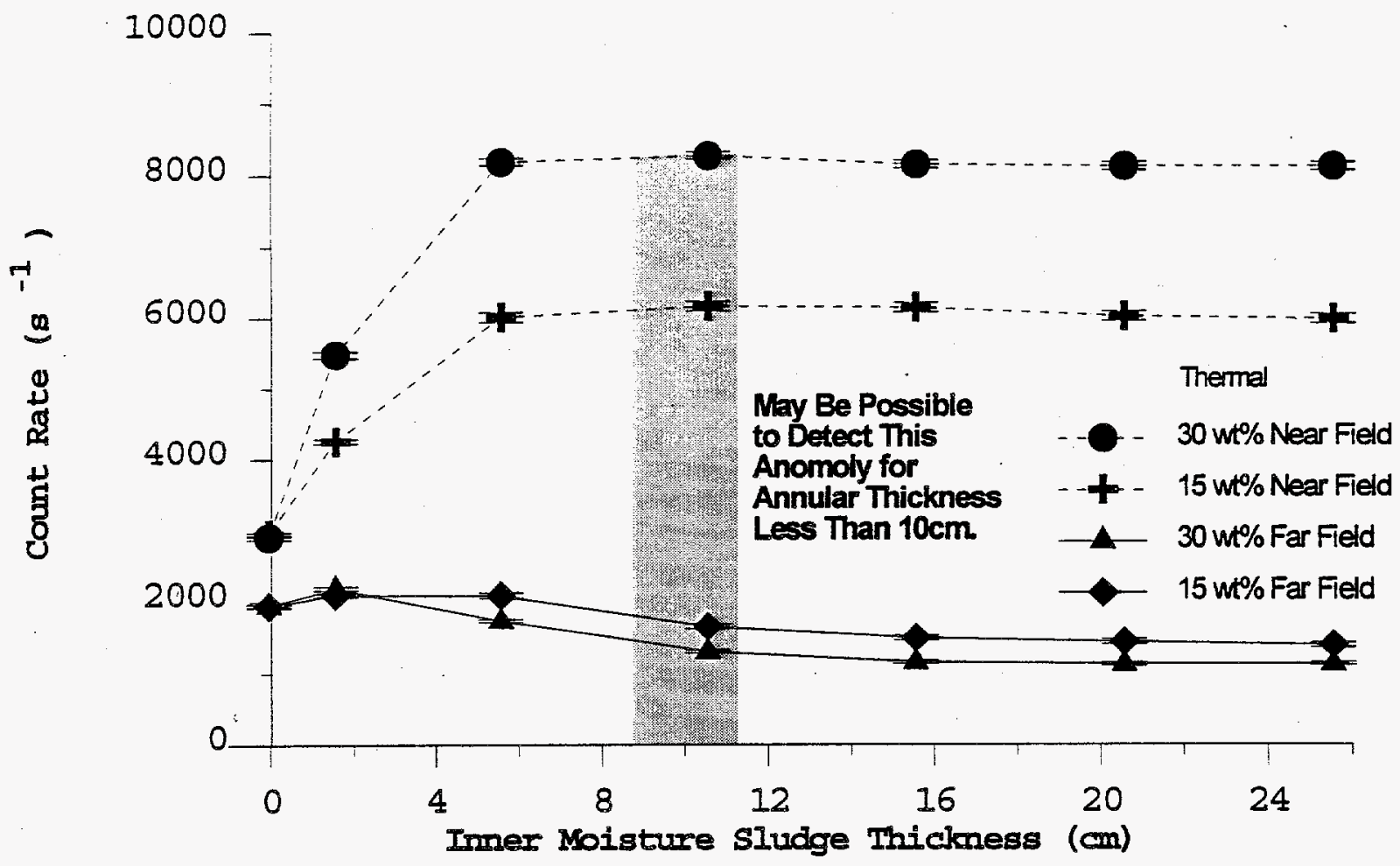

Figure 3-21. Epithermal Neutron Detector Response to Different Thickness 15 to 30 Wto Moisture Waste Regions Surrounded by 0 wt: Outer Annular Waste.

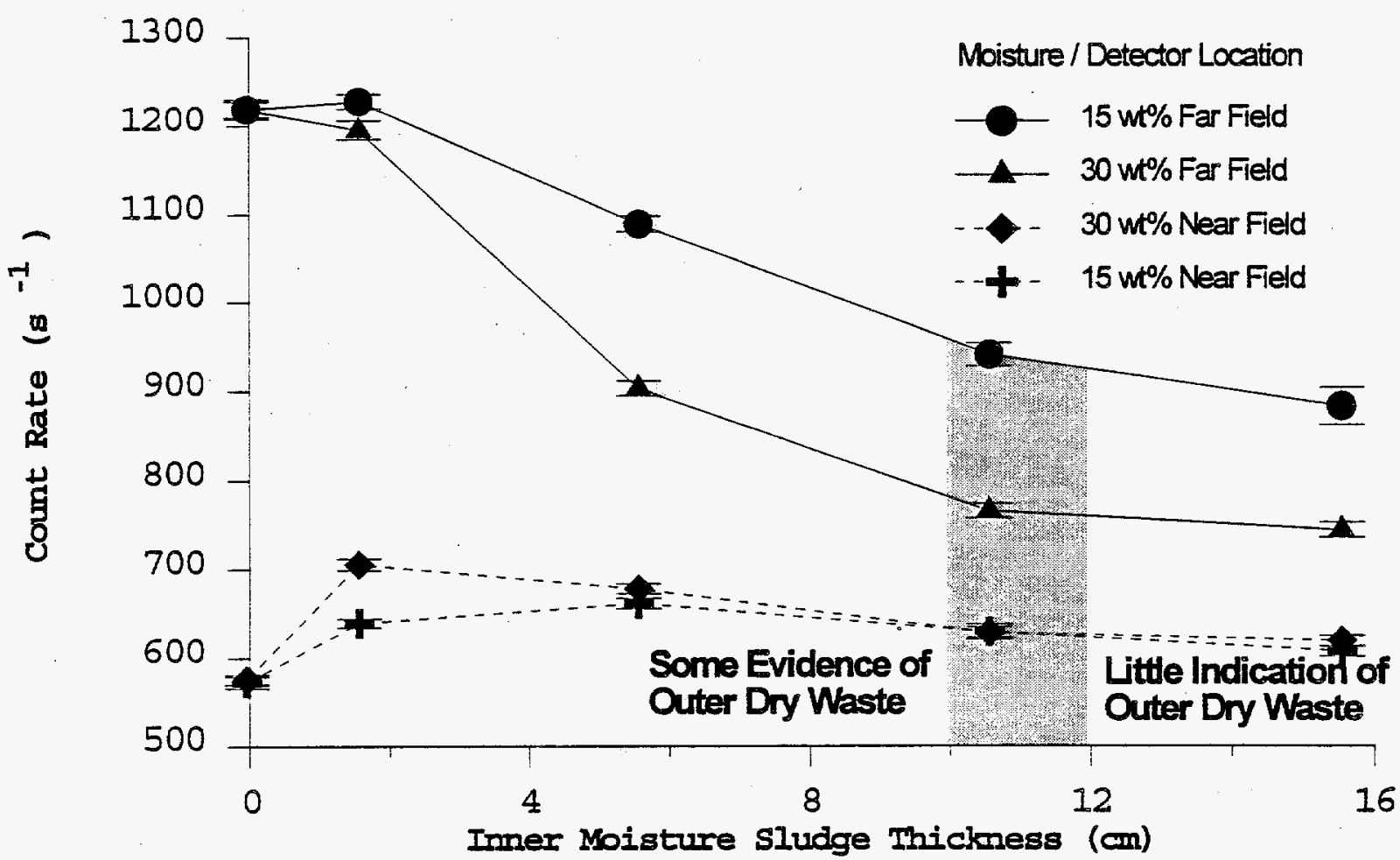


WHC-EP-0809

Figure 22. Thermal Neutron Detector Response to Different Thickness Water-Filled Annuli Surrounded by 15 to 30 Wt\% Moisture Waste.

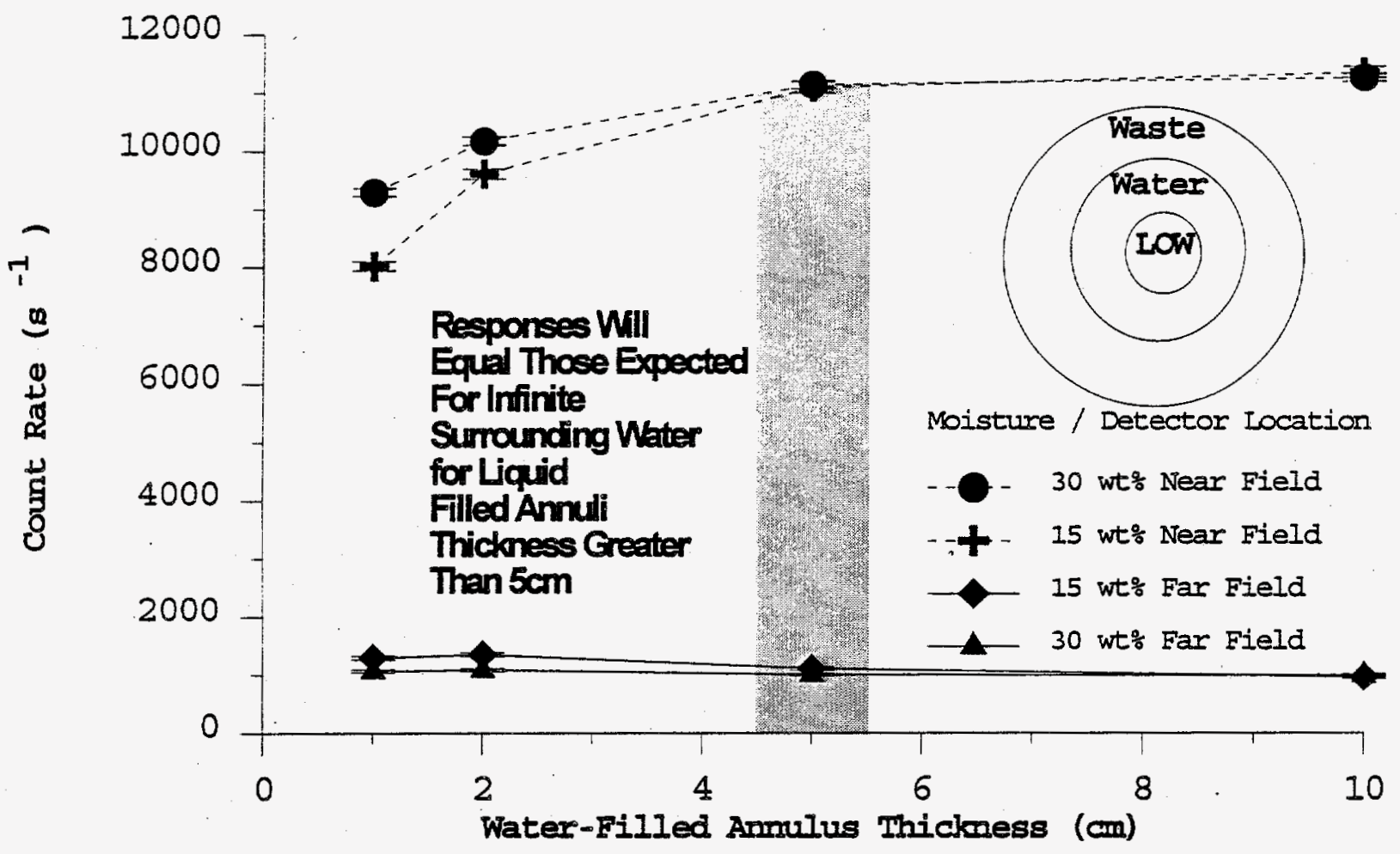

Figure 23. Epithermal Neutron Detector Response to Different Thickness Water-Filled Annulus Surrounded by 15 to 30 Wto Moisture Waste.

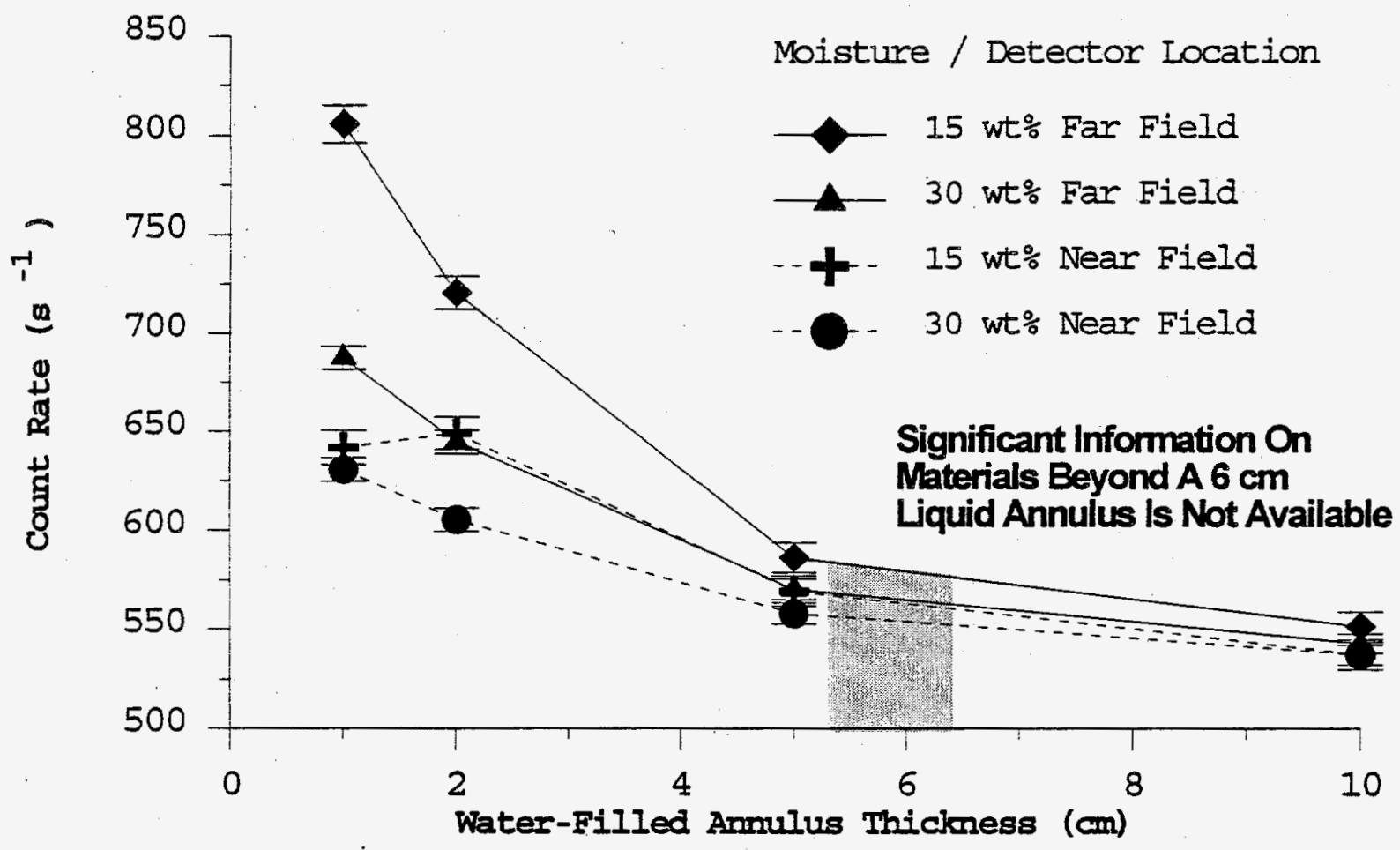




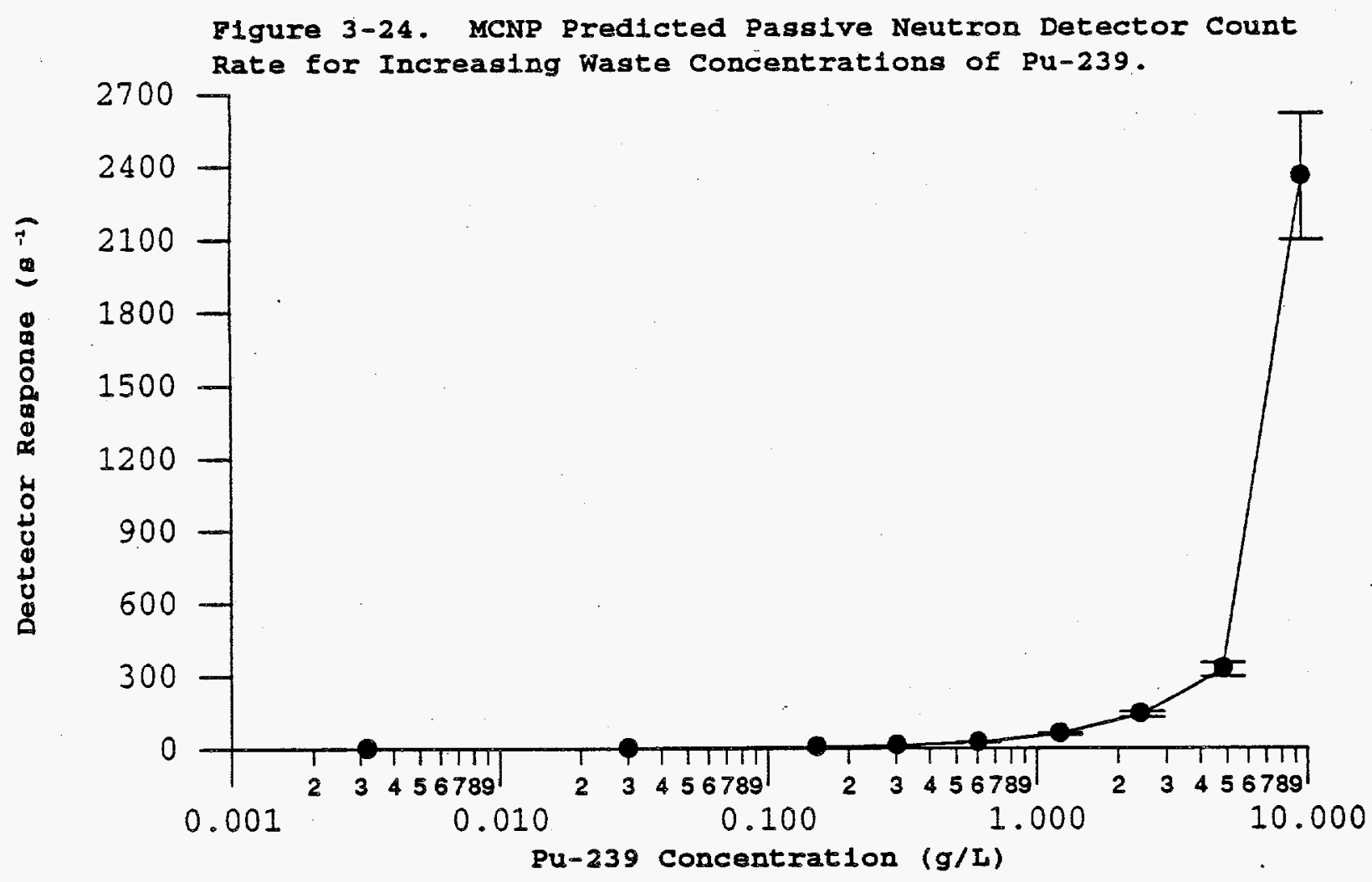

Neutrons are from spontaneous fissions and (alpha, n) reactions.

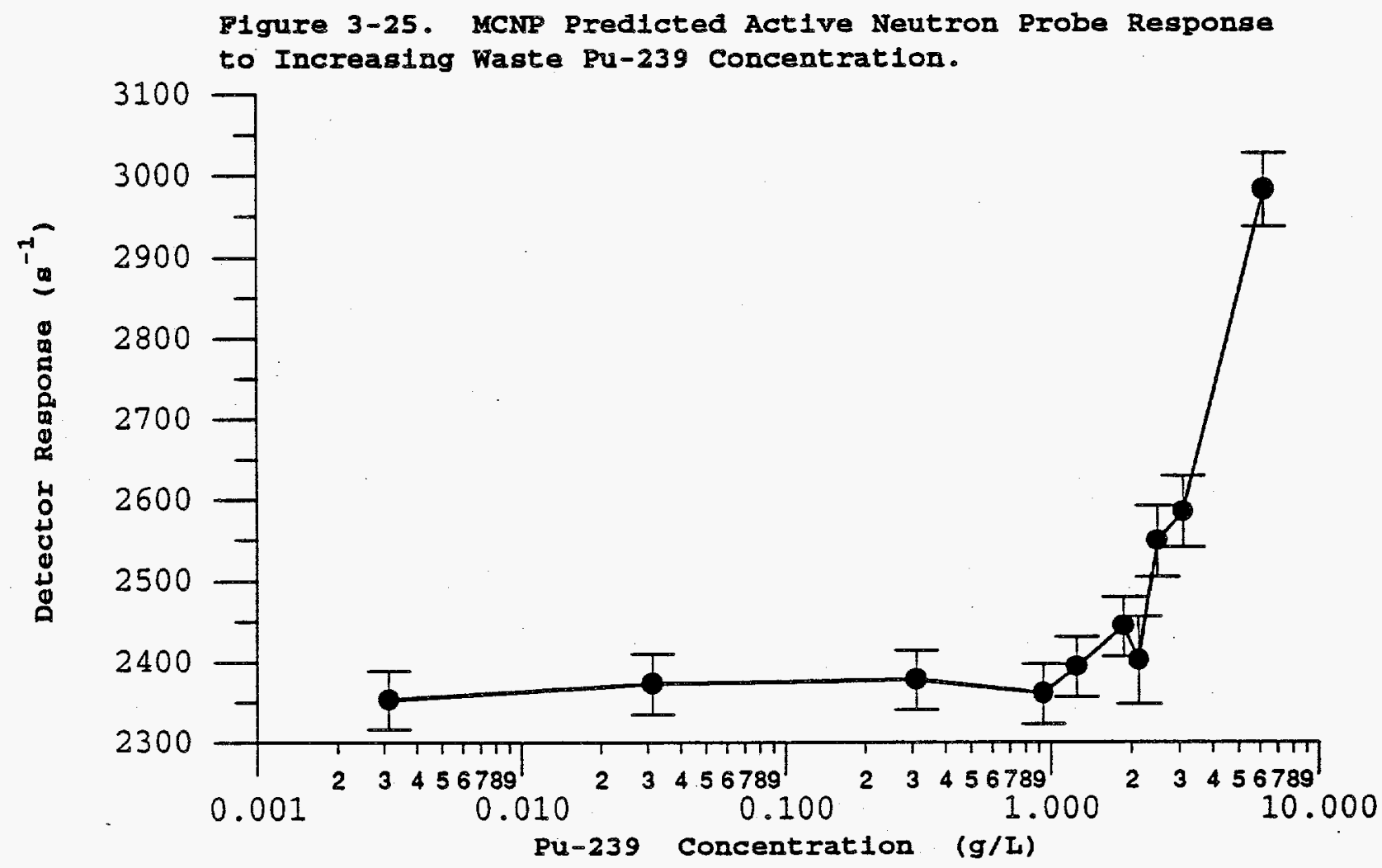

Neutrons are from probe ${ }^{241} \mathrm{AmBe}$ source and from induced fissions in the waste. 
Figure 3-26. Comparison of the Near- and Far-Field Detector Responses to Increasing Waste Moisture and to Transuranic (TRU) Concentration.

Near-Field Response to Increasing Moisture
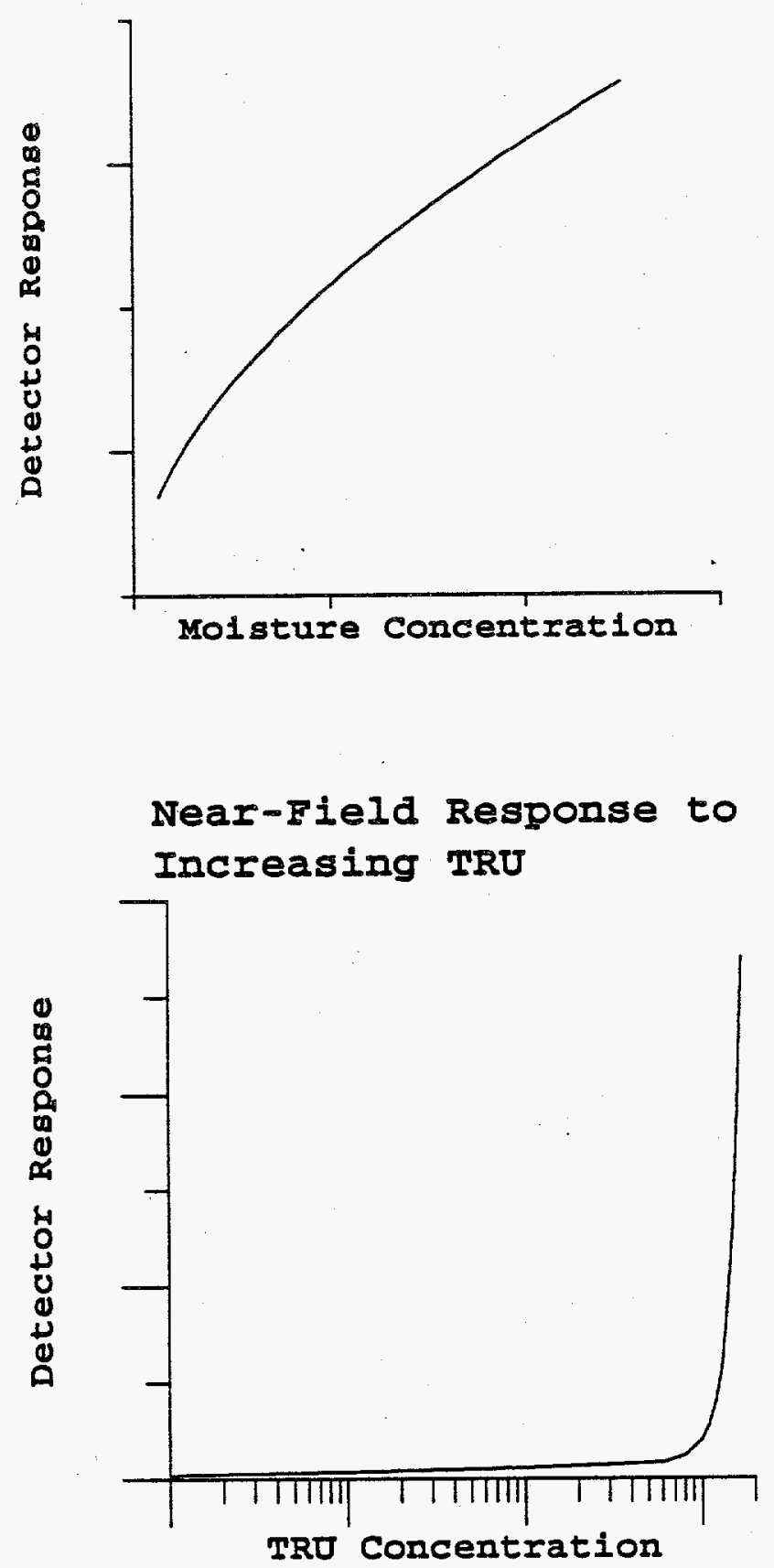

Far-Field Response to Increasing Moisture

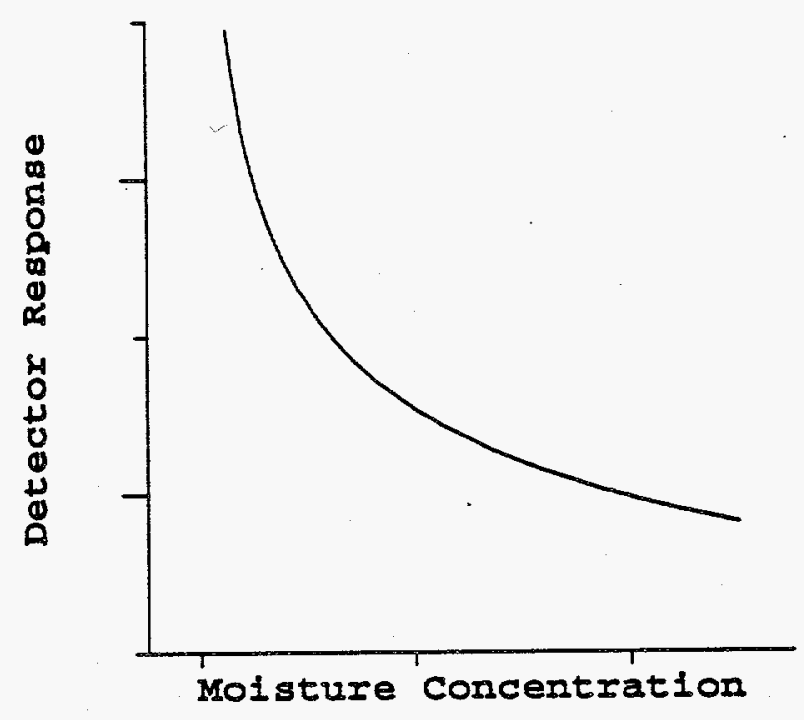

Far-Field Response to Increasing TRU

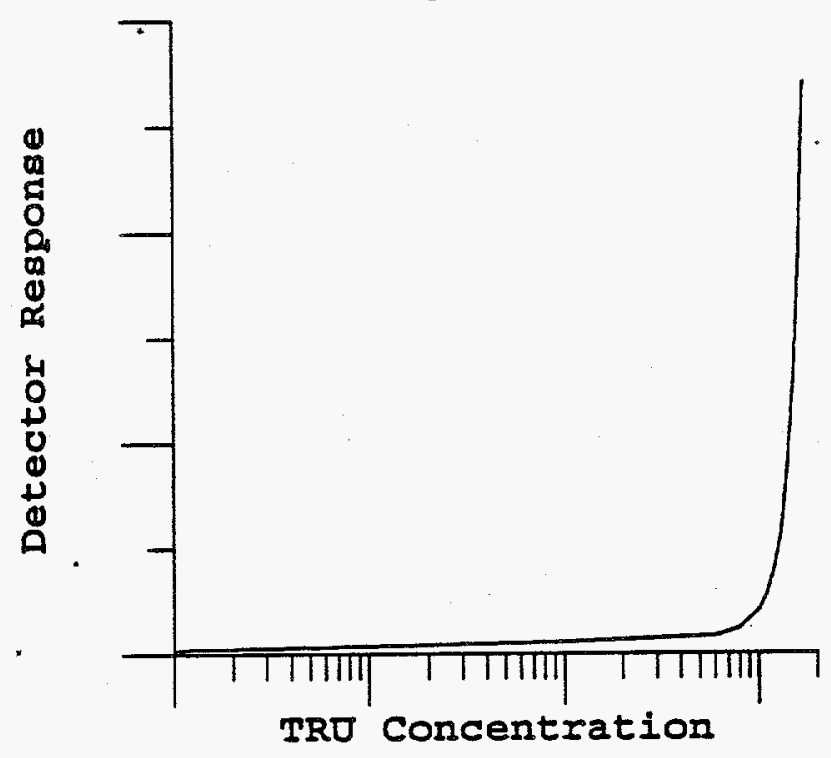


Figure 4-1. Cross-Sectional Sketch of Pulsed-Source Neutron Probe.

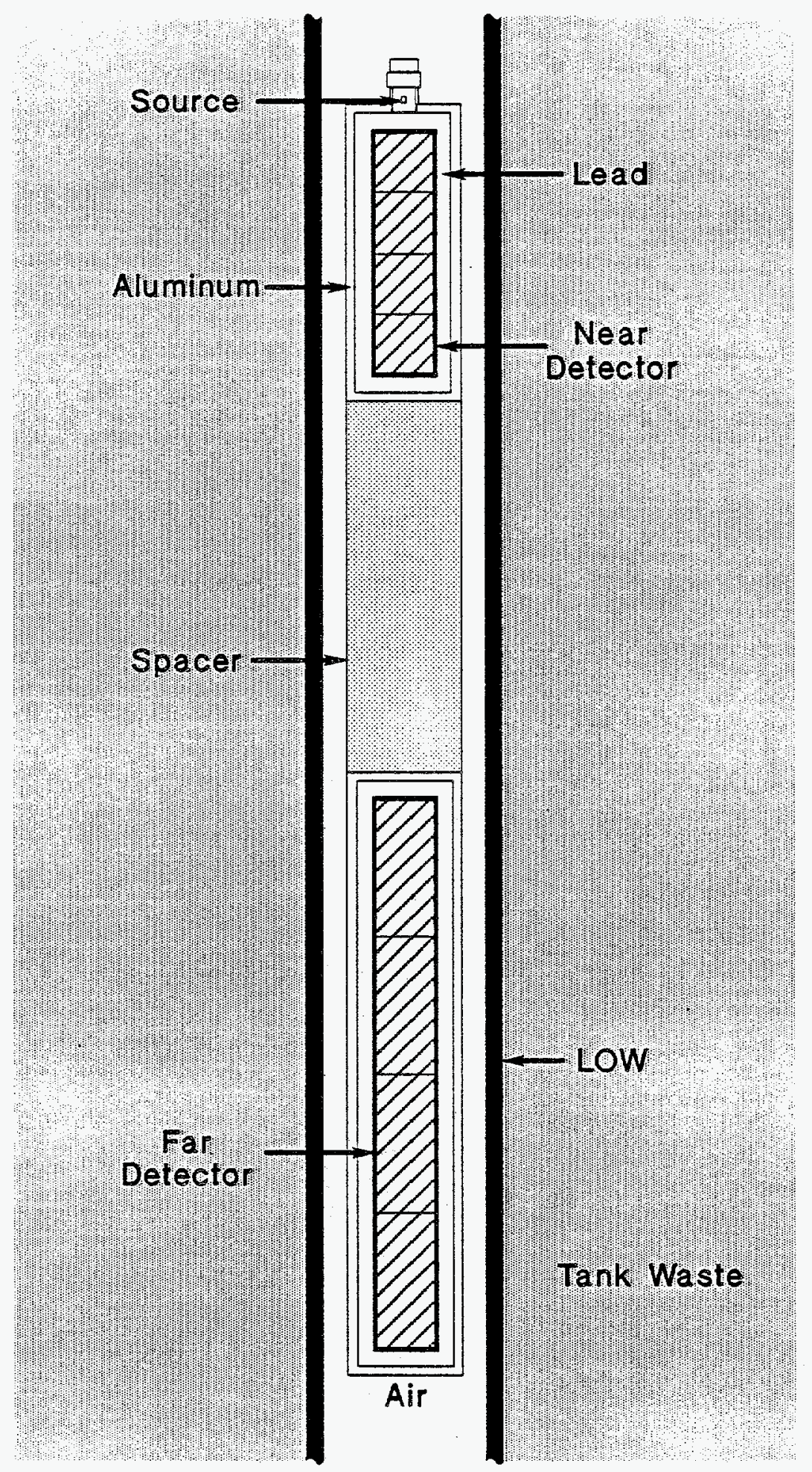


Figure 4-2. Near-Thermal Detector Time-Dependant Responses to the Waste Moisture Content.

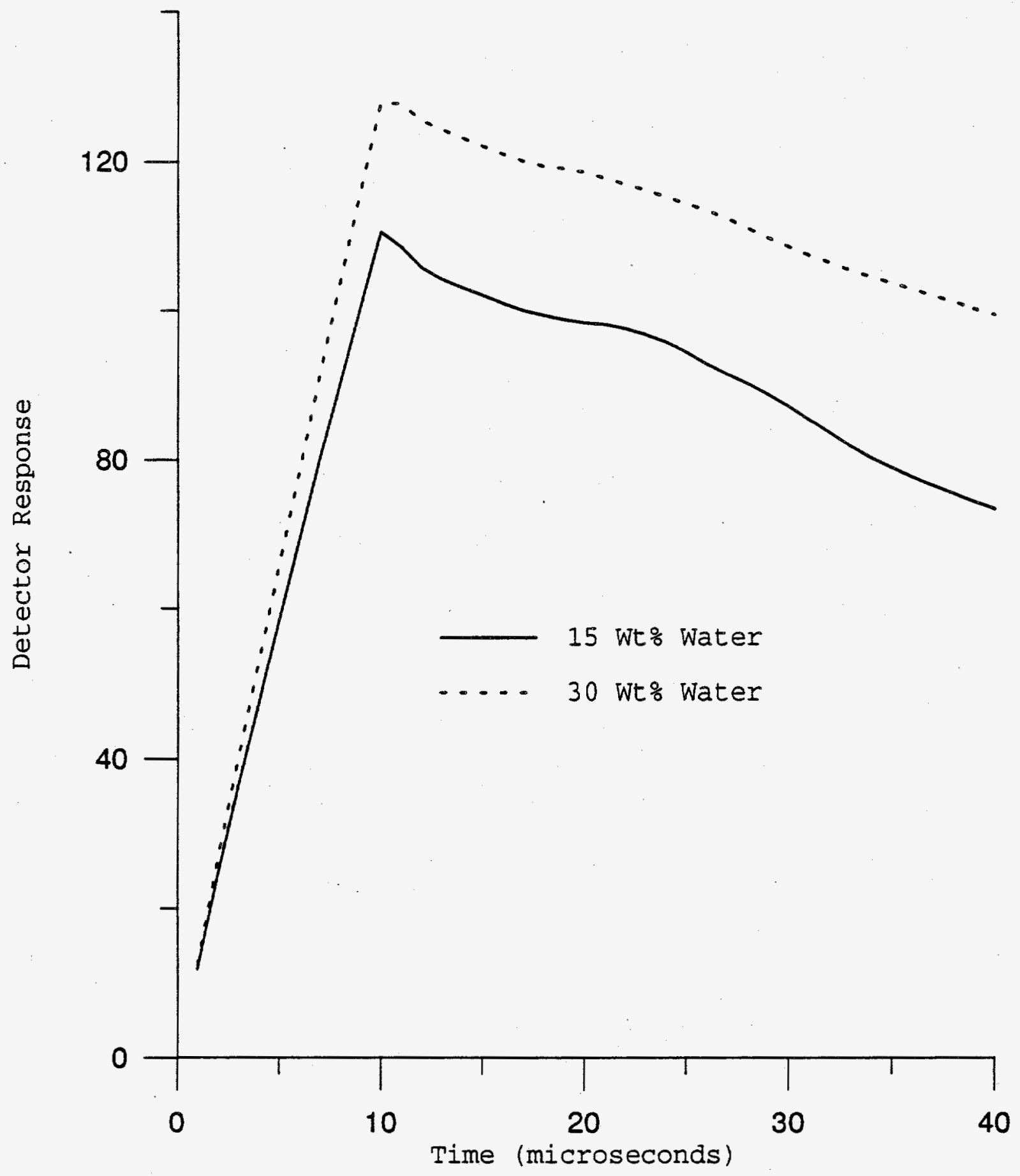


Figure 4-3. Far-Thermal Detector Time-Dependant Responses to the Waste Moisture Content.

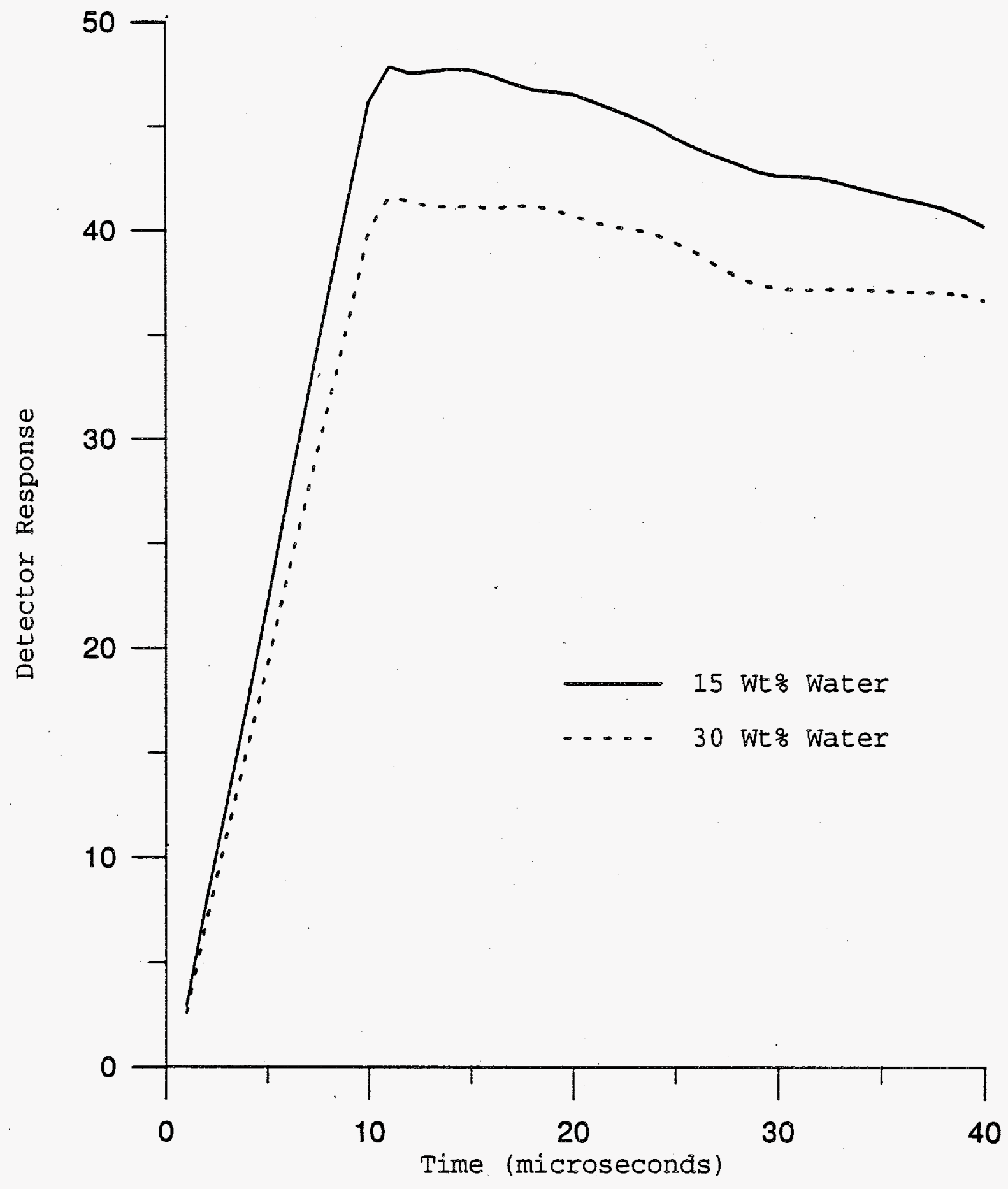


Figure 4-4. Normalized Near-Thermal Detector Time-Dependant Responses to the Waste Moisture Content.

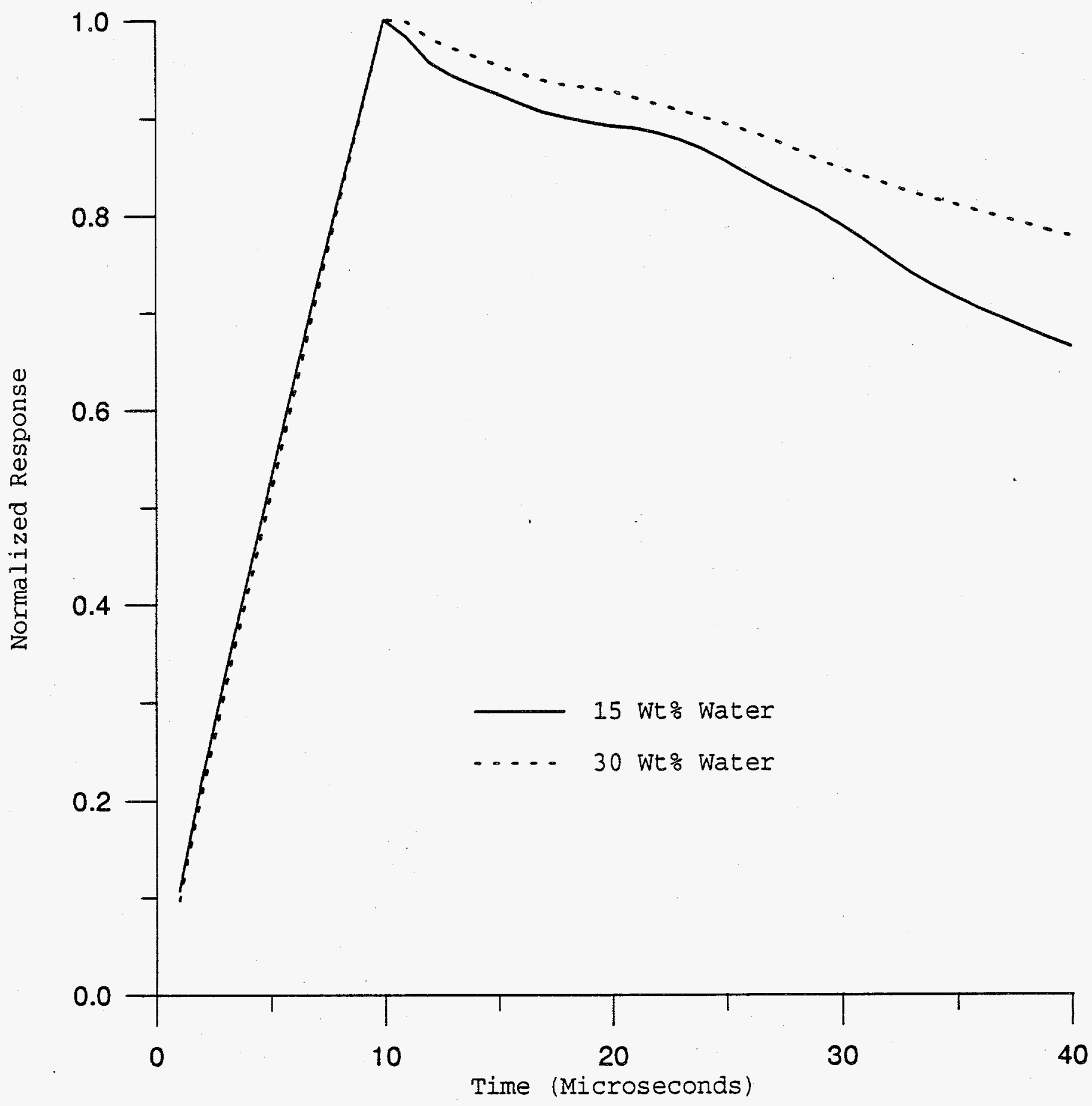


Figure 4-5. Normalized Far-Thermal Detector Time-Dependant Responses to the Waste Moisture Content.

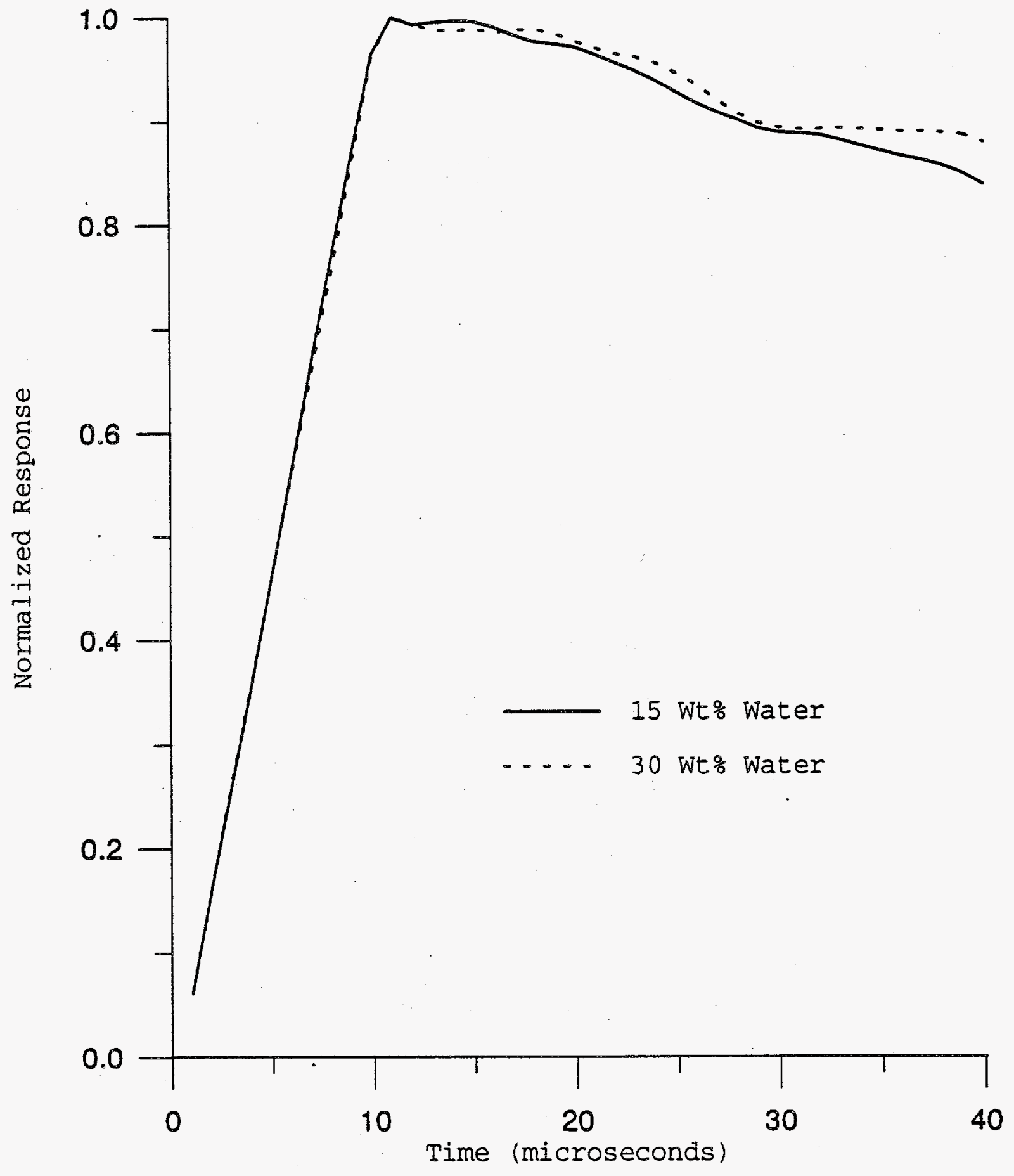


Figure 4-6. Near-Epithermal Detector Time-Dependant Responses to the Waste Moisture Content.

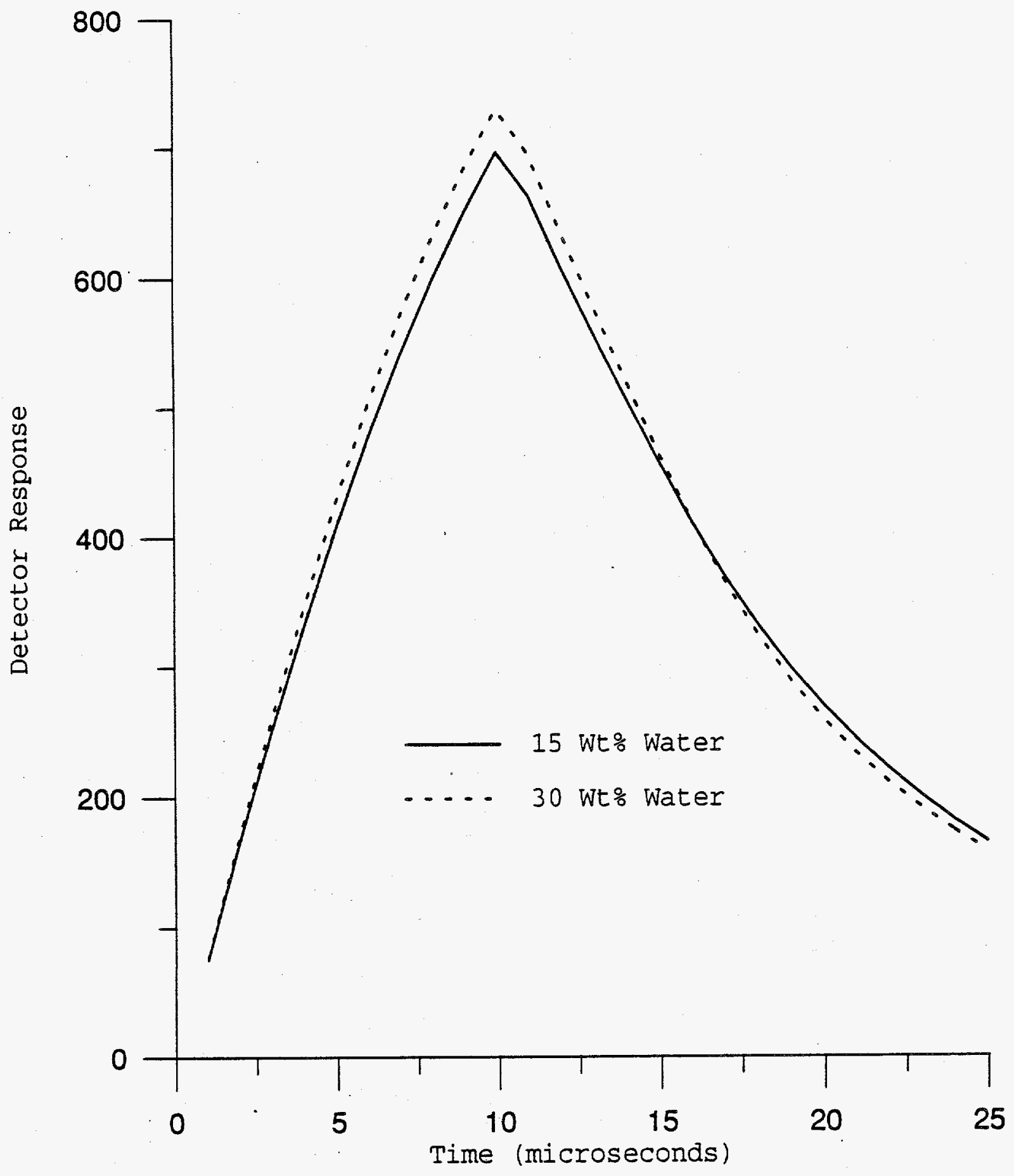


Figure 4-7. Normalized Far-Epithermal Time-Dependant Responses to the Waste Moisture Content.

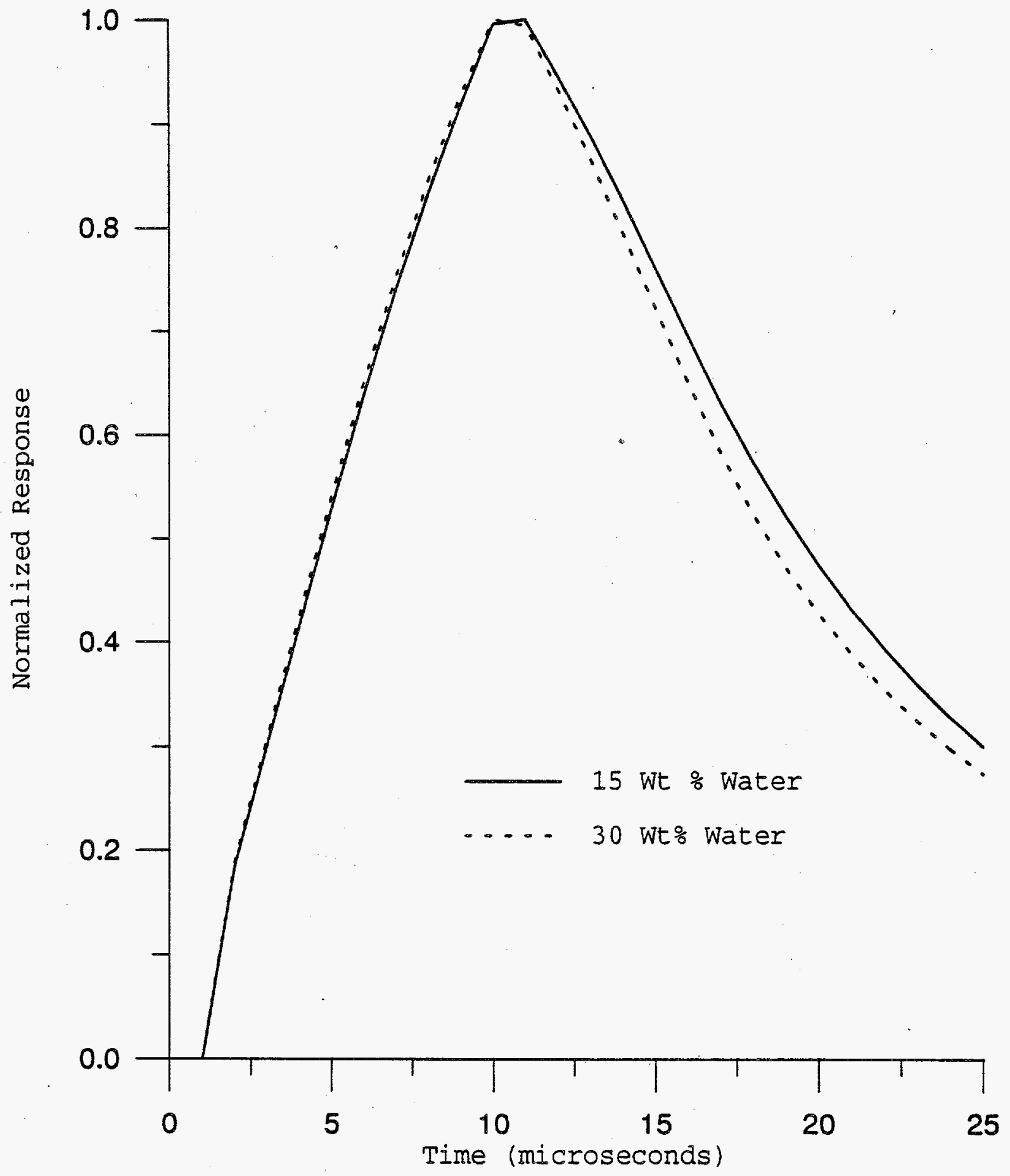


WHC-EP-0809

Figure 4-8. Normalized Near-Epithermal Detector Time-Dependant Responses to the Waste Moisture Content.

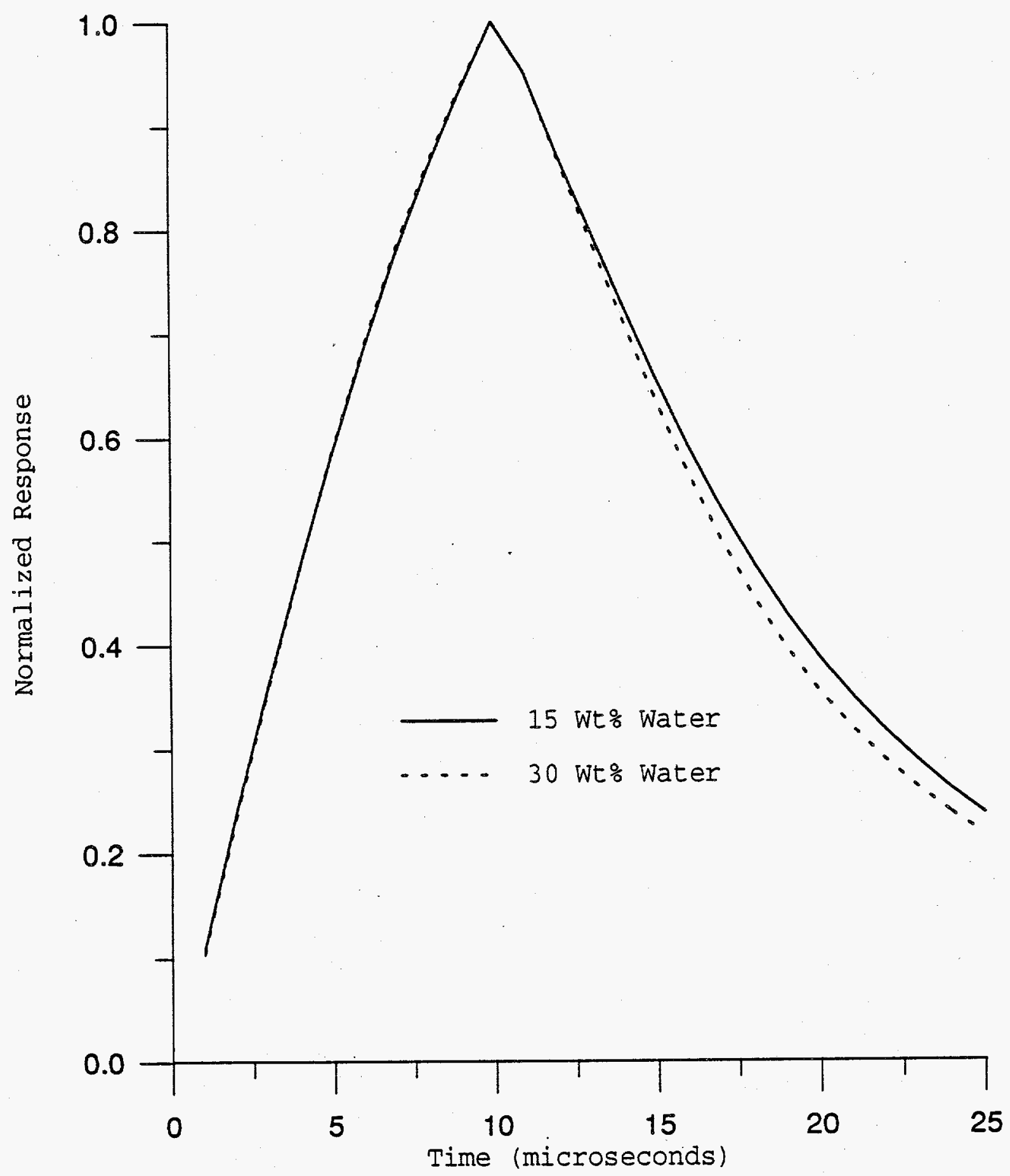


Figure 4-9. Far-Epithermal Detector Time-Dependant Responses to the Waste Moisture Content.

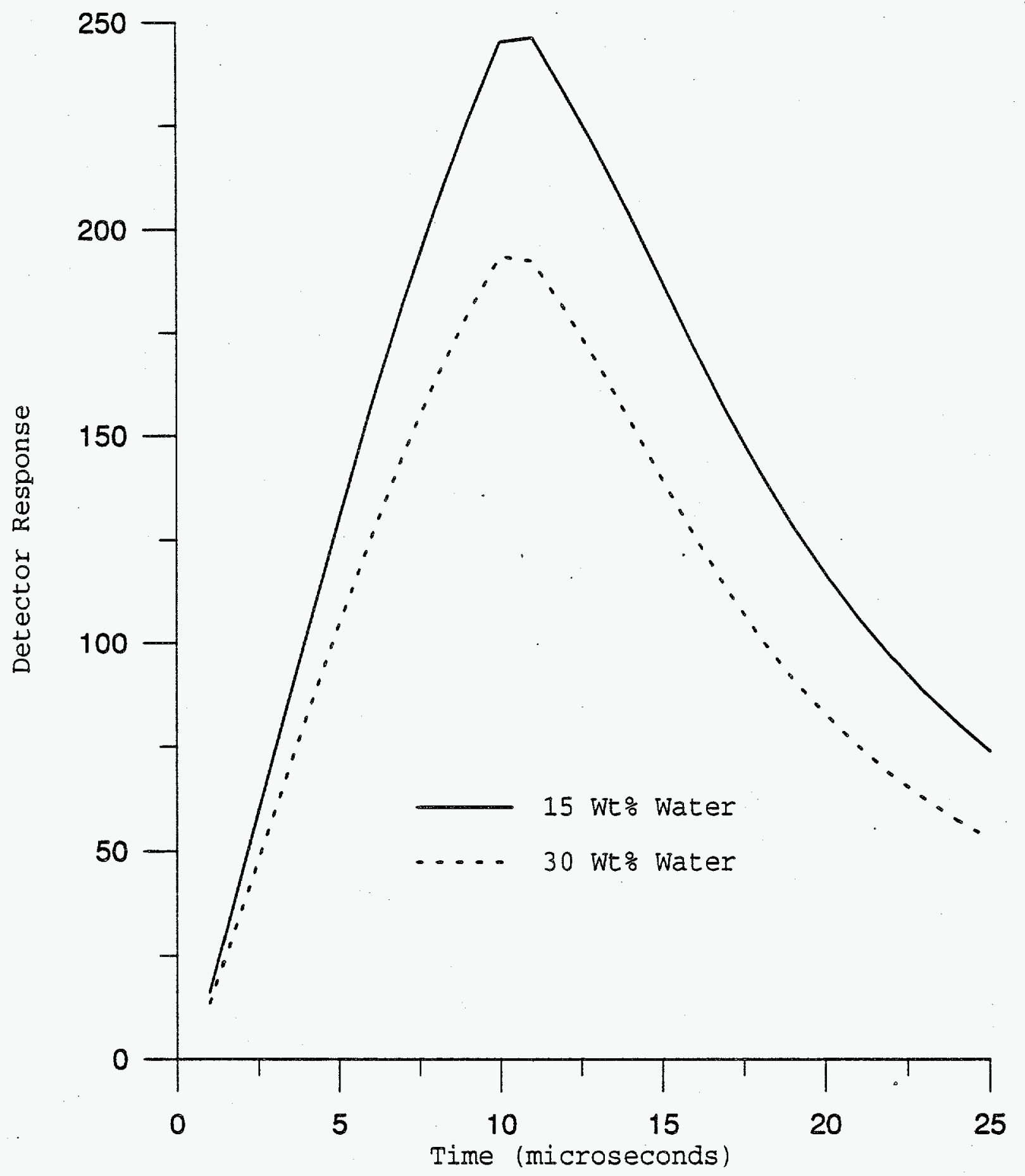


Figure 4-10. Near-Thermal Detector Time-Dependant Responses to Air-Filled Annuli.

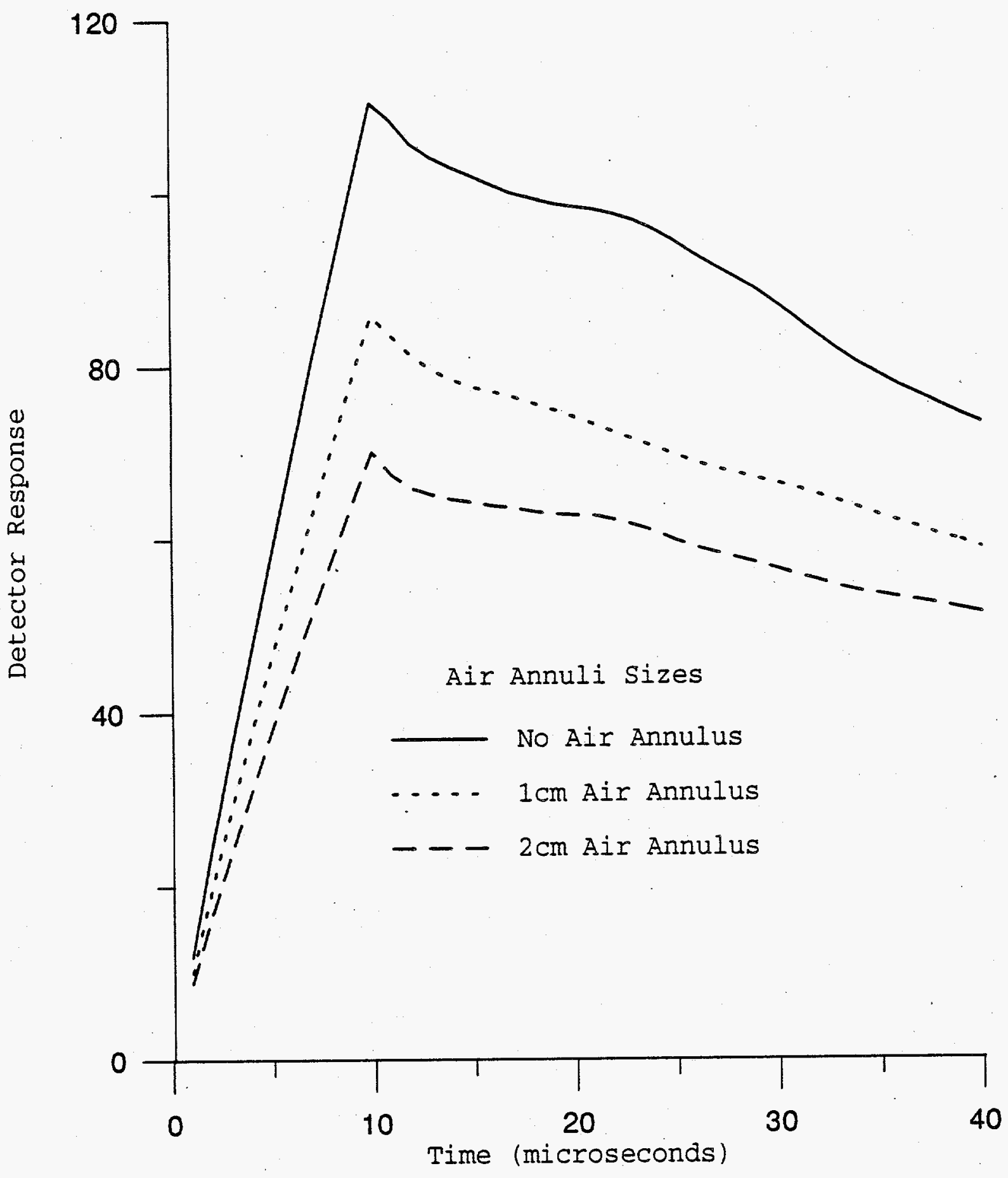

For 15 wt\% Moisture Waste 
Figure 4-11. Far-Thermal Detector Time-Dependant Responses to Air-Filled Annuli (For 15 wt\% Moisture Waste).

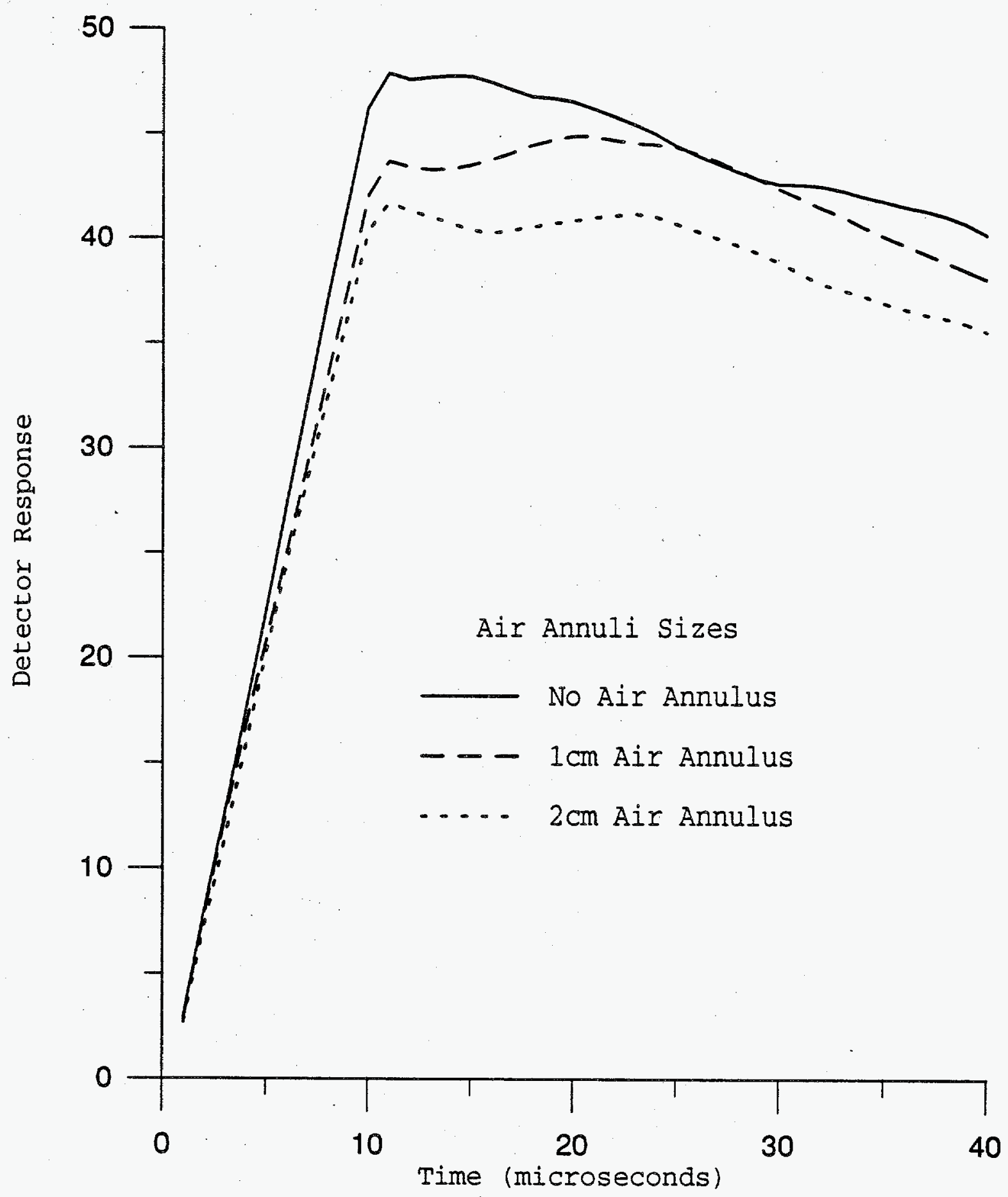


Figure 4-12. Normalized Near-Thermal Detector Time-Dependant Responses to Air-Filled Annuli.

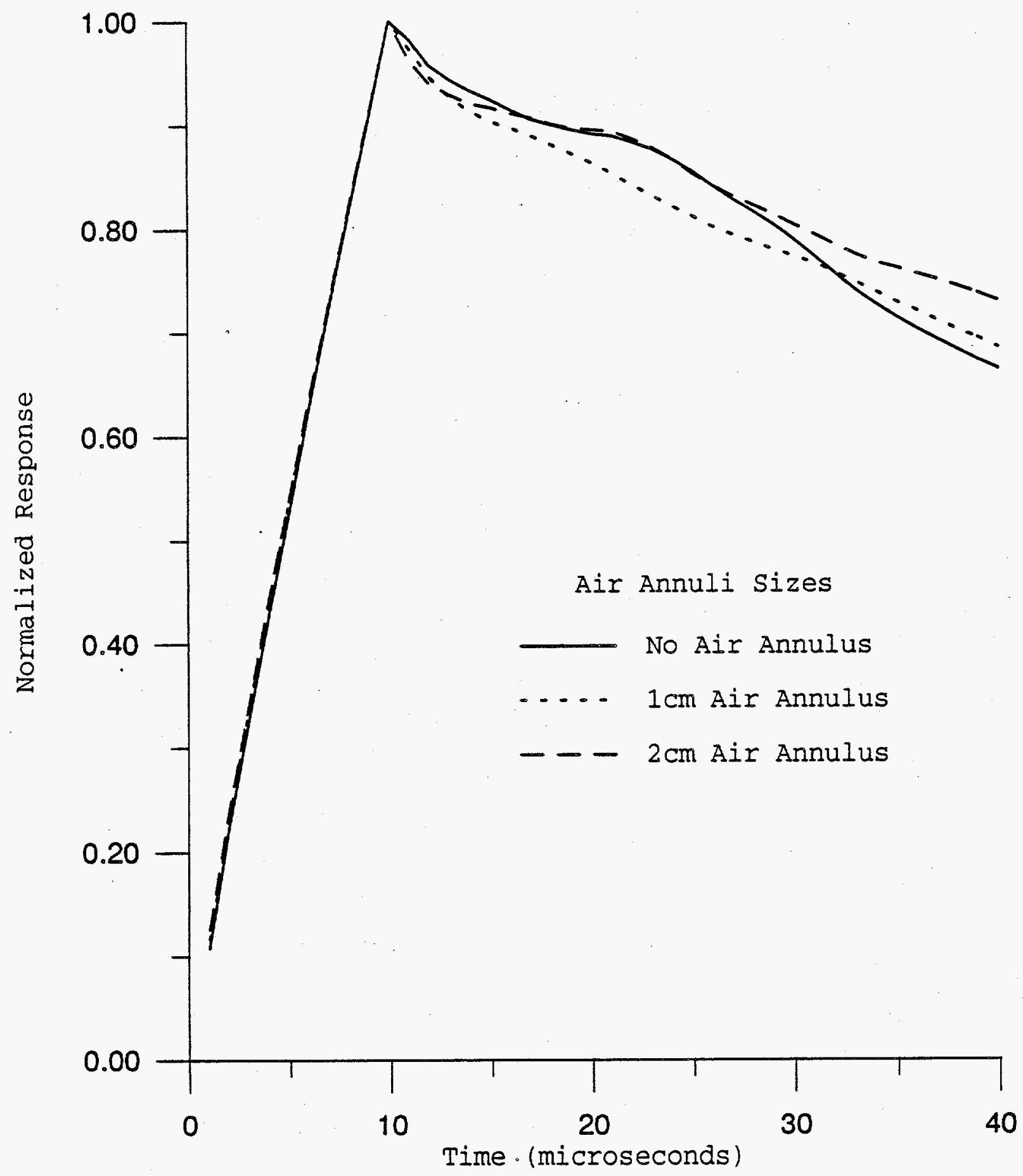

For 15 wt\% Moisture Waste 
Figure 4-13. Normalized Far-Thermal Detector Time-Dependant Responses to Air-Filled Annuli.

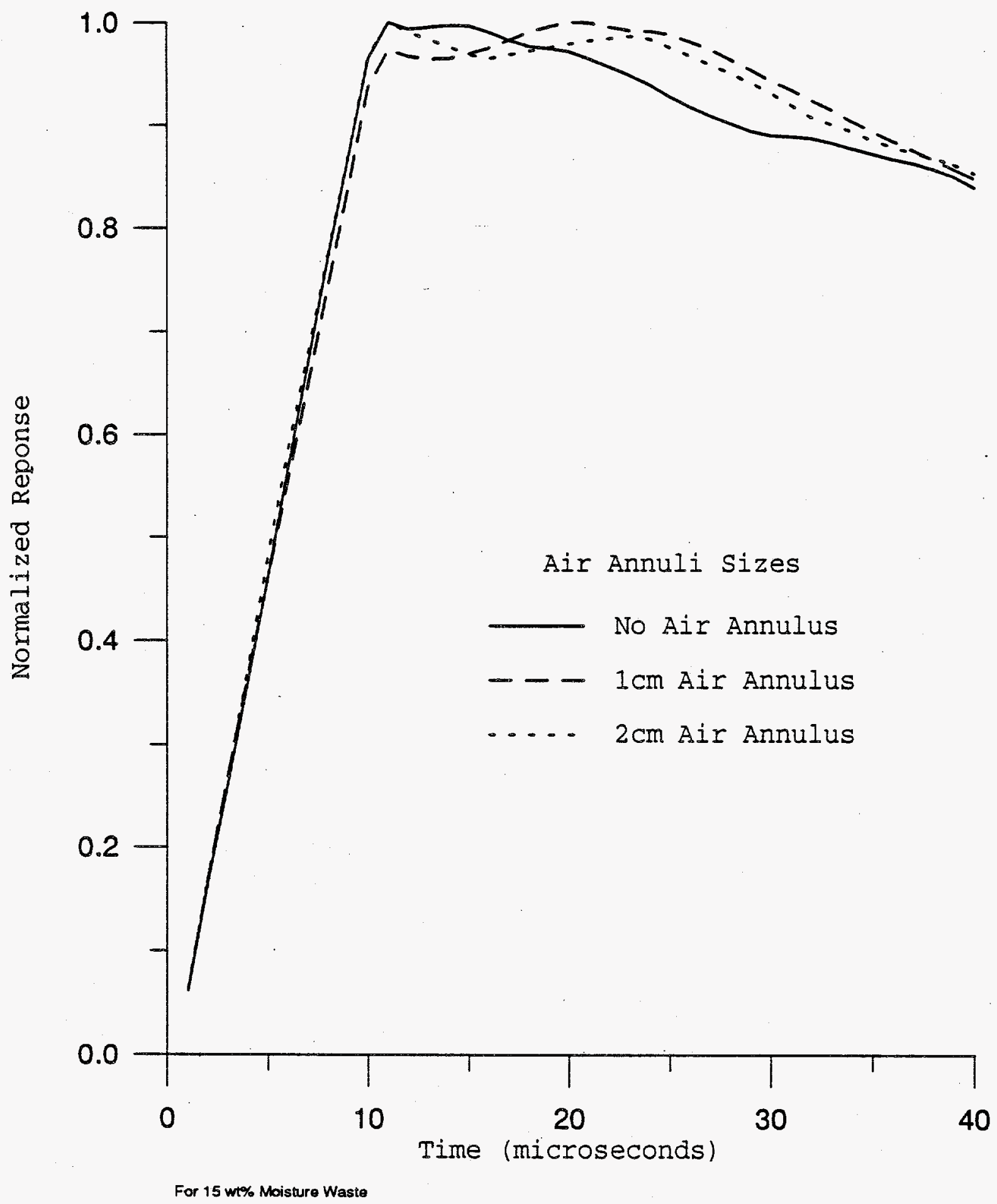


Figure 4-14. Near-Epithermal Detector Time-Dependant Responses to Air-Filled Annuli.

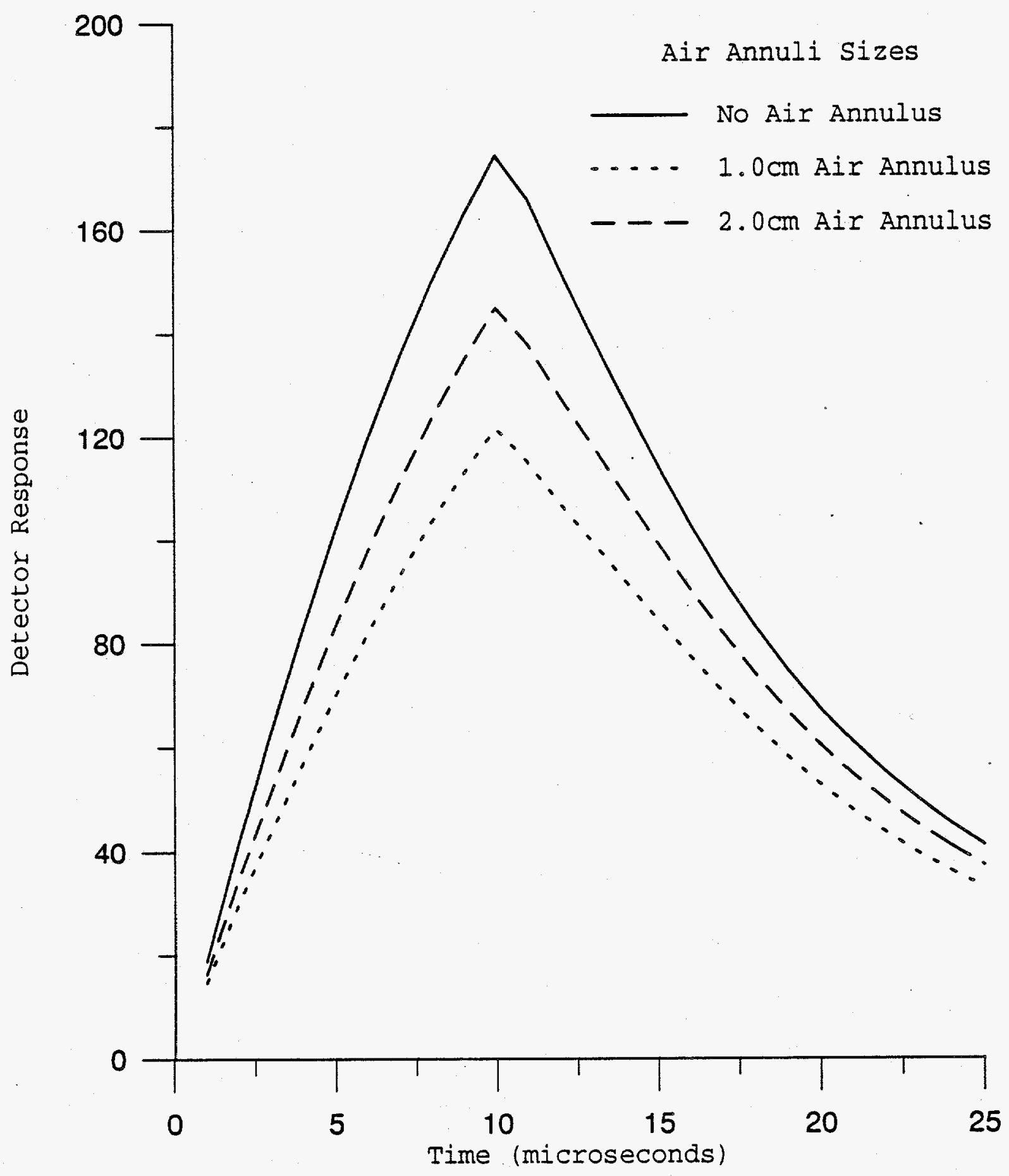

For 15 wt\% Moisture Waste 
Figure 4-15. Far-Epithermal Detector Time-Dependant Responses to Air-Filled Annuli.

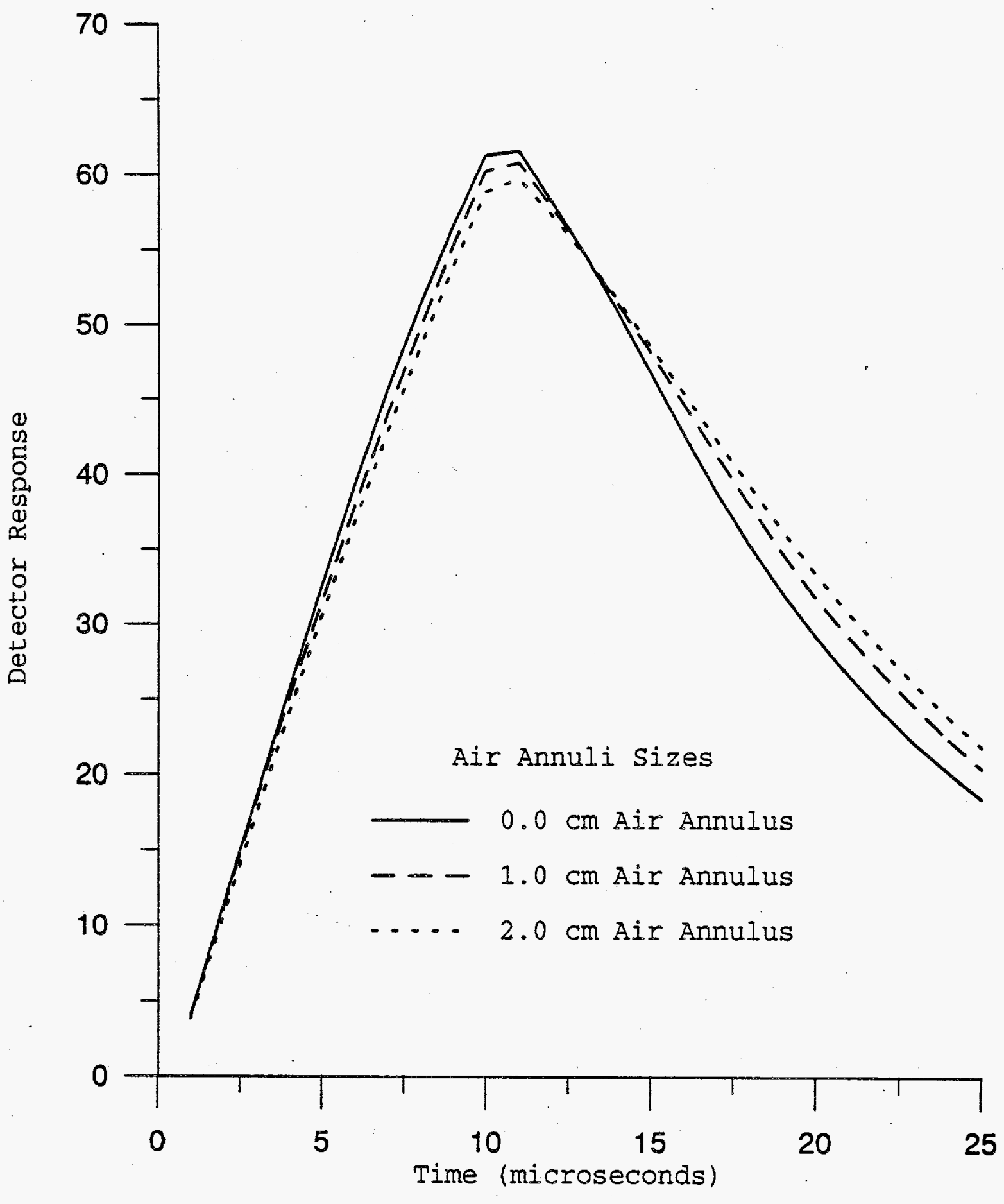

For 15 wt\% Moisture Waste 
Figure 4-16. Normalized Near-Epithermal Detector Time-Dependant Responses to Air-Filled Annuli.

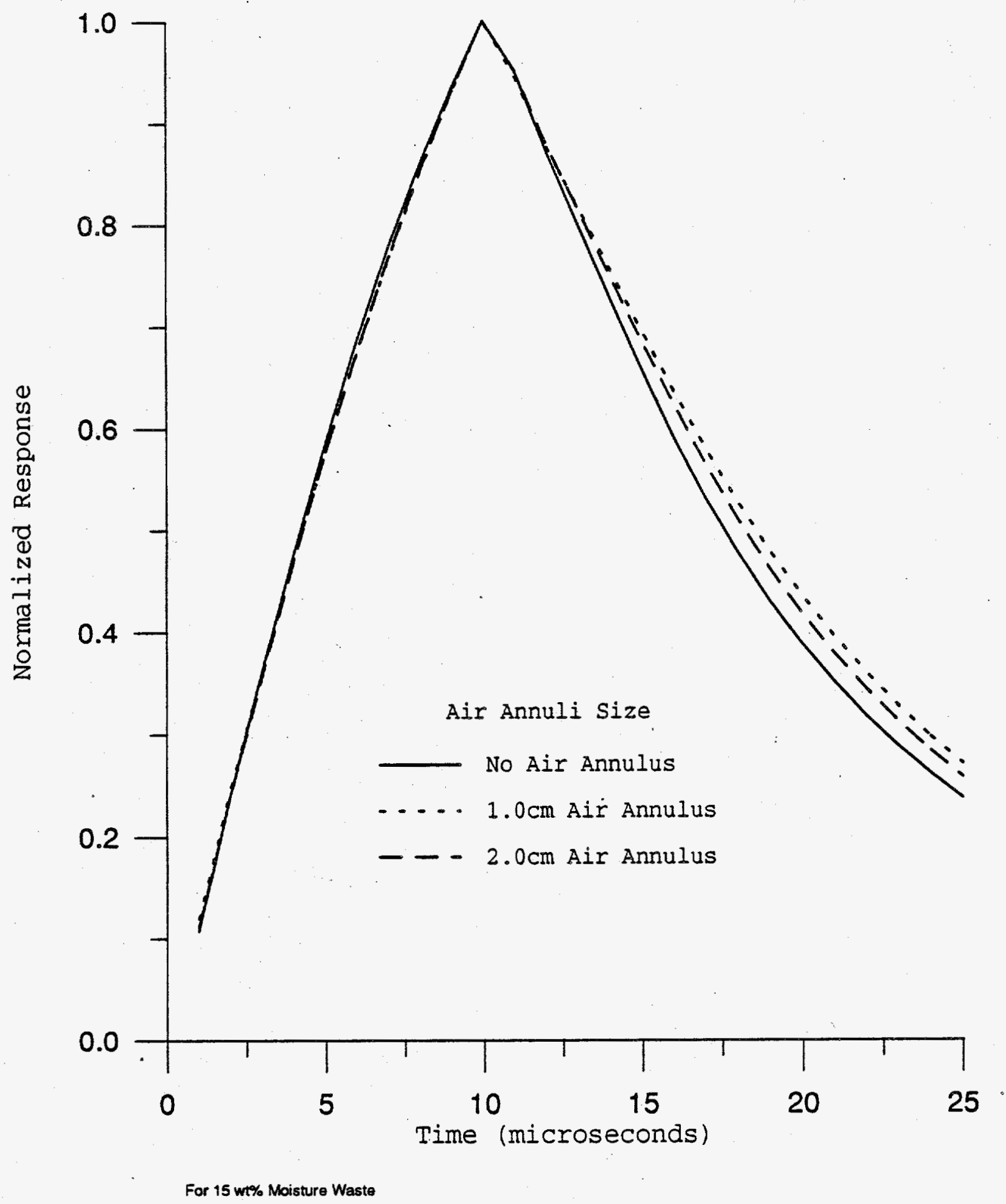


Figure 4-17. Normalized Far-Epithermal Time-Dependant Responses to Air-Filled Annuli.

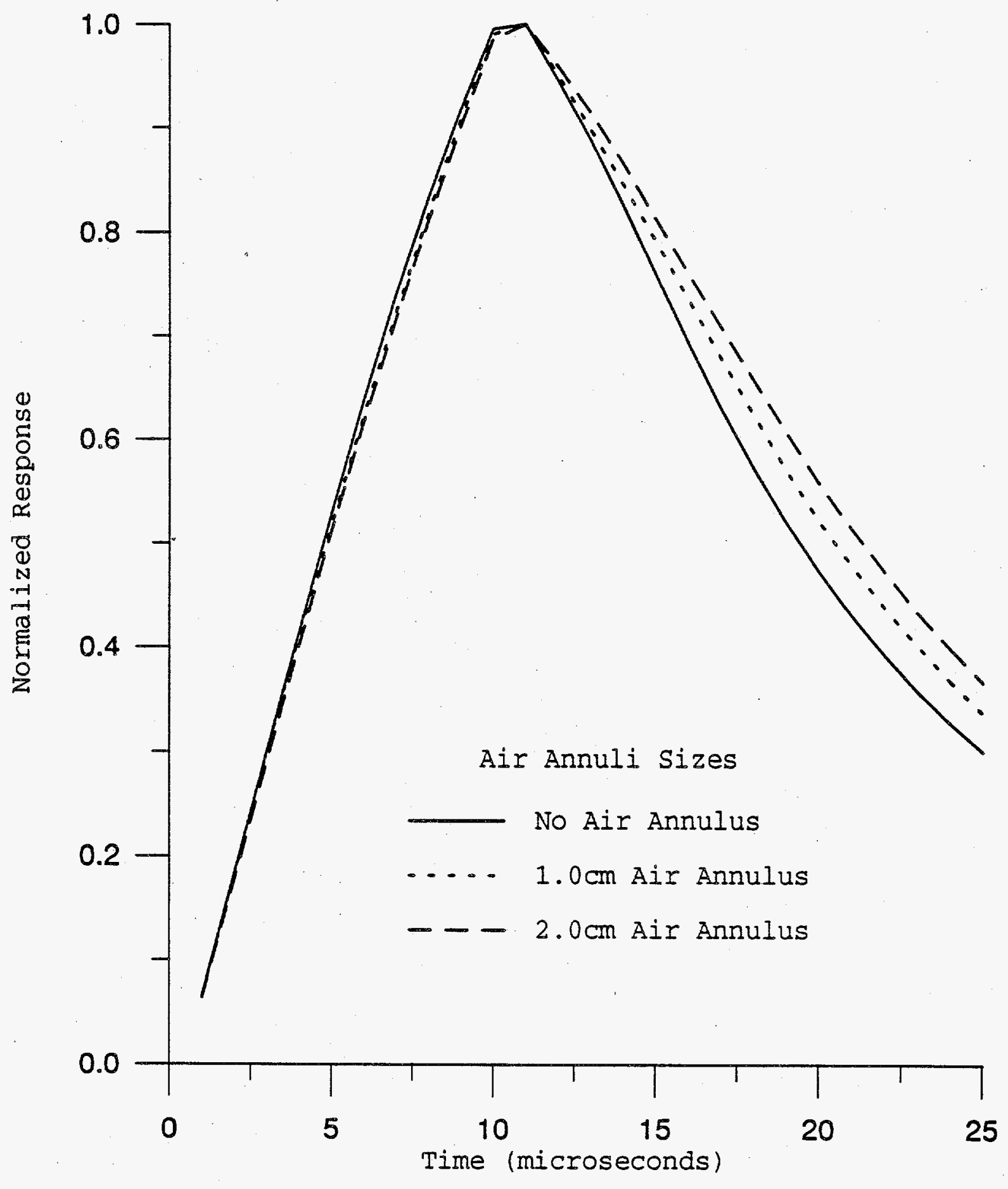

For 15 wt\% Moisture Waste 
Figure 4-18. Near-Thermal Detector Time-Dependant Responses to Water-Filled Annuli.

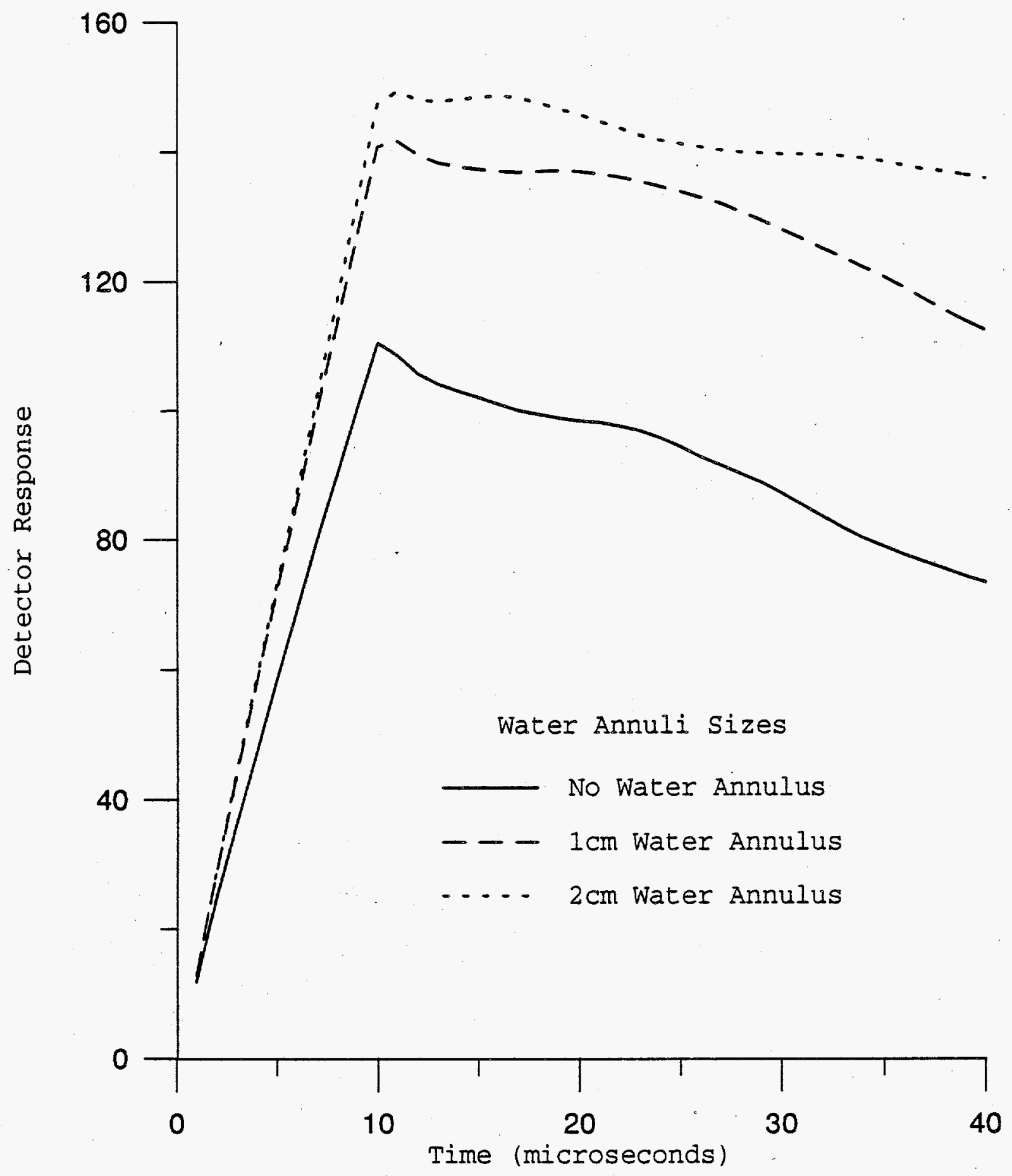

For 15 wt\% Moisture Waste 
WHC-EP-0809

Figure 4-19. Far-Thermal Detector Time-Dependant Responses to Water-Filled Annuli.

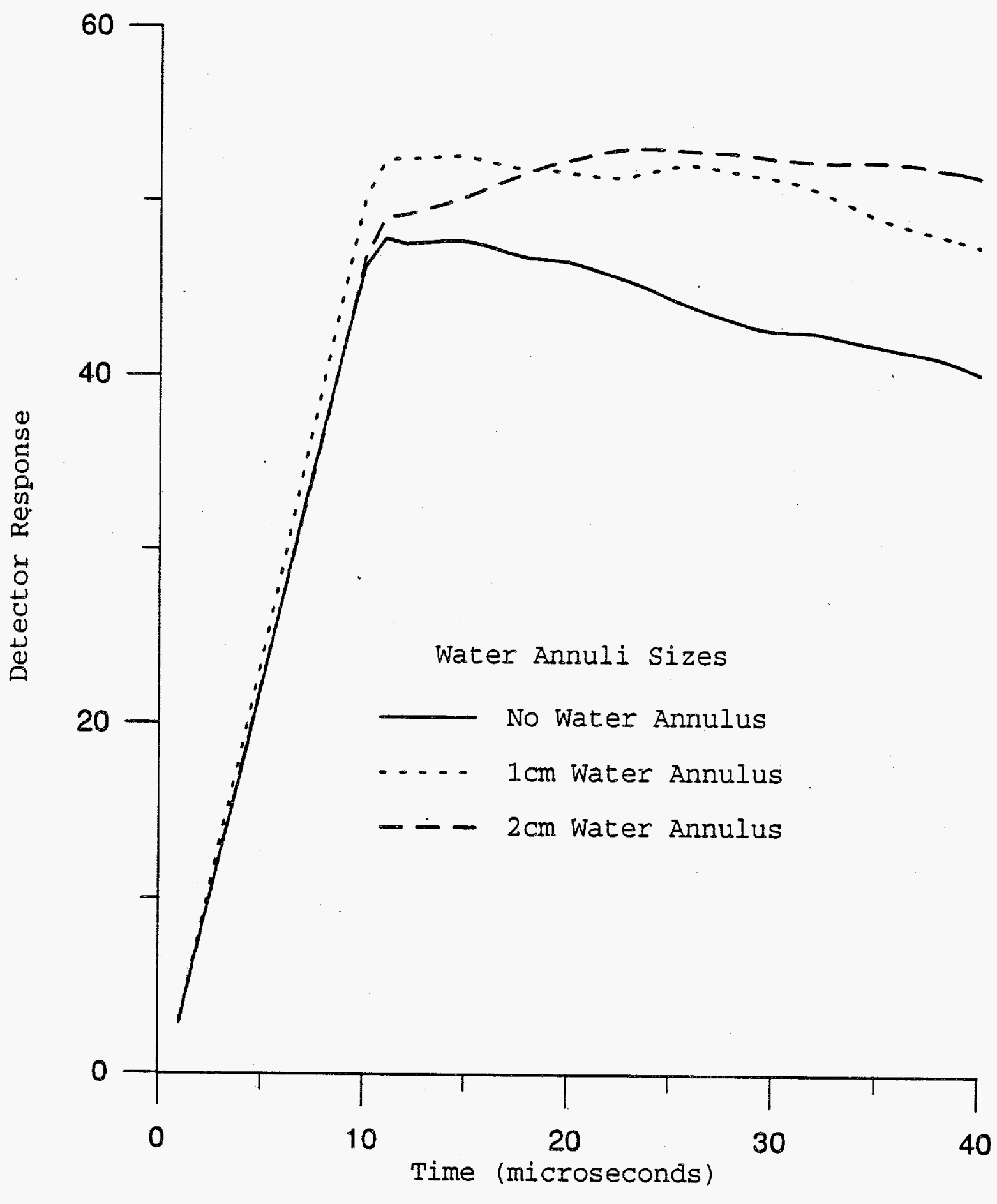

For 15 wt\% Moisture Waste 
Figure 4-20. Normalized Near-Thermal Detector Time-Dependant Responses to Water-Filled Annuli.

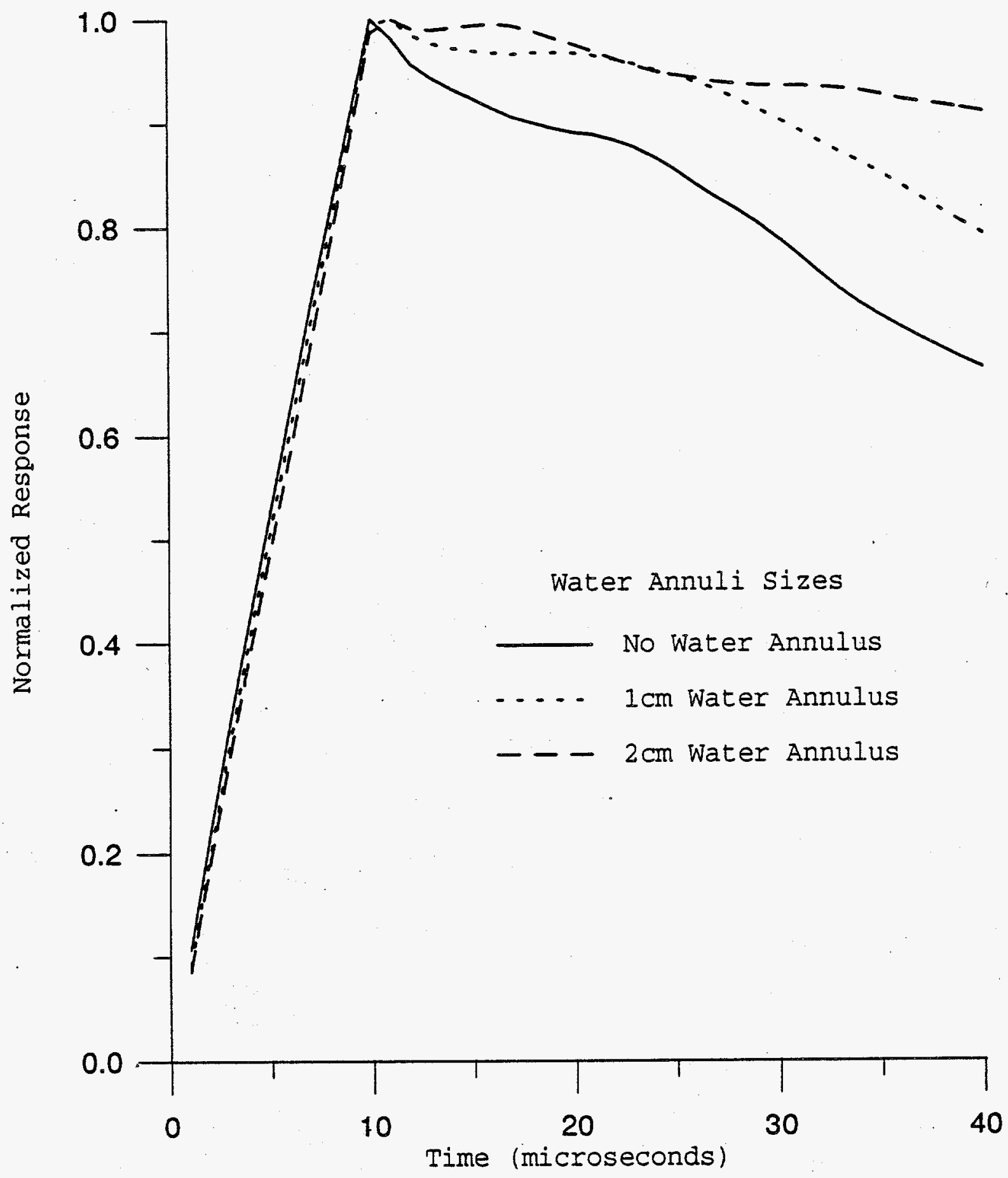

For 15 wt\% Moisture Waste 
Figure 4-21. Normalized Far-Thermal Detector Time-Dependant Response to Water-Filled Annuli.

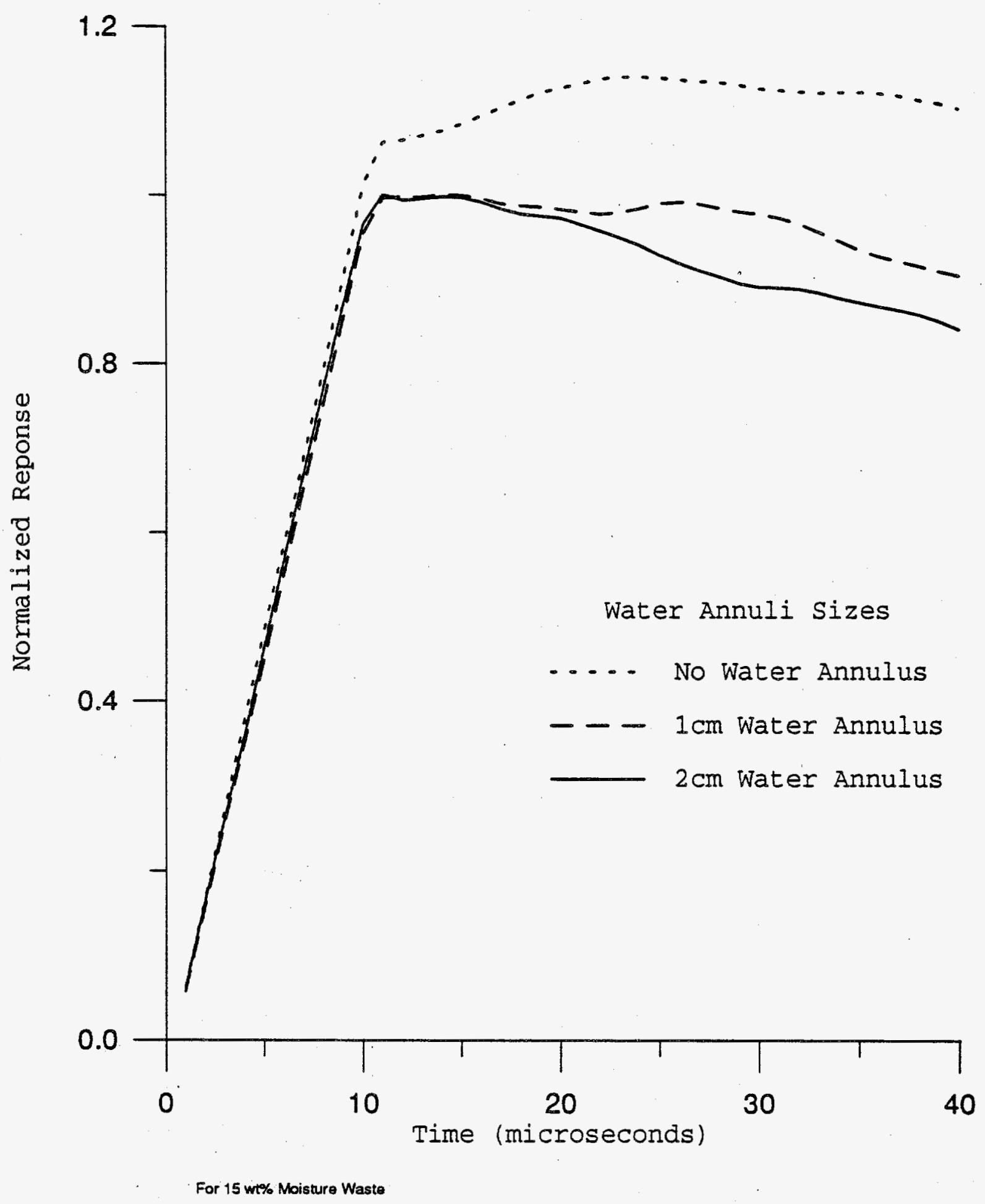


WHC-EP-0809

Figure 4-22. Near-Epithermal Detector Time-Dependant Responses to Water-Filled Annuli.

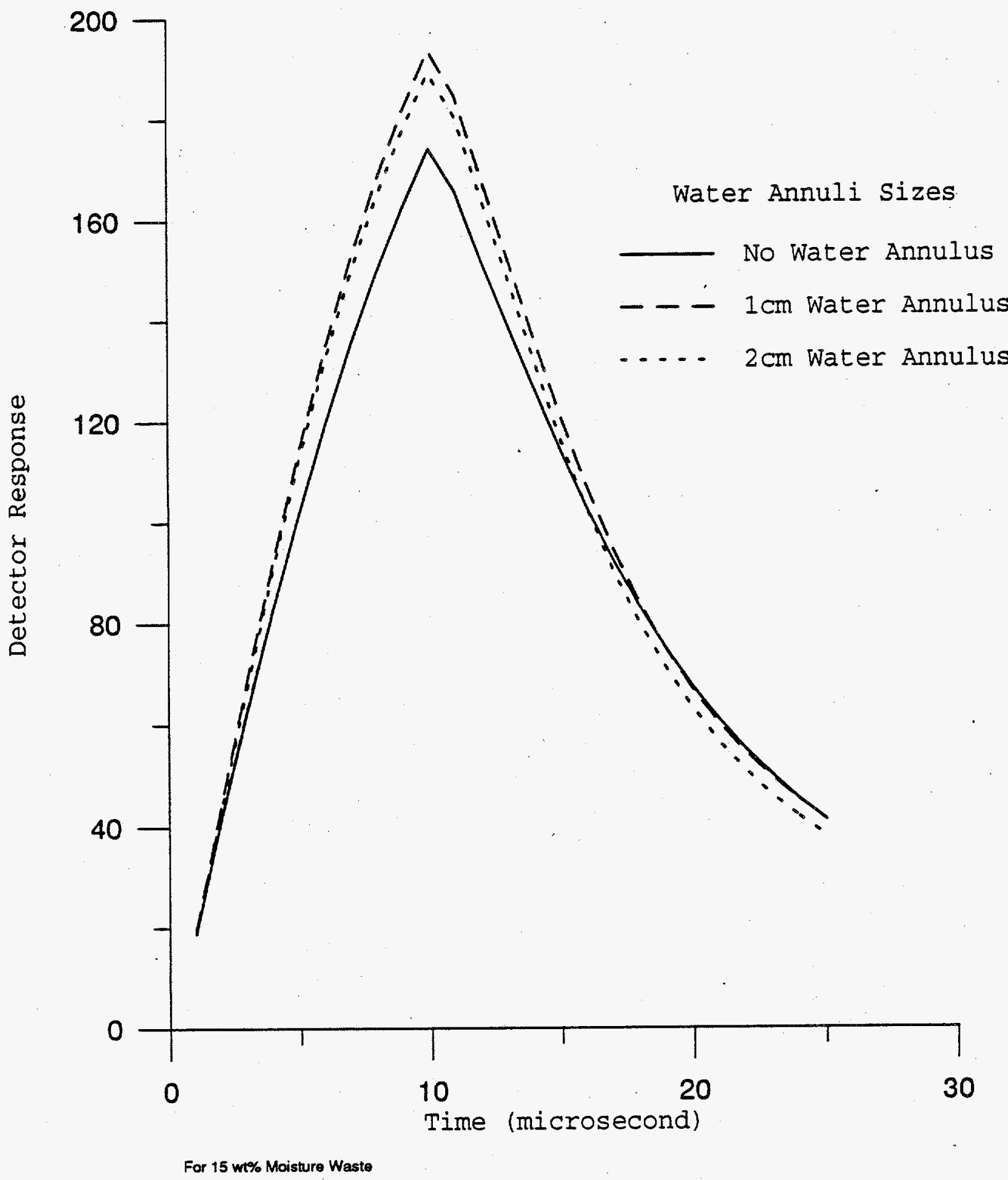


Figure 4-23. Far-Epithermal Detector Time-Dependant Responses to Water-Filled Annuli.

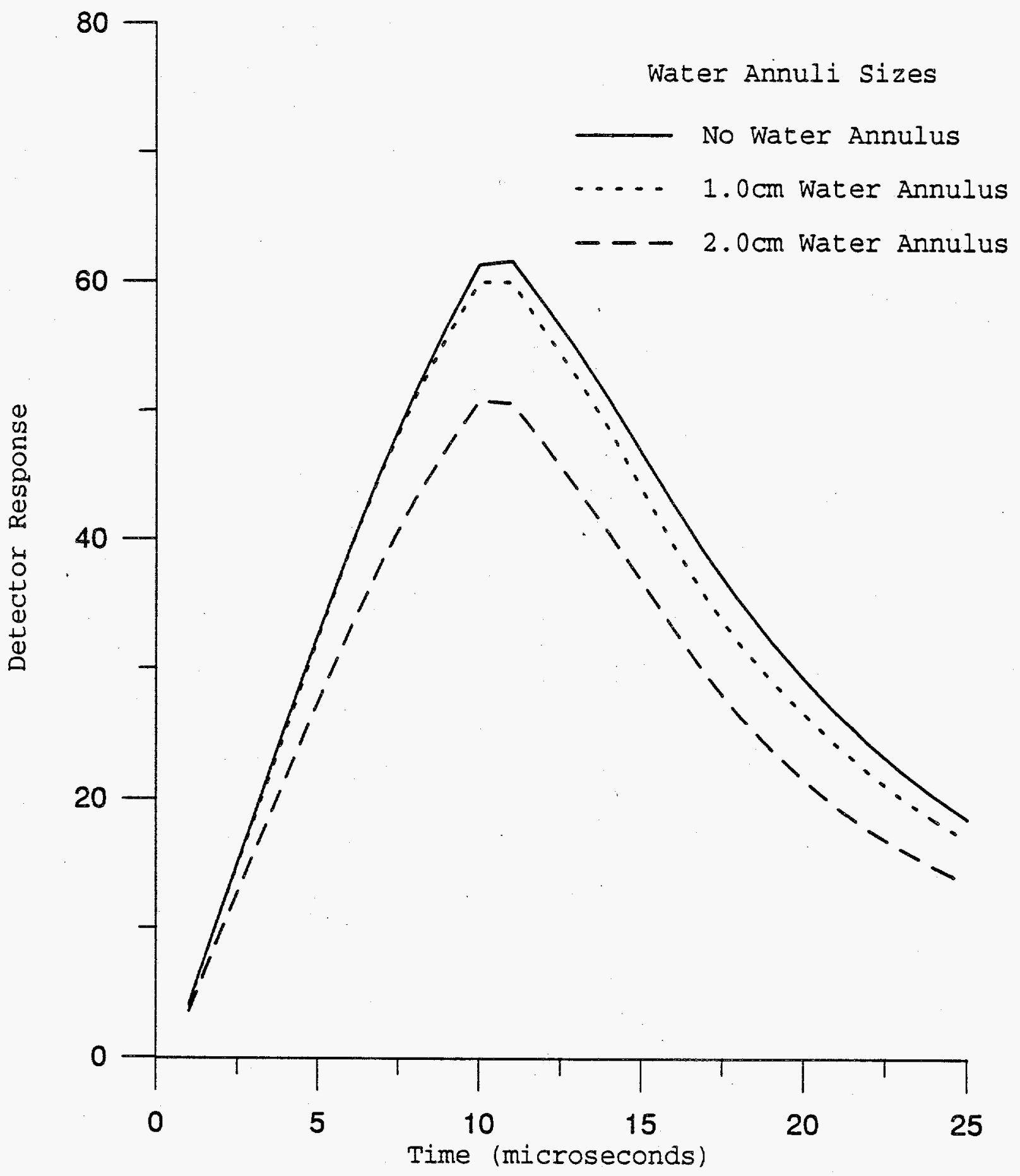

For 15 wt\% Moisture Waste 
Figure 4-24. Normalized Near-Epithermal Detector Time-Dependant Responses to Water-Filled Annuli.

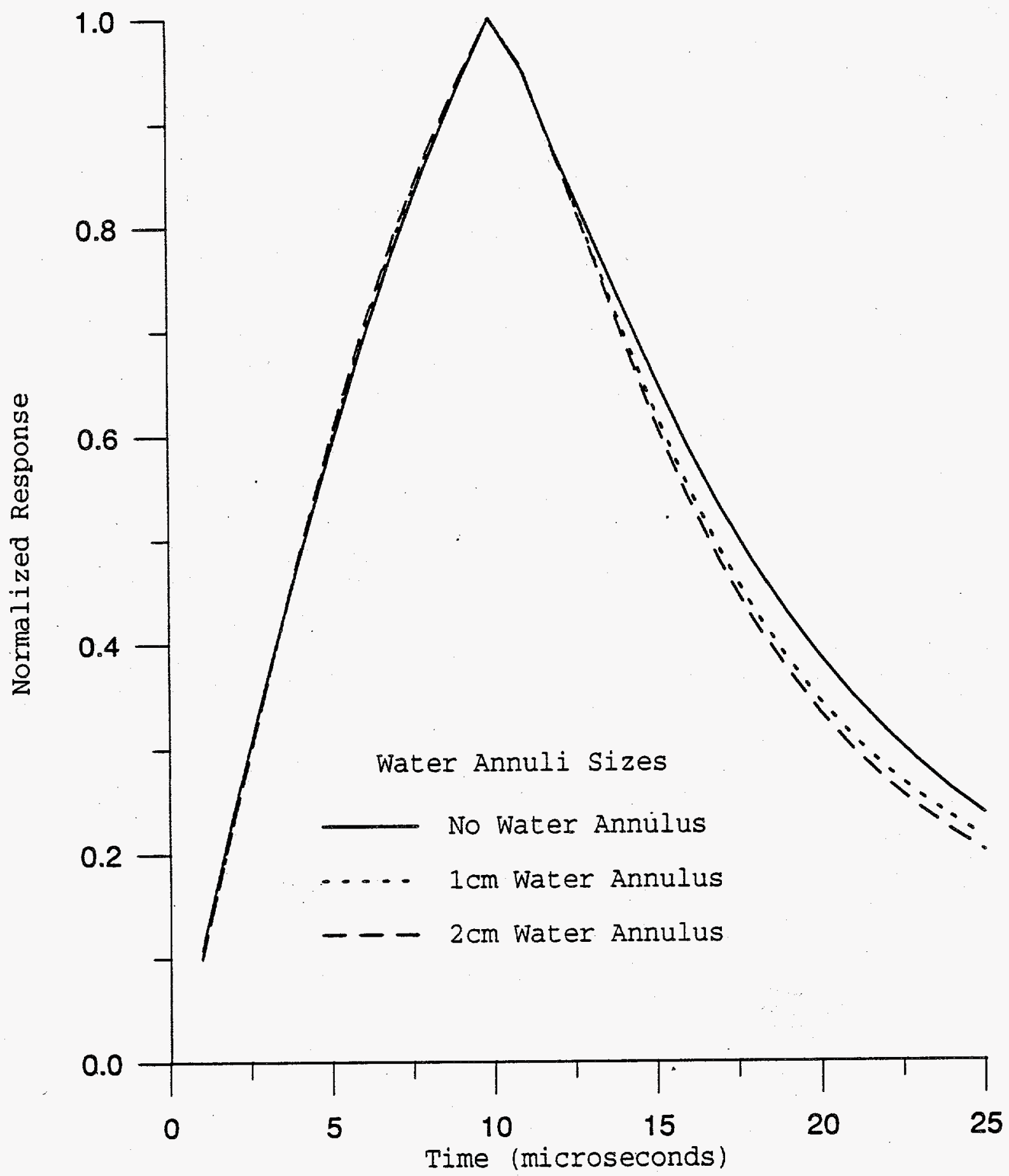

For 15 wt\% Moisture Waste 
Figure 4-25. Normalized Far-Epithermal

Time-Dependant Responses to Water-Filled Annuli.

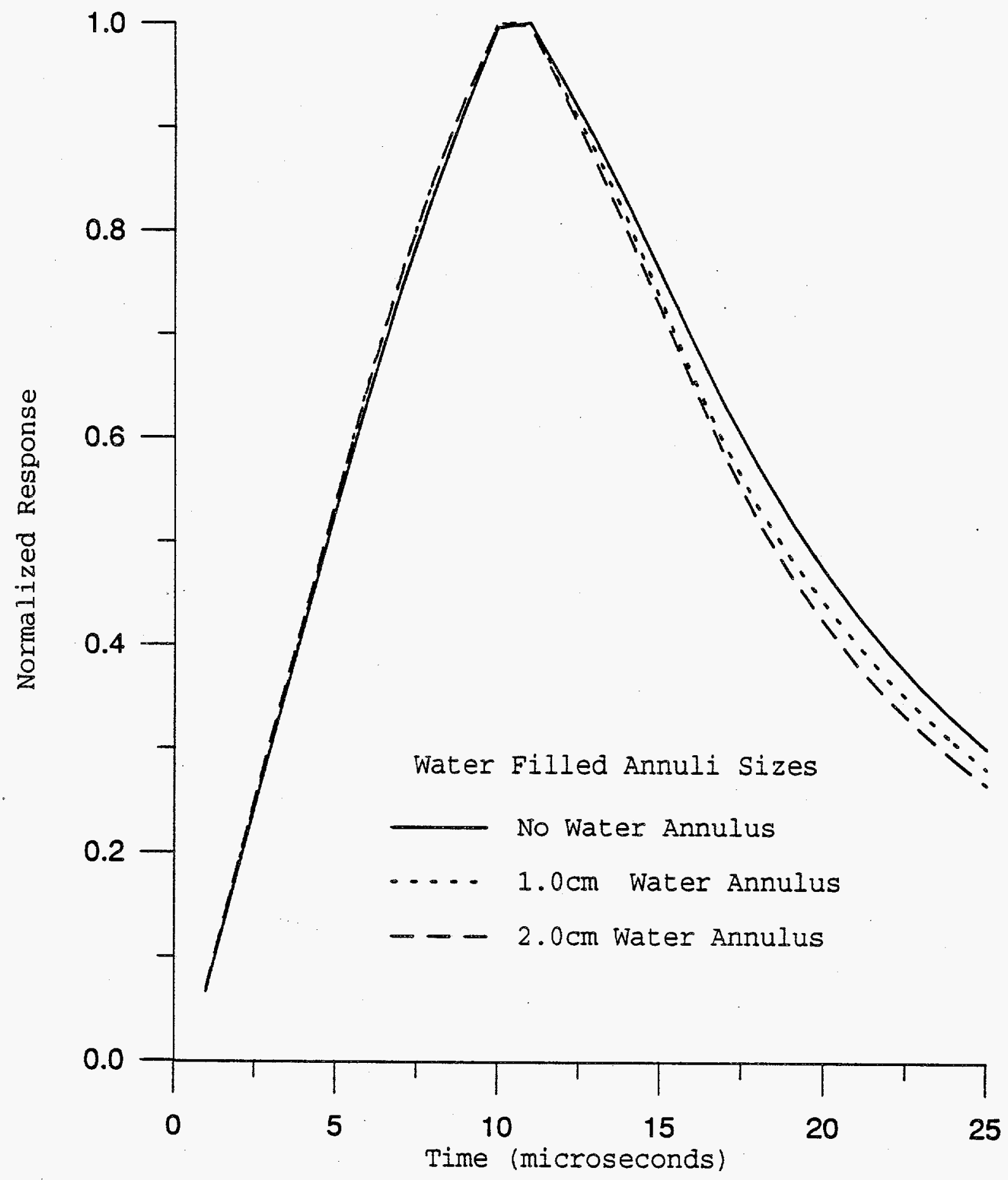

For 15 wt\% Moisture Waste 
WHC-EP-0809

DISTRIBUTION

Number of copies

OFFSITE

7

U.S. Department of Energy EM-36, Trevion II 12800 Middlebrook Road Germantown, Maryland 20874

J. V. Antizzo

K. Lang

C. O'Dell (5)

U.S. Department of Energy

Billy C. Hudson 2472 Marbury Road

Livermore, California 94550

1

Ashe Analytics

Post Office Box 4172

Butte, Montana 59702

J. Ashe

EG\&E Idaho

Post Office Box 1625

Idaho Fal1s, Idaho 83415-2070

A. Arave

1

H. Lamonds

3435 Tanto Circle

Las Vegas, Nevada 89121

5

Los Alamos National Laboratory

Post Office Box 1663

Los Alamos, New Mexico 87545

S. F. Agnew

S. W. Eisenhawer

C. Hatcher

H. Hoida

T. E. Larson

1

MIT/Department of Nuclear Engineering 77 Massachusetts Avenue Room 24-102

Cambridge, Massachusetts 02139

M. S. Kazimi 
WHC-EP-0809

Number of copies

OFFSITE

2

Oak Ridge National Laboratory

Post Office Box 2008

MS-6495

Oak Ridge, Tennessee 37831-6495

C. W. Forsberg

Post Office Box 2009

9108, MS-8088

Oak Ridge, Tennessee 37831-8088

Thomas S. Kress

Sandia National Laboratory

Post Office Box 5800

MS 0741

Albuquerque, New Mexico 87185-5800

S. E. Slezak

1

D. Powers, Consultant

Sandia National Laboratory

7964 Sartan Way N.E.

Albuquerque, New Mexico 87109

5

Science Applications International Corporation 20300 Century BTvd, Suite 200-B

Germantown, Maryland 20874

R. S. Daniels (3)

M. Gupta

H. Sutter

1

Systems Support, Inc. 12003 Bob White Drive

Catharpin, Virginia 22018-1322

R. Moler

1 University of Washington

Center for Process Analytical Chemistry

Chemistry Department BG-10

Seattle, Washington 98195

B. R. Kowalski 
Number of copies

1

Vanderbilt University

Post Office Box 1596, Station B

Nashville, Tennessee 37235

F. L. Parker

\section{ONSITE}

4

U.S. Department of Energy, Richland Operations Office

R. F. Christensen

$57-54$

R. E. Gerton

S7-54

R. G. Harwood

S7-54

RL Public Reading Room

$\mathrm{H} 2-53$

5

Pacific Northwest Laboratory

R. M. Bean

P8-08

G. F. Schiefelbein

P8-38

D. C. Stromswold

P8-01

J. J. Toth

K7-94

Technical Files

P8-55

Westinghouse Hanford Company

H. Babad

$\mathrm{R} 2-78$

D. A. Barnes

R1-51

D. C. Board

S1-57

G. L. Borsheim

R2-11

V. C. Boyles

R1-49

W. G. Brown

$\mathrm{S} 2-45$

R. J. Cash

R2 -78

W. G. Brown

$\mathrm{S} 2-45$

R. J. Cash

R2-78

C. Defigh-Price

ST-30

G. T. Dukelow (2)

R2-78

S. H. Finfrock

HO-38

J. M. Grigsby

$\mathrm{H} 4-62$

M. N. Islam

R3-08

N. W. Kirch

R2-11

R. B. Mailhot

L7-05

J. E. Meacham

R2-78

T. L. Moore, Sr

H5-09

S. R. Moreno

B3-06

M. A. Payne

R2-50

R. S. Popiel arczyk

R1-30

T. E. Rainey

F. R. Reich

R4-02

L5-63 
WHC-EP-0809

C. P. Schroeder

L7-06

R. G. Stickney

B5-20

H. Toffer

HO-38

D. A. Turner

S7-15

W. T. Watson

HO-38

W. D. Winkelman

L5-55

Central Files

L8-04

Document Processing

and Distribution (2)

Central Files

L8-15

Information Release

Administration (3)

L8-04

TFIC

L8-07

EDMC

R1-20

H6-08 